\title{
Reliability of sacroiliac joint tests in experienced and inexperienced examiners
}

Danielle Lueck

West Virginia University

Follow this and additional works at: https://researchrepository.wvu.edu/etd

\section{Recommended Citation}

Lueck, Danielle, "Reliability of sacroiliac joint tests in experienced and inexperienced examiners" (2009). Graduate Theses, Dissertations, and Problem Reports. 2772.

https://researchrepository.wvu.edu/etd/2772

This Thesis is protected by copyright and/or related rights. It has been brought to you by the The Research Repository @ WVU with permission from the rights-holder(s). You are free to use this Thesis in any way that is permitted by the copyright and related rights legislation that applies to your use. For other uses you must obtain permission from the rights-holder(s) directly, unless additional rights are indicated by a Creative Commons license in the record and/ or on the work itself. This Thesis has been accepted for inclusion in WVU Graduate Theses, Dissertations, and Problem Reports collection by an authorized administrator of The Research Repository @ WVU. For more information, please contact researchrepository@mail.wvu.edu. 
Reliability of Sacroiliac Joint Tests in Experienced and Inexperienced Examiners

Danielle Lueck, BS, ATC

Thesis submitted to the College of Physical Activity and Sport Sciences

at West Virginia University

in partial fulfillment of the requirements

for the degree of

Master of Science in Athletic Training

Michelle A. Sandrey, PhD, ATC, Chair

Mia Erickson, EdD, PT, ATC

Richie Martin, PT, ATC

College of Physical Activity and Sport Sciences

Morgantown, WV

2009

Key Words: Sacroiliac joint biomechanics, Sacroiliac joint examination, Sacroiliac joint testing 


\begin{abstract}
Reliability of Sacroiliac Joint Tests in Experienced and Inexperienced Examiners
\end{abstract}

Danielle Lueck, BS, ATC

Context: The sacroiliac joint is the largest axial joint in the body. Based on the function of transferring loads and providing stability, there is an increase risk of dysfunction. Sacroiliac joint tests exist to assess mobility and pain; however, there are few reliable tests for sacroiliac joint dysfunction and virtually no study which examined the reliability of experienced and inexperienced athletic trainers. Objective: The purpose of this study is to determine inter- and intrarater reliability for a battery of sacroiliac joint tests for experienced and inexperienced examiners. Design: This study was a single blind prospective reliability study. Setting: This study took place at HealthWorks Rehab and Fitness in Morgantown, WV. Patients and Other Participants: A total of four examiners were used for this study. Two examiners were inexperienced graduate certified athletic trainers while the other two examiners had five or more years of experience. A total of four recorders recorded data for each examiner. A total of 31 healthy male and female subjects age $20.7 \pm 2.4$ years old without a previous history of back surgery or lower limb surgery within the last two years volunteered for this study. Interventions: After a practice session, two experienced and two inexperienced examiners performed a battery of sacroiliac joint tests on the subjects. The tests performed were the standing flexion test, standing stork/Gillet test, seated flexion test, and supine-to-sit test. The examiners performed each test three times and then reported to a recorder if the test was positive or negative. This procedure was completed in two rounds, the original day and again after the first round was completed. Main Outcome Measures: The expectations of this study was to determine if the experienced examiners had moderate to high interrater and intrarater reliability for sacroiliac joint tests as compared to inexperienced examiners who were anticipated as having low to moderate intrarater and interrater reliability for sacroiliac joint tests. Results: Intrarater reliability of the March test ranged from .351 to .53 . Interrater reliability of the March test for all examiners ranged from - .090 to .335 . Intrarater reliability of the Standing Flexion test ranged from .410 to .686. Interrater reliability of the Standing Flexion test for all examiners ranged from -.220 to .384 . The interrater reliabilityof the Seated Flexion test ranged from .517 to .708 . Interrater reliability of the Seated Flexion test for all examiners ranged from -.069 to .184. Intrarater reliability of the Supine to Long Sit test for each examiner ranged from . 241 to .735. Interrater reliability of the Supine to Long Sit test for all examiners ranged from -.091 to .479 . Percent agreement for all four tests ranged from $35 \%$ to $100 \%$. Overall, intrarater reliability was higher than interrater reliability; however, there was no clear distinction between experienced and inexperienced examiners as defined by the study. Conclusion: This study found that intrarater reliability is higher than interrater reliability for four sacroiliac joint tests. Interrater reliability was extremely variable amongst the four examiners. It is important to note that it is not experience in years, but rather amount of daily exposure to sacroiliac joint testing that equates to increased reliability. These results support the need for a standardized teaching protocol for SIJ tests to increase interrater reliability. Because of the high intrarater reliability and low interrater reliability, one can also deduce that, from a clinical standpoint, the same individual should evaluate and treat the same patient daily. 


\section{ACKNOWLEDGEMENTS}

First and foremost, I would like to thank all of the examiners, recorders, and subjects who participated in this study. I appreciate the sacrifices you made to be a part of my study. Without all of you, this would not have been possible.

I would like to thank Mia Erickson and Richie Martin for being on my committee. I am extremely grateful for your time and efforts. The feedback you provided to me throughout this process was extremely valuable. It was a pleasure working with both of you.

I would like to thank Dr. Michelle A. Sandrey for allowing me to be a part of the graduate athletic training program at West Virginia University as well as a graduate assistant athletic trainer at Waynesburg Central High School.

Thank-you to everyone who is a part of the the University of Wisconsin undergraduate athletic training program. All of you provided me with the foundation to pursue my graduate studies.

To my friends and classmates without whom I would not have been able to keep my sanity. Thank-you for all your support and wonderful memories. Best of luck in your future endevors.

I would like to thank my sisters, Kristen and Marybeth, and my brothers, Matthew and Andrew. Despite the 11+ hour drive between us, you have always been there for me through phone, e-mail, or mail. Thank-you for your encouragement, support, and endless humor towards life.

Lastly, I would like to thank my Mom. You have always supported me thoughout all of my decisions in life. Thank-you for enduring my tears, laughter, frustrations, defeats, and small victories throughout my two years here. Without your constant love and guidance, I would not be who I am today. You are my hero and if there is one thing this world needs, it is more people like you. 


\section{TABLE OF CONTENTS}

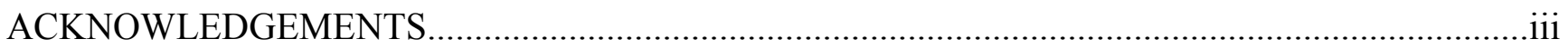

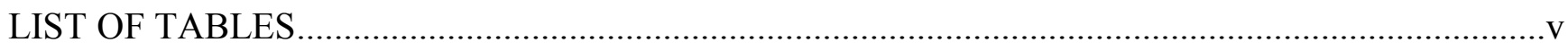

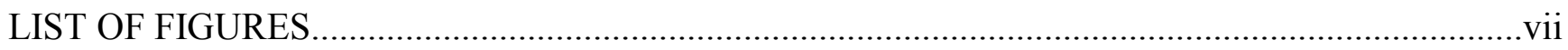

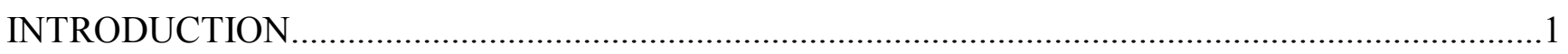

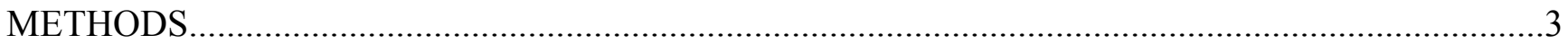

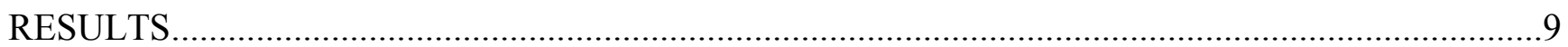

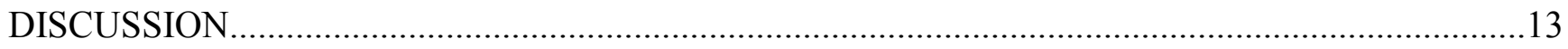

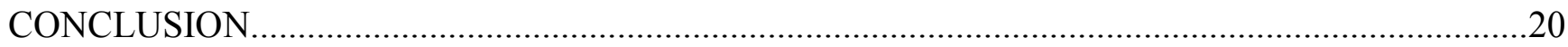

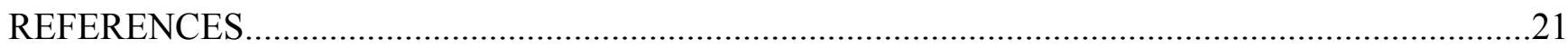

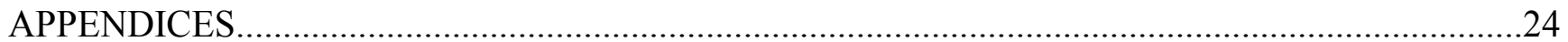

APPENDIX A: THE PROBLEM...............................................................................25

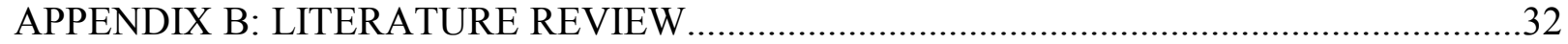

APPENDIX C: ADDITIONAL METHODS...................................................................59

APPENDIX D: ADDITIONAL RESULTS.................................................................. 74

APPENDIX E: RECOMMENDATIONS FOR FUTURE RESEARCH...............................90

ADDITIONAL REFERENCES......................................................................................... 91 


\section{LIST OF TABLES}

Table $\quad$ Page

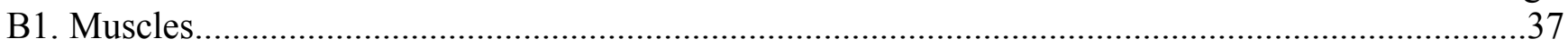

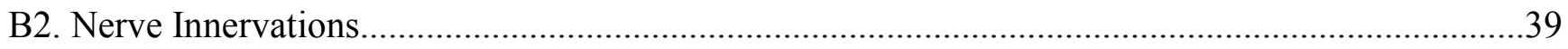

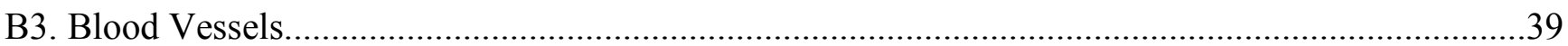

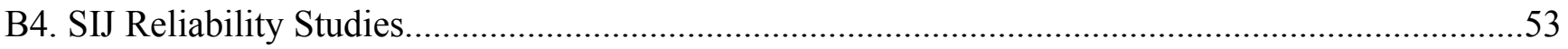

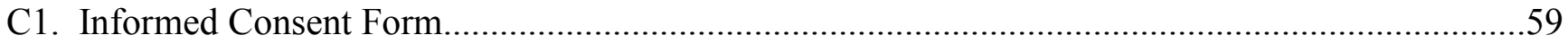

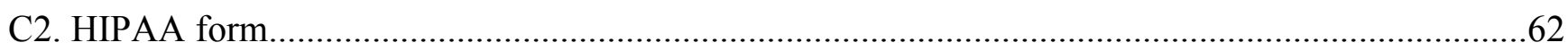

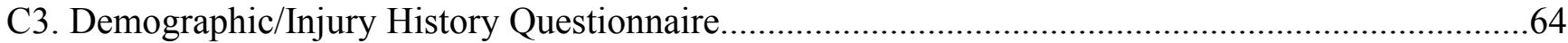

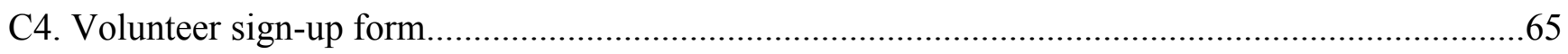

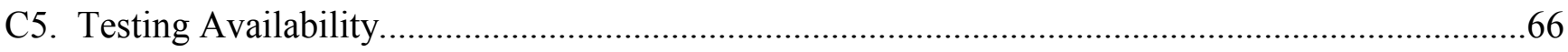

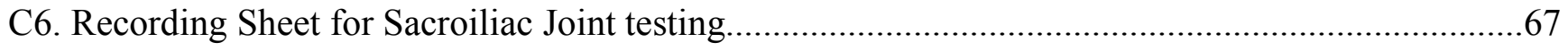

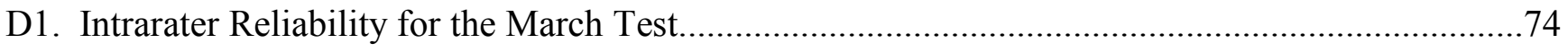

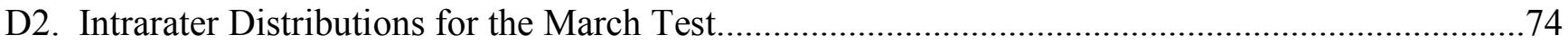

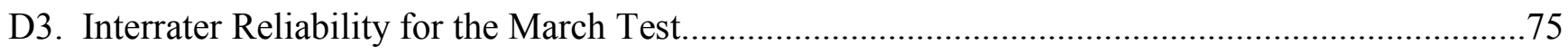

D4. Interrater Distributions for the March Test..............................................................................75

D5. Intrarater Reliability for the Standing Flexion Test........................................................

D6. Intrarater Distributions for the Standing Flexion Test........................................................78

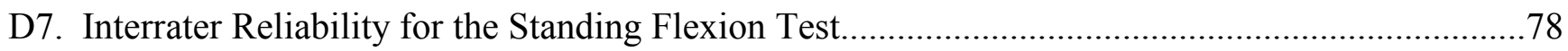

D8. Interrater Distributions for the Standing Flexion Test........................................................79

D9. Intrarater Reliability for the Seated Flexion Test............................................................ 81

D10. Intrarater Distributions for the Seated Flexion Test.............................................................8

D11. Interrater Reliability for the Seated Flexion Test........................................................82

D12. Interrater Distributions for the Seated Flexion Test..........................................................82 
D13. Intrarater Reliability for the Supine to Long Sit Test......................................................84

D14. Intrarater Distributions for the Supine to Long Sit Test......................................................85

D15. Interrater Reliability for the Supine to Long Sit Test.........................................................85

D16. Interrater Distributions for the Supine to Long Sit Test.....................................................86

D17. Interrater Comparisions of Experienced and Inexperienced Examiners.................................8 


\section{LIST OF FIGURES}

Figure

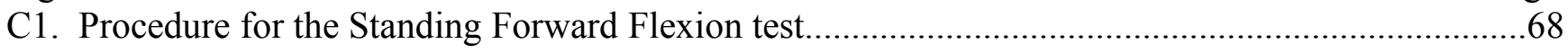

C2. Procedure for the Seated Forward Flexion test.....................................................................69

C3. Procedure for the March/Gillet/Stork test............................................................................70

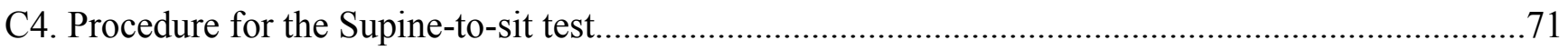

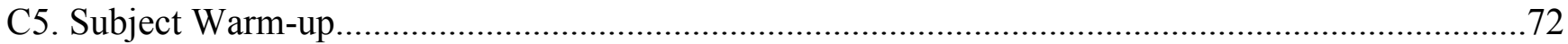

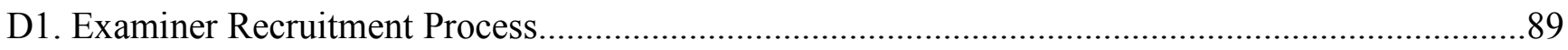

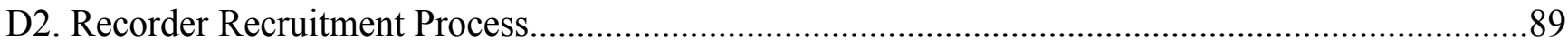

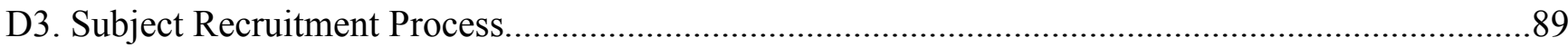




\section{INTRODUCTION}

The pelvis is formed by 2 innominates and the sacrum. An ilium, ischium, and pubis comprise each innominate. The ilium and sacrum articulate with each other to form the sacroiliac joint (SIJ), which is the largest axial joint in the human body. The SIJ is a diarthrodial, synovial joint ${ }^{1-4}$ designed primarily for stability and transferring loads. ${ }^{3-10}$ The SIJ has six degrees of freedom ${ }^{11-13}$ and rotates around three axes $(\mathrm{X}, \mathrm{Y}$, and $\mathrm{Z})$ with the origin lying halfway between the left and right PSIS. ${ }^{1,2,6,7,12-14}$ A very small amount of motion (about 2.5 degrees) occurs through the SIJ. ${ }^{1,2,6,7}$

The SIJ transmits and dissipates forces created by the body as well as gravity to add stability. ${ }^{2,6,7}$ Hip flexion is coupled with posterior rotation of the innominate while hip extension is coupled with anterior rotation. During nutation of the sacrum or posterior rotation of the innominate, the SIJ is in a closed-pack or self-braced position. ${ }^{6,7,15}$ When the sacrum is in counternutation and the innominate is anteriorly rotated, the SIJ is in a less stable position. ${ }^{6,712}$ The SIJ is vulnerable to axial compression and axial torsion overloading. ${ }^{3}$

Individuals who participate in activities requiring repetitive, unidirectional pelvic shear and torsional forces typically develop a sacroiliac joint dysfunction. ${ }^{3}$ There can be many causes that contribute to sacroiliac dysfunction, which leads to the difficulty in evaluating and formulating assessments of this area. Pregnancy, gait abnormalities, muscle strains, and kyphotic postures increase the likelihood of SIJ pain and dysfunction, to name a few. In the United States, the estimated cost of treating and compensating those with SIJ dysfunction exceeds 14 billion dollars per year. ${ }^{16}$ Ninety percent of the population will experience back pain during the course of their lives, ${ }^{5}$ and it is estimated that SIJ pain occurs in as little as .4 percent and up to as much as 98 percent of this portion of the population. $^{4,6,7,17-19}$ 
In the last ten years, the focus of clinical assessment procedures for pelvic girdle function has shifted from SIJ mobility testing to functional assessment procedures. ${ }^{6,7}$ The diagnosis of SIJ pain is made through a thorough history and physical evaluation; however, studies have demonstrated that neither of these consistently identify SIJ dysfunction/pain. ${ }^{1,2,17}$

Four tests have been described in the literature that have been used in other reliability studies. These tests are the standing forward flexion test, Gillet/Stork stand test, seated forward flexion test, and supine-to-sit test. Authors ${ }^{20-24}$ describe the standing forward flexion test as assessing the movement of the innominate on the sacrum. Several authors ${ }^{1,21,25}$ describe the seated or sitting forward flexion test as a test used to determine the side of the dysfunction of the sacrum moving on the innominate bone. The supine-to-long sitting requires that the level of the malleoli are compared bilaterally in two positions: laying down and in a long sit position. ${ }^{1,20,21,23,25}$ All of these tests have relatively low kappa scores when used alone..$^{21,2326}$ The reliability of these tests tend to increase when used in conjunction with other sacroiliac joint tests. The Stork stand test is also referred to as the Gillet or March test. 1,4,6,7,21,25,27,28 $_{\text {Hungerford et }} \mathrm{al}^{15}$ found that when physical therapists used a two point scale by reporting negative or positive results when identifying the presence of a dysfunction, reliability of this test increases. ${ }^{6,7}$ While the motion performed by the patient for the March test is the same throughout the literature, there is debate about the landmarks that are palpated. This lack of standardization among evaluators creates issues with reliability. Despite these disparities between the application of the test, it is accepted that this test assesses the ability of the patient to maintain a stable alignment of the innominate bone relative to the sacrum during load transfer thereby identifying any sacral restriction. ${ }^{1,4,6,21,25,27,28}$ The results of the test are also generally accepted.

Previous reliability studies have utilized either chiropractors or physical therapists as the examiners in SIJ testing. These studies have compared experienced and inexperienced examiners using either a single test or a battery of tests. Results of these studies reported a vast range of kappa scores. 
Despite the use of SIJ tests by athletic trainers in the clinical setting, there is no research examining reliability of a battery of sacroiliac joint tests for inexperienced and experienced certified athletic trainers. With certified athletic trainers often performing SIJ testing on patients, it stands to reason that reliability studies should be conducted using this population. It is important for athletic trainers in the educational setting to understand these elements of each test when teaching future generations of athletic trainers. It is crucial that the best clinical and evidence based practice be employed so as to advance the profession of athletic training. Therefore, the aim of this study is to determine intra and interrater reliability for a battery of sacroiliac joint tests for inexperienced and experienced examiners. The battery of sacroiliac joint tests that were used include the standing stork or Gillet test, the standing flexion test, the seated flexion test, and the supine-to-sit test.

\section{METHODS}

The research design was a single-blind prospective reliability study that examined the interrater reliability of experienced and inexperienced examiners for a battery of four sacroiliac joint tests. The second part of the study examined test-retest (intrarater) reliability of the examiners using a battery of four sacroiliac joint tests.

\section{Participants}

Examiners and recorders: Four examiners participated in this study. Two of the examiners were inexperienced and two examiners were experienced. In this study, inexperienced examiners (I1 and I2) were defined as graduate assistant certified athletic trainers that have been introduced to SIJ evaluation in their graduate and undergraduate courses. Experienced examiners (E1 and E2) were defined as certified athletic trainers with five or more years of experience in evaluating the SIJ. One experienced examiner was a certified athletic trainer employed in a clinical setting while the other 
experienced examiner was an undergraduate athletic training program director. Four graduate athletic training students volunteered to record data for the data collection session, which allowed the examiners to be blinded. Refer to Figure D4 for the introductory procedures.

Subjects: Thirty-one subjects age $20.7 \pm 2.4$ yrs agreed to participate in this study. There were a total of 11 males and 20 females. The subjects were from a sample of convenience. The only exclusion criteria was a history of back surgery ${ }^{30}$ or lower limb surgery within the last two years. All examiners, recorders, and subjects signed both a consent and HIPAA form (TableC1-C2). The subjects completed a questionnaire (Table C3) prior to start of the study. These individuals indicated in writing (Table C4) if willing to volunteer. If eligible, they selected a thirty-five minute timeslot for the testing day (Table C5). This study was approved by the University Office of Research Compliance. Refer to Figure D3 for the introductory procedures.

Instrumentation

A battery of four sacroiliac joint tests were used in this study: the standing forward flexion test, the Gillet/Stork stand test, the seated flexion test, and the supine-to-sit test. The Gillet/Stork stand test assessed the ability of the patient to maintain a stable alignment of the innominate bone relative to the sacrum during load transfer thereby identifying any sacral restriction. ${ }^{1,4,6,721,25,27,28}$ Authors have reported inconsistent values for the reliability and validity of this test; however, this test becomes more reliable if only negative or positive results are recorded instead of attempting to identify the discrepancy. ${ }^{6,7}$ The standing forward flexion assessed the movement of the innominate on the sacrum ${ }^{20-}$ ${ }^{24}$ The seated flexion test determined if a dysfunction of the sacrum moving on the innominate bone existed. ${ }^{1,21,25}$ The standing flexion test and the seated flexion test are not very reliable. Vincent-Smith and Gibbons ${ }^{30}$ reported low reliability for the standing flexion test. Tong et $\mathrm{al}^{21}$ found the individual reliability of both these tests to be low. The supine-to-long sitting requires that the level of the malleoli 
are compared bilaterally in two positions: laying down and in a long sit position. ${ }^{1,20,21,23,25}$ If differences exist, an innominate rotation has occurred. Performing this test with the stork test and standing flexion test increases reliability. ${ }^{21}$

Standing forward flexion test: In the standing forward flexion test, ${ }^{7,20,22}$ the subject were standing as the examiner assumed a position behind the subject with the subject's posterior hips at eye level. The right thumb was placed on the right PSIS and the left thumb was placed on the left PSIS The subject then slowly bent forward as far as possible. The examiner's thumbs remained on both PSIS's throughout the movement. A negative test was reported if both PSIS moved equally. A positive test was reported if one thumb moved before the other or if one thumb was higher at the end of the movement. $^{22}$

Gillet/Stork stand test: The Gillet or Stork stand test was performed using the method utilized by Hungerford et al. ${ }^{15}$ The subject was instructed to stand and place equal weight on both legs while the examiner knelt behind the subject with the subject's hip at eye level. The examiner palpated the right PSIS with the right thumb while the rest of the right hand remained in contact with the right innominate bone. The left thumb palpated the S2 spinous process of the sacrum. The examiner then asked the subject to slowly raise the right leg into 90 degrees of hip flexion and 90 degrees of knee flexion and then return to a standing position. The examiner continued to palpate the right PSIS and innominate bone relative to the sacrum throughout this movement. A positive test was reported if the PSIS moved cephalad to the sacrum while a negative test was reported if the PSIS remained in the same position or moves caudally to the sacrum. ${ }^{15}$ The same procedure was then performed for the left side using the respective positioning and recording procedure.

Seated flexion test: For the seated forward flexion test, ${ }^{1,21,22}$ the examiner assumed a position behind the seated subject with the subject's posterior hips at eye level. The right thumb was placed on the right PSIS and the left thumb was placed on the left PSIS. The subject then slowly bent forward as 
far as possible. The examiner's thumbs remained on both PSIS's throughout the movement. A negative test was reported if both PSIS moved equally. A positive test was reported if one thumb moved before the other or if one thumb was higher at the end of the movement. ${ }^{22}$

Supine-to-sit test: For the supine-to sit test, the patient lied supine and performed a bridge to clear the hips off of the table. The examiner's hand was placed around the ankle with thumbs on the inferior aspect of the medial malleoli and traction was applied. The positions of the medial malleoli were compared and then the subject sat up without shifting the pelvis while the examiner maintained positioning on the malleoli. The examiner then compared the positions of the medial malleoli again. A positive test was reported if at any point during the evaluation the malleoli were not level with each other while a negative test was reported if the malleoli remained even with one another throughout the test.

Procedures

Prior to testing, all examiners were provided with a packet of the SIJ tests that were used during data collection (Figures C1-C4). The examiners watched a video that explained the procedures for each test. They then practiced each of these evaluation procedures for thirty minutes or until they felt comfortable. The battery of tests used in this study were the standing forward flexion test, Gillet test, seated flexion test, and supine-to-sit test.

Examiners: At the beginning of the testing day, the examiners were directed to their own examination room until the break period. Each individual room had a randomized testing order that the examiners were required to follow. The subjects then entered the room and remained standing. The examiners then performed the standing flexion test, Gillet test on the right and left sides, seated flexion test,and supine-to-sit test in the order provided to them by the researcher. After each test was completed, the examiner indicated to the recorder "yes" if there was a positive or "no" if the test was 
negative. ${ }^{22}$ All examiners were allotted an hour break half-way through the testing day.

Subjects: Three to five subjects were scheduled for each thirty-five minute time slot. The subjects were instructed to wear shorts and a t-shirt on the data collection day. Prior to testing, the subjects were asked by the researcher to perform warm-up exercises provided on a handout (Figure C5). On data collection days, subjects waited in the Healthworks conference room until the principal investigator directed them to an examination room. Before entering the examination room, the subjects were asked to remove their shoes and socks and await instructions from the examiners. The subjects rotated between the examination rooms one through four until the testing procedure was completed.

Recorders: Each recorder was assigned to a room with an examiner for the duration of testing. They were given a data sheet (Table C6) and the testing order. The recorders were instructed to circle $\mathrm{Y}$ for a positive test or $\mathrm{N}$ for a negative test. At the end of the day, this sheet was returned to the principal researcher.

To complete the test-retest (intrarater) portion of this study, all subjects were randomized and sent through a second evaluation after the first round of evaluation was completed. The examiners, subjects, and recorders followed the same procedures described above.

\section{Statistical Analysis}

Demographic information was analyzed using means and standard deviations. Cohen's kappa coefficient with the alpha level set a $\mathrm{p}=.05$ was used to determine interrater and intrarater reliability. Intrarater reliability was measured by comparing each tester's results between the two rounds of testing. Interrater kappa correlation coefficients for the experienced examiners and inexperienced examiners, individual examiners, and for all examiners together were used. When calculating the values of the March test, the left side was randomly chosen. Data analyses were conducted using SPSS for Windows Software (Version 16.0, SPSS Inc, Chicago, Il). 
Cohen's kappa is the amount of agreement between two or more examiners rating a certain amount of subjects after the chance of agreement has been removed. ${ }^{31,32}$ It is particularly useful when one examiner has a tendency to use a specific category more often than any other category. ${ }^{33}$ The equation for Cohen's kappa is ${ }^{32}$ :

$$
\kappa=\left(p_{0}-p_{c}\right) /\left(1-p_{c}\right)
$$

$\mathrm{p}_{\mathrm{o}}$ is the observed proportion [percentage] of agreement $=(1 / \mathrm{n}) \Sigma_{\mathrm{i}} \mathrm{n}_{\mathrm{ji}}$ (Observed proportion(percentage) is calculated by adding the total of agreed data and dividing by the total possible data. ${ }^{2,31-33}$ Agreement can be positive or negative and shows which type of answer is most likely. ${ }^{23}$ )

$p_{c}$ is the chance of proportion (percentage) of agreement $=\left(1 / \mathrm{n}^{2}\right) \Sigma_{\mathrm{i}} \mathrm{n}_{\mathrm{i} \cdot \mathrm{n}} \cdot \mathrm{n}_{\cdot j}$ $\mathrm{n}_{\mathrm{ij}}$ is the observed frequency in the $\mathrm{i}$, jth cell, also known as the number of subjects assigned rating $\mathrm{i}$ by Rater 1 and rating $\mathrm{j}$ by Rater 2 .

$\mathrm{n}_{\mathrm{i}}$. is the marginal row frequencies $=\Sigma_{\mathrm{j}} \mathrm{n}_{\mathrm{ij}}$ $\mathrm{n}_{\cdot \mathrm{j}}$ is the marginal column frequencies $=\Sigma_{\mathrm{i}} \mathrm{n}_{\mathrm{ij}}$

To use kappa, three assumptions must be met including the objects or subjects to be rated are independent of one another, the raters operate independent of one another, and the categories are mutually exclusive and complete. ${ }^{31-33}$ Kappa scores range from -1 to 1 with scores closer to one indicating better reliability. ${ }^{6,30,32,34}$ Positive scores signify agreement better than chance while a negative value is worse than chance. Zero means that the agreement is no better than chance. ${ }^{30}$ Using the Landis and Koch scale, ${ }^{6,30,32-35}$ kappa scores are poor if $\kappa<0$, indicate slight agreement if $\kappa$ is between 0 and .20 , indicate fair agreement if $\kappa$ is between .21 and .40 , indicate moderate agreement if $\kappa$ is between .41 and .60 , indicate substantial agreement if $\kappa$ is between .61 and .80 , and perfect if between .81 and $1 . .^{15,33,34,36}$

When kappa scores are expected to be skewed, maximum kappa and kappa/kappa maximum 
can be calculated. ${ }^{23}$ The maximum kappa is typically calculated with low kappa scores and is the best agreement that can occur without chance in the present distribution ${ }^{31,33}$ This will be helpful if the kappa score is low while observed proportion(percentage) of agreement is high. Maximum kappa was calculated as follows:

$$
\kappa \max =(\mathrm{Pm}-\mathrm{Pc}) /(1-\mathrm{Pc})
$$

$\mathrm{Pm}$ is a percentage taken from the lowest pair of marginal data from row and column totals while Pc is the "proportion of units for which agreement is expected by chance." ${ }^{33,31}$ It is found by multiplying each row and column total together and then summing the results.

$\mathrm{Kappa/kappa} \mathrm{maximum} \mathrm{is} \mathrm{the} \mathrm{proportion} \mathrm{of} \mathrm{the} \mathrm{maximum} \mathrm{kappa} \mathrm{coefficient} \mathrm{that} \mathrm{kappa} \mathrm{was}$ able to reach. When this proportion is high, the two examiners could agree well, and chance is not a factor. By taking the difference between kappa and kappa maximum, the amount of disagreement truly present can be found..$^{31,33}$

\section{RESULTS}

March Test

Intrarater reliability exceeded interrater reliability for the March test for each examiner. Intrarater reliability ranged from .35 to .53 . Three of the examiners results were statistically significant. Examiner E1 $(\kappa=.53, \mathrm{P}=.003)$ had moderate agreement. Examiner I1 $(\kappa=.41, \mathrm{P}=.022)$ had moderate agreement while $\mathrm{I} 2(\kappa=.35, \mathrm{P}=.05)$ had fair agreement. Percent agreement ranged from $71 \%$ (inexperienced) to $100 \%$ (experienced). The $\kappa m a x$ for intrarater reliability ranged from . 87 (inexperienced) to 1 . The obtained $\kappa / \kappa m a x$ intrarater reliability ranged from $40 \%$ (inexperienced) to 53\% (experienced). Results for intrarater reliability of the March test are shown in Tables D1 and D2. Interrater reliability of the March test for all examiners ranged from -.090 to .335 . Due to 
experienced examiner two, interrater reliability for experienced examiners was unable to be calculated while for inexperienced examiners it was -.04 and -.09. Interrater reliability ranged from -.04 to .34 during round one and ranged from -.09 to .26 during round two. Statistically significant results were obtained for I1 and $\mathrm{E} 1(\kappa=.34, \mathrm{P}=.03)$, which occurred during round one. It is also to be noted that reliability could not be calculated for three pairs (I1 and E2, I2 and E2, and E1 and E2) for both round one and round two. All other results were not significant. Percent agreement ranged from 42\% (I1 and I2) to $87 \%$ (I2 and E2) during round one and from 58\% (I1 and I2) to $84 \%$ (I2 and E2) during round two. The kmax ranged from .19 (I1 and I2) to .53 (I2 and E1) during round one and from .27 (I1 and I2) to .64 (I2 and E1) during round two. The obtained $\kappa / \kappa m a x$ for interrater reliability ranged from $-19 \%$ (I1 and $\mathrm{I} 2$ ) to $30 \%$ (I2 and E1) during round one and from $-33 \%$ (I1 and I2) to $51 \%$ (I1 andE1) during round two. Results for interrater reliability of the March test are shown in Tables D3 and D4.

\section{Standing Flexion Test}

Intrarater reliability of the Standing Flexion test for each examiner exceeded interrater reliability. Intrarater reliability ranged from .41 to .69 . All of the examiners' results were statistically significant. Examiner E1 $(\kappa=.56, \mathrm{P}=.002)$ had moderate agreement while E2 $(\kappa=.686, \mathrm{P}=.000)$ had substantial agreement. Examiner I1 $(\kappa=.587, \mathrm{P}=.001)$ had moderate agreement while $\mathrm{I} 2(\kappa=.410$, $\mathrm{P}=.023$ ) also had moderate agreement. Percent agreement ranged from $74 \%$ (inexperienced) to $84 \%$ (experienced). The $\mathrm{kmax}$ for intrarater reliability ranged from .69 (experienced) to 1 (experienced and inexperienced). The obtained $\kappa / \kappa m a x$ intrarater reliability ranged from $41 \%$ (inexperienced) to $95 \%$ (experienced). Results for intrarater reliability of the Standing Flexion test are shown in Tables D5 and D6.

Interrater reliability of the Standing Flexion test for all examiners ranged from -.220 to .384 . Interrater reliability for experienced examiners was -.22 and -.03 while for inexperienced examiners it 
was -.15 and .01 . Interrater reliability ranged from -.22 to .38 during round one and ranged from -.06 to .27 during round two. Statistically significant results were obtained for $\mathrm{I} 2$ and $\mathrm{E} 2(\kappa=.38, \mathrm{P}=.029)$, which occurred during round one. All other results were not significant. The percent agreement ranged from $52 \%$ (E1 and E2) to $71 \%$ (I2 and E2) during round one and from $35 \%$ (E1 and E2) to $68 \%$ (I1 and E1) during round two. The kmax ranged from .50 (I1 and E2) to 1 (I2 and E1) during round one and from .30 (I2 and E1) to .79 (E1 and E2 ) during round two. The obtained $\kappa / \kappa m a x$ for interrater reliability ranged from $-28 \%$ (E1 and E2) to $49 \%$ (I2 and E2) during round one and from $-11 \%(\mathrm{I} 2$ and E1) to $52.5 \%$ (I2 and E2) during round two. Results for interrater reliability of the Standing Flexion test are shown in Tables D7 and D8.

\section{Seated Flexion}

Intrarater reliability of the Seated Flexion test for each examiner exceeded interrater reliability. The intrarater reliability ranged from .52 to .71 . All of the examiners' results were statistically significant. Examiner E1 ( $\kappa=.67, \mathrm{P}=.000)$ had moderate agreement while $\mathrm{E} 2(\kappa=.67, \mathrm{P}=.000)$ had substantial agreement. Examiner I1 $(\kappa=.71, \mathrm{P}=.000)$ had substantial agreement while I2 ( $\kappa=.52$, $\mathrm{P}=.004$ ) had moderate agreement. For the four examiners, percent agreement ranged from $77 \%$ (inexperienced) to $90 \%$ (inexperienced). The $\kappa m a x$ for intrarater reliability ranged from ..83(experienced) to .93 (experienced and inexperienced). The obtained $\kappa / \mathrm{\kappa max}$ intrarater reliability ranged from $56 \%$ (inexperienced) to $80 \%$ (experienced). Results for intrarater reliability of the Seated Flexion test are shown in Tables D9 and D10.

Interrater reliability of the Seated Flexion test for all examiners ranged from -.069 to .184. Interrater reliability for experienced examiners was -.07 and -.27 while for inexperienced examiners it was .04 and .14 . Interrater reliability ranged from -.07 to .18 during round one and ranged from -.27 to .19 during round two. All results were not significant. The percent agreement ranged from 52\% (E1 
and E2, I2andE1) to $68 \%$ ( I1 and E1) during round one and from 42\% (E1 and E2) to $71 \%$ (I1 and E1) during round two. The kmax ranged from .63 (I2 and E1) to 1 (I2 and E2) during round one and from .50 (I1 and E2) to .91 (I1 and E1) during round two. The obtained $\kappa / \kappa m a x$ for interrater reliability ranged from $-9 \%$ (I2andE1, E1 andE2) to $18 \%$ (I2 and E2) during round one and from $-47 \%$ (E1 and E2) to 22\% (I1 and I2, I2 andE2) during round two. Results for interrater reliability of the Seated Flexion test are shown in Tables D11 and D12.

\section{Supine to Long Sit}

Intrarater reliability of the Supine to Long Sit test for each examiner ranged from .24 to .74. Three of the examiners results were statistically significant. Examiner E1 $(\kappa=.54, \mathrm{P}=.002)$ had moderate agreement. Examiner I1 $(\kappa=.68, \mathrm{P}=.000)$ had substantial agreement while $\mathrm{I} 2(\kappa=.74, \mathrm{P}=.000)$ also had substantial agreement. Percent agreement ranged from $65 \%$ (experienced) to $87 \%$ (inexperienced). The $\kappa$ max for intrarater reliability ranged from .69 (experienced) to 1 (inexperienced). The $\kappa / \kappa m a x$ intrarater reliability ranged from $26 \%$ (experienced) to $78 \%$ (experienced). Results for intrarater reliability of the Supine to Long Sit test are shown in Tables D13 and D14.

Interrater reliability of the Supine to Long Sit test for all examiners ranged from -.09 to .48. Interrater reliability for experienced examiners was .15 and .05 while for inexperienced examiners it was -.09 and .11. Interrater reliability ranged from -.091 to .479 during round one and ranged from -.01 to .12 during round two. Only two results were significant. During round one, Il and E1 had moderate agreement $(\kappa=.48, \mathrm{P}=.006)$ while $\mathrm{I} 1$ and $\mathrm{E} 2$ had fair agreement $(\kappa=.36, \mathrm{P}=.038)$. The Po ranged from 45\% ( I2 and E1) to 61\% ( I2 and E2) during round one and from 45\% (I1 and I2, I2 and E1) to $68 \%$ (I1 and E2) during round two. The kmax ranged from .52 (E1 and E2) to .93 (I2 and E2) during round one and from .28 (E1 and E2) to .86 (I2 and E2) during round two. The obtained $\kappa / \kappa m a x$ for interrater reliability ranged from -11\% (I2 and E1) to 65\% (I1 and E1) during round one and from - 
2\% (I2 and E1) to 22\% (I1 and I2, I1 and E1, and I2 and E2) during round two. Results for interrater reliability of the Supine to Long Sit test are shown in Tables D15 and D16.

\section{DISCUSSION}

To the author's knowledge, this study is the first to examine the interrater and intrarater reliability between experienced and inexperienced certified athletic trainers. Previous studies have utilized chiropractors, physical therapist students, osteopathic students, and physiotherapists. ${ }^{6,15,21,23,26,27,30}$ Of these studies, only Herzog et al. ${ }^{27}$ deliberately compared inexperienced to experienced examiners. All authors provided a standardized set of procedures for the examiners to follow. The subject population varied from study to study in regards to the presence of LBP or SIJ dysfunction, or lack thereof.

The main goal of this study was to determine the intrarater and interrater reliability for and between inexperienced and experienced examiners for four sacroiliac joints tests: the March test, standing flexion test, seated flexion test, and supine to long sit test. These tests were chosen based on their presence in previous reliability studies examining SIJ testing. Prior to the current study, it was hypothesized that experienced examiners would have higher intrarater and interrater reliability when compared to inexperienced examiners for all SIJ tests. The results of this study were extremely variable. Based on these results, the hypotheses are rejected.

Overall, the intrarater reliability of all four SIJ tests was high for both experienced and inexperienced examiners. Intrarater reliability for the March test could only be calculated for experienced examiner one (moderate reliability) since experienced examiner two chose the response "no" throughout both testing sessions; therefore, kappa could not be calculated For inexperienced examiners, intrarater reliability ranged from fair to moderate. This test exists in many different forms, which may explan this discrepancy. While training was provided, it is difficult to ascertain whether the newly learned procedures were implemented throughout the data collection. 
For the standing flexion test, intrarater reliability ranged from moderate to substantial for the experienced examiners while the inexperienced examiners only had moderate agreement. This is similar to a study by Vincent-Smith and Gibbons ${ }^{30}$ where moderate agreement was found when calculating intrarater reliability for the standing flexion test. Both the present study as well as the one performed by Vincent-Smith and Gibbons ${ }^{30}$ utilized graduate students. The seated flexion test yielded moderate to substantial intrarater reliability for both the inexperienced and experienced examiners. Experienced examiners had intrarater reliability ranging from slight to substantial for the supine to long sit test while the inexperienced examiners had substantial intrarater reliability. These results were not surprising since it is easier for an individual examiner to consistently perform each test in the same fashion multiple times and reach the same conclusion than it is for two examiners to report the same result on separate occasions. ${ }^{30}$

Unlike intrarater reliability, interrater reliability for the four SIJ tests yielded inconsistent results. Table D17 summarizes the interrater comparisions of experienced examiners versus inexperienced examiners. The author hypothesized that experienced examiners would have higher interrater reliability than inexperienced examiners. Overall, years of experience performing SIJ testing was not associated with higher reliability. Both Hungerford et al. ${ }^{15}$ and Tong et al. ${ }^{21}$ examined the March test in their respective studies. Neither Hungerford et al. ${ }^{15}$ nor Tong et al. ${ }^{21}$ examined inexperienced versus experienced examiners, so the results obtained in this study could be considered similar. Tong et al. ${ }^{21}$ utilized physicians as examiners and recruited volunteers with low back pain while Hungerford et al. ${ }^{15}$ utilized physical therapists as examiners and recruited any volunteer who was eighteen or older. Tong et al. ${ }^{21}$ found the interrater reliability of the March test to be fair for physicians, but Hungerford et al. ${ }^{15}$ found the reliability of this test to be substantial for physical therapists. In this study, the inexperienced examiners had poor interrater reliability while reliability could not be calculated for the experienced examiners for the March test. These results were 
surprising since the same methodology used in the Hungerford et al. ${ }^{15}$ study was implemented in this study.

For the standing flexion test, inexperienced examiners as well as the experienced examiners had poor interrater reliability when compared to their respective partner. Both Vincent-Smith and Gibbons ${ }^{30}$ as well as Tong et al. ${ }^{21}$ found slight interrater reliability of this test while Riddle et al. ${ }^{23}$ found this test to have fair interrater reliability. During rounds one and two, I1 and E1 had slight agreement while I2 and E2 had fair agreement. The experienced examiners had poor agreement for the seated flexion test while the inexperienced examiners had slight agreement. I1 and E1 as well as I1 and E2 had slight agreement. Tong et al. ${ }^{21}$ found this test to have slight interrater reliability.

For the supine to long sit test, experienced examiners had slight agreement while inexperienced examiners had agreement ranging from poor to slight. During round one, I1 and E1 had moderate agreement while I2 and E2 had slight agreement. I1 and E2 had fair agreement. In a study by Riddle et al., ${ }^{23}$ the supine to long sit test was found to have slight reliability. These results could be due to an increase in laxity around the SIJ from repeated evaluation.

There were a few significant correlations in this study. Overall, intrarater reliability was higher than interrater reliability. Two strong examiners were evident within this study. Experienced examiner one is an athletic trainer working standard hours in a clinic with a variety of patients while experienced examiner two is almost solely an athletic trainer in an educational setting without much patient interaction Between the two experienced examiners, examiner one had the most statistically significant intrarater reliability with kappa values ranging from moderate to substantial agreement. Between the inexperienced examiners, examiner one had the most consistently significant intrarater reliability ranging from moderate to substantial. Experienced examiner one (E1) and inexperienced examiner one (I1) were considered the stronger examiner for their respective groups since they had more daily exposure to SIJ evaluation. I1 had the most significant interrater reliability with one or 
both experienced examiners during the course of the study. These results indicate that years of overall experience alone was not associated with higher reliability.

Maximum kappa is calculated when there is a low kappa coefficient. It determines the strength of agreement while maintaining the proportions of positive ratings demonstrated by each clinician. It also describes the examiner's overall potential for providing a rating given the surrounding factors and constraints. ${ }^{38}$ Maximum kappa is the best agreement that can occur with chance ruled out for the existing data distribution. The $\kappa$ max is useful when examining $\kappa / \kappa m a x, \kappa$, and percent agreement. For intrarater reliability, $\mathrm{kmax}$ ranged from .26 to 1 . A $\kappa$ max of 1 was found for the intrarater reliability of E1 during the March test; E1, I1, and I2 for the standing flexion test; and I2 for the supine to long sit test. For interrater reliability, kmax ranged from .17 to 1 . A $\mathrm{kmax}$ of 1 was found for the interrater reliability of I2 and E1 for the standing flexion test and inexperienced examiner one and E2 for the seated flexion test.

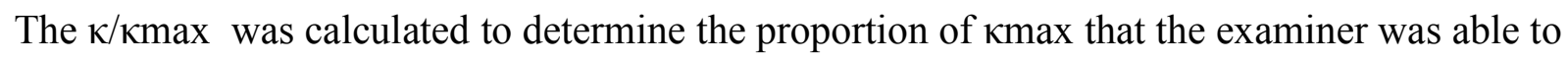
reach. The $\kappa / \kappa m a x$ is reported as the percentage of $\kappa m a x$ that the examiner was able to achieve with the given kappa score. When there is a large discrepancy between each examiner's decision and the best agreement that can occur without chance there will be a low $\kappa / \kappa m a x$ proportion and vice versa. By examining $\kappa, \kappa / \kappa \max$, and Po together, one can deduce how much of the results was due to chance. Interrater $\kappa / \kappa m a x$ ranged from $-33 \%$ to $73 \%$. For intrarater reliability, the $\kappa / \kappa m a x$ proportion ranged from $26 \%$ (E2 for the supine to long sit test) to $95 \%$ (E2 for the standing flexion test). This particular examiner had very little clinical responsibility and so did not employ the SIJ tests on a regular basis.

Unlike Cohen's kappa, percent agreement does not adjust for the agreement expected by chance. Because of this, percent agreement can be high while the kappa is low. This indicates that percent agreement overestimated the reliability of the examiners, as was the case in this study. 
Factors of Low Reliability

Inconsistency with the testing and palpation techniques and a true history of the examiners' experience can contribute to low reliability. A standardized testing protocol was shown and practiced prior to data collection. During the training session, the investigator assumed all examiners were capable of palpating the ASISs, which may not have been the case. Freburger and Riddle ${ }^{26}$ stated that an uncontrollable source of error is the ability of examiners to palpate bony landmarks. It is also

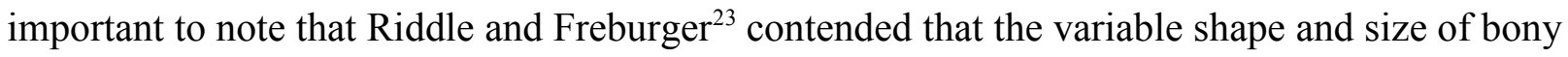
landmarks would make it difficult to make reliable decisions based on palpation during the small amount of movement that the SIJ undergoes. Tong et al. ${ }^{21}$ mentioned that many authors examining interater reliability of palpatory examinations of the sacrum and pelvis yielded poor to fair reliability.

While the testing procedure was standardized, the examiners were only given one, forty-five minute session to practice the tests prior to the data collection. This brief introduction to the procedures may have left room for error if the examiners were uncomfortable or unfamiliar with the testing procedures. Examiners who might have been uncomfortable with the new procedure might have unintentionally utilized a previously learned version of the test instead of the one chosen for the protocol. Vincent-Smith and Gibbons ${ }^{30}$ found that despite being introduced to a standardized procedure, many examiners failed to consistently perform the protocol as described during the training period. It cannot be stated for certain that this may or may not have happened during this study as, the examiners were not supervised while in their own testing room. Therefore, the examiners may benefit from more than one training session to improve reliability.

Another potential source of low reliability is each individual's decision rule when undergoing the visual and palpation aspects of each test. This element has the potential to create high intrarater reliability but low interrater reliability. In the case of experienced examiner two and the March test, "no" was reported for the entire two rounds of testing. 
While information on hand and eye dominance was not requested, these elements may have played a role in each examiner's results, particularly in the case of the March test when one side is being examined at a time. In a study by Dane et al., ${ }^{39}$ left handed examiners were at an advantage for spatial and nonverbal perception. It is hypothesized that left handed individuals may focus both eyes on a closer distance as opposed to right handed individuals. The motion around the SIJ is minimal, so a left handed individual may be at an advantage for detecting this movement. Much like hand dominance, eye dominance could also have an effect. For example, those with left eye dominance would have a higher reliability when performing the March test on the left side. Despite this, Dane et al. ${ }^{39}$ found no apparent discrete distribution with eye dominance.

Clinical Implications

Sacroiliac joint (SIJ) dysfunction is often a contributing factor to nonspecific low back pain. It is prevalent in all active populations from professional sports to recreational activities. Despite this, the evaluation tools used have remained mostly ambiguous. The literature on reliability, sensitivity, and specificity of SIJ tests often presents conflicting results. A thorough history taking process is a vital focus of low back and SIJ evaluation. It guides the clinician through the objective evaluation and special tests. One can argue that when SIJ special tests are employed without a patient history, the accuracy of the test may decrease. It might be beneficial for future studies to examine not only intrarater and interrater reliability but also the reliability of the overall multi-test regimen ${ }^{30}$ along with patient history information to guide the examiners.

The results showed inconsistency with interrater reliability. Consistent low reliability among examiners for some of these tests might indicate a need to provide more opportunities for practice to increase proficiency so that there is more consistency with SIJ testing throughout the athletic training profession. Reliability is a measure of reproducibility. It is not a gauge of accuracy. ${ }^{30}$ Since this study demonstrated that most of these tests cannot be replicated between examiners but can be replicated by 
one examiner on two different occasions, one must question the clinical worth of these tests, especially if a patient is evaluated and treated by more than one clinician. In the case of this study, clinical experience did not equate to reliability. This further demonstrates the need for standardization through undergraduate and graduate athletic training programs as well as the need for continuing education for the SIJ.

More research needs to be conducted comparing the reliability of the measurement techniques between experienced and inexperienced examiners, particularly with symptomatic populations. Workshops on SIJ evaluation as well as standardized procedures in athletic training education programs will further educate by identifying the reliability of motion palpation and pain provocation tests in conjunction with a thorough history taking process. This will then ensure the best evidence based and clinical practice possible. Once evaluation techniques have been perfected experienced and inexperienced clinical athletic trainers will be able to properly identify and treat patients with SIJ dysfunction who participate in a physically active environment.

Limitations

There were a few limitations in this study that need to be addressed. There was not a consensus of agreement in the literature on which SIJ tests are considered reliable and valid. Because of this, the instruments used may not be standardized to other studies. Another potential limitation was the possibility of false positives. The subjects were provided with both mandatory and optional warm-up activities; however, this may not have been sufficient. The lack of rest time between round one and round two may have also contributed to this. As testing went on, an increase in laxity at the SIJ was evident with repeated movement. A selection bias also existed since both the examiners and subjects used were from a sample of convenience. The examiners did not truly reflect inexperienced and experienced examiners since years since first exposure to SIJ testing, not daily exposure, was examined used as inclusion criteria. 


\section{CONCLUSION}

This study found that intrarater reliability is higher than interrater reliability for four sacroiliac joint tests. Interrater reliability was extremely variable amongst the four examiners. It is important to note that it is not experience in years, but potentially amount of daily exposure to sacroiliac joint testing that equates to increased reliability. This is an area to be examined in future studies. These results support the need for a standardized teaching protocol for SIJ tests to increase interrater reliability. Because of the high intrarater reliability and low interrater reliability, one can also deduce that, from a clinical standpoint, the same individual should evaluate and treat the same patient daily. 


\section{REFERENCES}

1. Cattley P, Winyard J, Treaskis J, Eaton S. Validity and reliability of clinical tests for the sacroiliac joint. Academy Chiroprac Ortho. 2002;10(2):73-80.

2. Cohen SP. Sacroiliac joint pain: a comprehensive review of anatomy, diagnosis, and treatment. Anest Analg. 2005;101:1440-1453.

3. Forst SL, Wheeler MT, Fortin JD, Vilensky JA. The sacroiliac joint: anatomy, physiology, and clinical significance. Pain Phys. 2006;9:61-68.

4. Zelle BA, Gruen GS, Brown S, George S. Sacroiliac joint dysfunction. Clin J Pain. 2005;21(5):446-452.

5. Weksler N, Velan GJ, Semiono M, Gurevitch B, Klein M, Rozentsveig V, Rudich T. The role of sacroiliac joint dysfunction in the genesis of low back pain: the obvious is not always right. Arch Orthop Trauma Surg. 2007;127:885-888.

6. Hungerford BA, Gilleard W, Moran M, Emmerson C. Evaluation of the ability of physical therapists to palpated intrapelvic motion with the stork test on the support side. Phys Ther. 2002;87(7):879-886.

7. Hungerford B, Gilleard W, Lee D. Altered patterns of pelvic bone motion determined in subjects with posterior pelvic pain using skin markers. Clin Biomech. 2004;19:456-464.

8. Harrison DE, Harrison DD, Troyanovich SJ. The sacroiliac joint: a review of anatomy and biomechanics with clinical implications. JManipulative Physiol Ther. 1997;20(9):607-616.

9. Sebastian D. The anatomical and physiological variations in the sacroiliac joint of the male and female; clinical implications. J Man andManipulative Ther. 2000;8(3):127-134.

10. Foley BS. Sacroiliac joint pain: anatomy, biomechanics, diagnosis, and treatment. Am J Phys Med Rehab. 2006;85(12)997-1000.

11. Alderink GJ. The sacroiliac joint: review of anatomy, mechanics, and function. J Orthop Sports Phys Ther. 1991;13(2):71-84.

12. Cappaert TA. The sacroiliac joint as a factor in low back pain: a review. J Sport Rehabil. 2000;9:169-183.

13. Goode A, Hegedus Ej, Sizer Jr, P, Brismee J, Limberg A, Cook CE. Three-dimensional movements of the sacroiliac joint: a systematic review of the literature and assessment of clinical utility. J Man Manipulative Ther. 2008;16(1):25-38.

14. Gudgel JW, Colloca CJ. Neuromechanical considerations of the sacroiliac joint. Am Chiroprac. 2007;12:30-33. 
15. Hungerford BA, Gilleard W, Moran M, Emmerson C. Evaluation of the ability of therapists to palpate intrapelvic motion with the stork test on the support side. Phys Ther. 2007;87(7)879887.

16. Gemmell HA, Jacobson BH. Incidence of sacroiliac joint dysfunction and low back pain in fit college students. JManipulative Physiol Ther. 1990;12(2):63-66.

17. Robinson HS, Brox JI, Robinson R, Bjelland E, Solem S, Telje T. The reliability of selected motion and pain provocation tests for the sacroiliac joint. Man Ther. 2007;12:72-79.

18. Al-Eisa E, Egan D, Deluzio K, Wassersug R. Effects of pelvic asymmetry and low back pain on trunk kinematics during sitting: a comparison with standing. Spine. 2006;31(5):E135-E143.

19. Levangie PK. The association between static pelvic asymmetry and low back pain. Spine. 1999;24(12):1234-1242.

20. Cibulka MT, Koldenhoff R. Clinical usefulness of a cluster of sacroiliac joint tests in patients with and without low back pain. J Orthop Sports Phys Ther. 1999;29(2)83-92.

21. Tong HC, Heyman OG, Lado DA, Isser M. Interexaminer reliability of three methods of combining test results to determine side of sacral restriction, sacral base position, and innominate bone position. J Am Osteopath Assoc. 2006;106(8):464-468.

22. van Deursen LLJM, Patijn J, Ockhuuysen AL, Vortman BJ. The value of some clinical tests of the sacroiliac joint. J Man Med. 1990;5:96-99.

23. Riddle DL, Freburger JK. Evaluation of the presence of sacroiliac joint region dysfunction using a combination of tests: a multicenter intertester reliability study. Phys Ther. 2002;82(8):772-780.

24. Egan D, Cole J, Twomey L. The standing forward flexion test: an inaccurate determinant of sacroiliac joint dysfunction. Physiother. 1996;82(4):236-242.

25. Levangie PK. Four clinical tests of sacroiliac joint dysfunction: the association of test results with innominate torsion among patients with and without low back pain. Phys Ther. 1999;79(11):1043-1056.

26. Freburger JK, Riddle DL. Using published evidence to guide the examination of the sacroiliac joint region. Phys Ther. 2001;81:1135-1143.

27. Herzog W, Read LJ, Conway PJW, Shaw LD, McEwen MC. Reliability of motion palpation procedures to detect sacroiliac joint fixations. JManipulative Physiol Ther.. 1989;12(2):86-92.

28. Dreyfuss P, Michaelsen M, Pauza K, McLarty J, Bogduk N. The value of medical history and physical examination in diagnosing sacroiliac joint pain. Spine. 1996;21(22):2594-2602. 
29. Meijne W, Neerbos KV, Aufdemkampe G, van der Wurff P. Intraexaminer and interexaminer reliability of the Gillet test. JManipulative Physiol Ther. 1999;21(1)4-9.

30. Vincent-Smith B, Gibbons P. Inter-examiner and intra-examiner reliability of the standing flexion test. Man Ther. 1999;4(2):87-93.

31. Cohen JA. A coefficient of agreement for nominal scales. Educ Psychol Meas. 1960;20:37-46

32. Soeken KL, Prescott PA. Issues in the use of kappa to estimate reliability. Med Care. 1986;24(8):733-741.

33. Shirk C. Reliability of position and mobility of the first ray in experienced and inexperienced examiners. 2004 Master's Thesis West Virginia University.

34. May S, Littlewood C, Bishop A. Reliability of procedures used in the physical examination of non-specific low back pain: a systematic review. Aust J Physiotherapy. 2006;52:91-102.

35. Watson CJ, Propps M, Galt W, Redding A, Dobbs D. Reliability of McConnell's classification of patellar orientation in symptomatic and asymptomatic subjects. J Orthop Sports Phys Ther. 1999;29:378-385.

36. Landis JR, Koch GG. The measurement of observer agreement for categorical data. Biometrics. 1977;33:159-174.

37. Beekman S. Asymmetry and the athlete. PodiatryManagement. 2007;4:79-87.

38. Sim J, Wright CC. The kappa statistic in reliability studies: use, interpretation, and sample size requirements. Phys Ther. 2005; 85(3):257-269.

39. Dane S, Gumustekin K. Correlation between hand a preference and distance of focusing point of two eyes in the horizontal plane. Int J Neurosci. 2002;112(10):1141-1147. 
APPENDICES 


\section{APPENDIX A}

\section{THE PROBLEM}

\section{Research Question}

Sacroiliac joint (SIJ) dysfunction is common in athletes and workers who participate in activities requiring repetitive, unidirectional pelvic shear and torsional forces. ${ }^{3}$ Overall, 90 percent of the population will experience back pain during the course of their lives. ${ }^{5}$ Of this percentage, it is estimated that SIJ pain occurs in as little as .4 percent and up to as much as 98 percent of people classified as having nonspecific chronic low back pain. ${ }^{4,6,7,17-19}$ In the United States, the estimated cost of treating and compensating those with SIJ dysfunction exceeds 14 billion dollars per year. ${ }^{16}$ Despite these seemingly high numbers, there are few reliable procedures available to assist in the evaluation of decreased function and associated pain of the pelvic girdle. ${ }^{4,6,7,17,18,25}$ As a clinical athletic trainer, one will come into contact with many populations complaining of nonspecific low back pain, which points to the possibility of SIJ dysfunction. Knowledge of the anatomical structures and the biomechanics associated with the pelvic girdle is crucial to recognizing the dysfunction, as well as understanding and implementing appropriate evaluation procedures.

The primary function of the SIJ is stability through the transmission and dissipation of forces created by the body as well as gravity. ${ }^{2,67}$ This load transfer is achieved through a self-bracing mechanism. This mechanism causes nutation of the sacrum through neuromuscular activation as well as tensioning of the ligaments and fascia causing compressive forces to act on the joint surface. ${ }^{6,7}$ The SIJ is vulnerable to axial compression and axial torsion overload. ${ }^{3}$

There can be many contributing factors to sacroiliac dysfunction, adding to the difficulty in evaluating and formulating assessments of this area. Factors such as leg length discrepancies, ${ }^{2,16,40-42}$ gait abnormalities, ${ }^{2,37}$ prolonged exercise, ${ }^{2}$ and scoliosis ${ }^{2,16}$ increase the likelihood of SIJ pain and 
dysfunction. These factors create pelvic asymmetry, which alters the biomechanics and places an increased amount of strain on the SIJ and other anatomical structures associated with it. ${ }^{2,3,18}$ Injury due to axial loading and an abrupt rotation, ligamentous tension, hypomobility, hypermobility, shearing forces, and excessive compression forces can also be a cause of asymmetry leading to SIJ dysfunction. ${ }^{2}$ Sacroiliac joint hypomobility, with or without innominate asymmetry, is a major concern. A hypomobile SIJ may stress surrounding tissues if one or both SIJ fail in their function of controlling the transfer of forces due to the biomechanics of the pelvis dissipating force. ${ }^{1,19}$

With limited experience in the evaluation of the SIJ, there have been several athletes who entered the athletic training room without a known mechanism of injury yet complained of severe low back pain. This was noticed especially while working with crew and track athletes. Minor events, such as stepping off a curb wrong or landing primarily on one foot while hurdling can cause increased low back pain days later. As an entry level athletic trainer, a thorough history along with a properly performed evaluation can identify SIJ dysfunction. To the author's knowledge, evaluation procedures of the SIJ has not been standardized among athletic training education programs, mainly since these procedures are constantly changing based on on-going research. In fact, the focus of clinical assessment procedures for pelvic girdle function has shifted in the last ten years from SIJ mobility testing to functional assessment procedures. ${ }^{6,7}$ The diagnosis of SIJ pain is made through a thorough history and physical evaluation; however, studies have demonstrated that neither of these consistently identify SIJ dysfunction/pain. ${ }^{1,2,17}$

There are two types of tests used to assess the SIJ: motion palpation to assess the movement or location of relevant landmarks, and the pain provocation that attempts to reproduce symptoms. Studies report conflicting results for motion palpation tests. Some have reported to have very low reliability while other have reported high reliability. ${ }^{1,7,17,21,23,27,30,34,43}$ Both motion palpation and pain provocation tests appear questionable with respect to their validity, sensitivity, specificity, and reliability. ${ }^{1,3,7,15,17,}$ 
25,27,44 Compared to mobility tests, pain provocation tests also have inconsistent reliability; ${ }^{17,41 \text {, Levin et al }}$ however, Slipman et al. (1998) found that neither a history nor positive pain provocation tests can truly confirm the presence of SIJ dysfunction since many disorders mimic SIJ dysfunction. The Standard for Tests and Measurements in Physical Therapy Practice require that when interpreting tests items such as sensitivity, specificity, and predictive value should be used, especially when classifying individuals into diagnostic groups. ${ }^{25}$ This may create problems when classifying tests into groups.

When evaluating SIJ tests, the intertester and intratester reliability of examiners is very important. More often than not, intratester reliability is higher than intertester reliability. ${ }^{1,7,17,21,23,27,30,34,43}$ Reliability increased in studies that utilized a testing regimen to determine SIJ dysfunction as opposed to one test. ${ }^{17,23,25,27,45,46}$ The Gillet or March test, standing flexion test, sitting flexion test, and supine-tosit test were often included in the regimen. ${ }^{21,25}$ Few SIJ reliability studies have compared inexperienced and experienced examiners. Furthermore, the examiners in SIJ testing were either chiropractors or physical therapists. With certified athletic trainers often performing SIJ testing on patients, it stands to reason that reliability studies should be conducted using this population. Since these evaluation techniques are taught to undergraduate and graduate athletic training students, one should also evaluate the difference between experienced and inexperienced examiners. It is important for athletic trainers in the educational setting to understand these elements of each test when teaching future generations of athletic trainers. It is crucial that the best clinical and evidence based practice be employed so as to advance the profession of athletic training. Therefore, research questions are:

1. Will experienced examiners have a higher reliability of testing than inexperienced examiners?

2. If so, will this study add in identifying the areas of SIJ testing in which inexperienced examiners need more training?

3. Can an effective, standardized evaluation procedure be created for utilization in athletic training education programs? 
Experimental Hypotheses

1. The interrater and intrarater reliability will be moderate to high for experienced examiners during motion palpation and mobility tests.

2. The interrater and intrarater reliability will be low to moderate for inexperienced examiners during motion palpation and mobility tests.

3. There will be an increase in interrater and intrarater reliability for inexperienced examiners during motion palpation and mobility tests when performing the procedure immediately following the first round of testing.

Assumptions

1. The examiners performed the various sacroiliac joint tests to the best of his or her ability and provided answers/feedback to the best of his or her knowledge.

2. Inexperienced and experienced examiners did truly reflect the operational definition.

3. Subjects met all of the predetermined criteria to participate in the study.

4. SIJ tests used were reliable and valid.

5. Data was properly reported and recorded.

Delimitations

1. Since only inexperienced and experienced examiners were used, the study is not generalizable to any other populations.

2. The battery of tests used in this study were standardized.

3. Only a select number of SIJ tests were selected for the study.

4. A heterogeneous mixture of subjects with and without SIJ dysfunction at the time of testing was used.

\section{Operational Definitions}

1. Asymmetry- Occurs when the SIJ does not move the same or has the same location of relevant landmarks.

2. Clinical significance- Determines if the results are meaningful in the real world.

3. Counternutation- Occurring with lumbosacral flexion, it is sacral base movement posterior and superior in relation to the ilium. . $^{3,74}$ 
4. Experienced examiner- A certified athletic trainer with at least 5 years of clinical experience or experience with SIJ evaluation.

5. Hypermobile- Increased movement of the SIJ.

6. Hypomobile- Decreased movement of the SIJ.

7. Ilium- The larger and most upper portion of the pelvis.

8. Inexperienced examiner- A certified athletic training graduate student with less than 5 years of clinical experience or experience with SIJ evaluation.

9. Kinematics- The study of motion without reference to any forces

10. Kinetics- The study of velocities, forces, and accelerations affecting a joint in the human body.

11. Motion palpation tests- Sacroiliac joint testing that assesses the way the SIJ moves or positioning of certain landmarks. ${ }^{1,48}$

12. Nutation- Occurring with lumbosacral extension, it is sacral base movement anterior and inferior in relation to the ilium ${ }^{3,7,47}$

13. Pain provocation tests- Sacroiliac joint testing that stresses the SIJ in order to reproduce painful symptoms. ${ }^{1}$

14. Reliability- Reproducibility of the measurement technique.

15. Sacroiliac joint (SIJ)- The largest axial joint in the human body. It is a diarthrodial, synovial joint that is comprised of the ilium and sacrum. ${ }^{1-4}$

16. Sacroiliac joint dysfunction- Pain in or around the SIJ that could be due to either abnormal movement or malalignment of the SIJs. ${ }^{4,23,47}$

17. Sacrum- Consists of five fused vertebra and also forms the pelvis.

18. Self-bracing mechanism- Mechanism through which load transfer is achieved. It causes nutation of the sacrum through neuromuscular activation as well as tensioning of the ligaments and fascia causing compressive forces to act on the joint surface. ${ }^{6,7}$

19. Sensitivity- The probability that the results of the test will be negative when the test is supposed to be negative.

20. Specificity- The probability that the results of the test will be positive when the test is supposed to be positive.

21. Statistical significance- If the results of the test meet the criterion level of $p>.05$, then the results is statistically significant.

Limitations

1. There was not 100 percent agreement in the literature on which SIJ tests are considered reliable 
and valid.

2. There was a practice effect for the examiners and subjects. The subjects began to know what was expected of him or her while the examiners became more proficient as the study went on.

3. The study had a selection bias since both the examiners and subjects were samples of convenience.

4. The principle investigator demonstrated SIJ testing techniques that were used in the study. Examiners felt confident in the testing procedures and did practice prior to testing to become more proficient in the technique.

Significance of the Study

Sacroiliac joint (SIJ) dysfunction is often the culprit of nonspecific low back pain. It is prevalent in all active populations from professional sports to recreational activities. Despite this, the evaluation tools used have remained mostly ambiguous. The literature on reliability, sensitivity, and specificity of SIJ tests often presents conflicting results. More research needs to be conducted comparing the reliability of the measurement techniques between experienced and inexperienced examiners since SIJ tests are taught in athletic training education programs. Once evaluation techniques have been perfected experienced and inexperienced clinical athletic trainers will be able to properly identify and treat patients with SIJ dysfunction.

The SIJ joint is a complex and intricate structure of the pelvis. The clinical significance of this study is to see how reliable clinicians will be when performing these tests. Understanding the differences between inexperienced and experienced clinicians during a physical evaluation of the SIJ will act as a stepping stone for developing an effective evaluation procedure to teach in undergraduate athletic training education programs. This study will contribute to the literature by identifying the differences between inexperienced and experienced clinicians so a more standardized procedure can be created in the future to aid entry-level athletic trainers. Workshops on SIJ testing as well as standardized procedures in athletic training education programs will educate ATC's by further 
identifying the reliability of motion palpation and pain provocation tests to ensure the best evidence based and clinical practice possible. Consistent low reliability among examiners for some of these tests could indicate a need to provide more opportunities for practice to increase proficiency so that there is more consistency with SIJ testing throughout the athletic training profession. By doing this, patients with SIJ dysfunction will be identified sooner and appropriately treated. 


\section{APPENDIX B}

\section{LITERATURE REVIEW}

Introduction

The pelvis is formed by the sacrum and 2 innominates, each of which is comprised of the ilium, ischium and pubis. The sacroiliac joint (SIJ) has been described as a true, diarthrodial, synovial joint that is designed primarily for stability and transferring loads. ${ }^{3-10}$ Force closure and form closure are important in pelvic stability. Form closure is provided by the bony structures while force closure provides compression using muscular and ligamentous structures. ${ }^{8,47,49,50}$ Many ligamentous and muscular structures interact with the SIJ via their attachments on the pelvis to maximize pelvic stability while minimizing SIJ movement. Muscles influencing the SIJ that provide force closure include latissimus dorsi, gluteal muscles, multifidus, biceps femoris, piriformis, iliopsoas, transverse abdominus, internal oblique, and diaphragm. The SIJs are stable when forces are at 90 degree angles but susceptible to injury with shear forces. Rotation is around three axes; however, only a very small amount of motion (estimated to be about 2.5 degrees) occurs, therefore a lot of intrapelvic motion is needed to transmit forces. ${ }^{1,2,6,7}$

Sacroiliac joint (SIJ) dysfunction is common in athletes and workers who participate in activities requiring repetitive, unidirectional pelvic shear and torsional forces. ${ }^{3}$ The etiology of SIJ dysfunction often includes sudden missteps, axial loading and rotation, or secondary causes such as

poor posture and unsupported sitting. ${ }^{2,12,51}$ Overall, 90 percent of the population will experience back pain during the course of their lives. ${ }^{5}$ A 1986 report claimed that 550 million days of work are lost annually due to pain, of this 56 percent is related to the low back. ${ }^{30}$ Of this percentage, it is estimated that SIJ pain occurs in as little as .4 percent and up to as much as 98 percent of individuals classified as having nonspecific chronic low back pain., ,6,7,17-19 
Many tests exist that assess mobility, including the stork stand, flexion-adduction of the hip, hip internal rotation, iliac crest tissue tension, lateroflexion, sitting forward flexion, standing forward flexion, spine, supine-to-sitting, thigh thrust SI motion, unilateral hip rotation, sacral base position with trunk flexion and extension, active straight leg raise, supine ASIS symmetry, prone knee flexion, neutral zone analysis, and sitting PSIS tests..$^{23,30,47}$ Motion palpation tests have been reported to have very low reliability. ${ }^{1,17,41}$ Compared to mobility tests, pain provocation tests produce reliability values ranging from poor to excellent. ${ }^{17,30,47,52}$ Examples of pain provocation tests are FABER, Gaenslens, posterior shear, resisted abduction, compression/distraction, Yeoman's, cranial shear, pubic symphysis springing, sacral sulcus tenderness, sacral thrust and resisted hip external rotation tests. Reliability studies that examine SIJ testing procedure often utilize chiropractors or physical therapists. More often than not, intratester reliability is higher than intertester reliability. ${ }^{1,7,17,21,23,27,30,34,43}$ Both motion palpation and pain provocation tests appear questionable with respect to their validity, sensitivity, specificity, and reliability. ${ }^{1,3,5,1725,27,44}$

This literature review includes anatomy, biomechanics, epidemiology, etiology, signs and symptoms, SIJ tests, SIJ reliability studies, and the kappa statistic.

\section{Anatomy}

Bone: The pelvis is formed by a convex-concave relationship between two innominates. ${ }^{10,37,53}$ Each innominate is comprised of the ilium, ischium and pubis, and the sacrum. The ilium has two halves that articulate with the pubic symphysis and sacrum. ${ }^{37}$ The ilium is L-shaped. There is a shorter segment vertically towards the head and a horizontally longer segment more caudally to facilitate weight bearing. ${ }^{10-12}$ Compared to females, male ilia are more vertical and less flared than female ilia. $^{8,11,12,53}$ The sacrum is shaped similar to the ilium to facilitate weight bearing. As an unpaired bone consisting of five sacral vertebra, the sacrum tapers posteriorly and caudally, to create an inverted 
triangle which acts as a narrow base. ${ }^{12,53}$ Important bony landmarks on the pelvis are the iliac crest, posterior superior iliac spine (PSIS), anterior superior iliac spine (ASIS), sacral sulcus, and inferior lateral angles(ILA) of the sacrum. ${ }^{53}$ The sacroiliac joint has been described as a true, diarthrodial, synovial joint that is designed primarily for stability and transferring loads. ${ }^{3-7,11}$ One set of authors ${ }^{54}$ argued that the SIJ should be considered a symphysis with some characteristics of a synovial joint since there is a distal cartilaginous portion at the iliac side. Although considered the largest axial joint in the body, with an average surface area of $17.5 \mathrm{~cm}^{2}$, the joint is only $1-2 \mathrm{~mm}$ wide. ${ }^{2,10}$ The SIJs are stable when forces are at 90 degree angles but susceptible to injury with shear forces. Both force closure and form closure are important in pelvic stability. Form closure is provided by the bony structures to increase joint congruity while force closure provides compression using muscular and ligamentous structures. The ligamentous structures prevent motion to maintain stability while the muscular structures increase stability by transmitting and absorbing forces being placed on the SIJ.

Ligamentous: Many large ligaments and muscles attach to the SIJ to increase the stability of the pelvic ring while minimizing SIJ movement. Ligaments of the pelvic girdle are extremely important when maintaining joint stability. Ligaments influencing the SIJ include the interosseous, iliolumbar, sacrotuberous, sacrospinous, pubic, long posterior sacroiliac and short posterior sacroiliac ligaments. These ligaments all assist in limiting various types of motion when tightened thereby providing force closure.

SIJ intrinsic ligaments include the long and short posterior sacroiliac, anterior sacroiliac, and the posterior interosseous ligament. ${ }^{8,10,12,51,53,55}$ The interosseous sacroiliac ligament creates the largest syndesmosis in the human body. ${ }^{8,12}$ This ligament is also considered the strongest support of the SIJ. ${ }^{12}$ The interosseous ligament's main function is to prevent anterior and posterior translation. ${ }^{8}, 12$ The anterior or ventral sacroiliac ligament is an inferior and anterior thickening of the joint capsule. ${ }^{8,11,12,51,53,56}$ This thin ligament is often the cause of a hypermobile SIJ. ${ }^{53}$ The short posterior SI 
ligament attaches from the sacrum to the ilium in a medial to lateral and lateral to medial fashion. ${ }^{8,10,12,51,53,55,56}$ The long posterior or dorsal ligament attaches from the posterior superior iliac spine (PSIS) to the sacrum to prevent anterior rotation..$^{8,10-12,51,53,55,56}$

The extrinsic ligaments of the SIJ are the sacrotuberous, sacrospinous, and iliolumbar ligaments. The iliolumbar ligament attaches from L5 to the iliac crest to prevent separation of the sacrum from the ilia. ${ }^{8,12,53,55,56}$ The sacrospinous ligament attaches from the sacrum and the coccyx to the spine of the ischium to control posterior rotation of the ilium and sacral forward flexion. ${ }^{8,12,51,53,55,56}$ The sacrotuberous controls the pelvis in the same manner as the sacrospinous; however, this ligament blends with the inferior fibers of the gluteus maximus and biceps femoris and attaches from the PSIS to the ischial tuberosity. ${ }^{8,10-12,51,53,56}$ Considered to be the "phylogenetically degenerated tendon of origin of the long head of biceps femoris, ${ }^{, 57}$ the sacrotuberous ligament also attaches to the ischial tuberosity. Due to this attachment, full tension generated by the biceps femoris cannot pass directly to the ligament. ${ }^{57}$

Muscle: It is important to remember that many authors ${ }^{10,53}$ argue that there are no muscular attachments on the SIJ while some ${ }^{11,53}$ argue that the piriformis attaches on the SIJ. Despite this, many muscles influence the SIJ as well as provide force closure. Force closure is achieved through a feedforward mechanism that inhibits certain muscle groups while activating other muscle groups. ${ }^{14}$ This aids the transfer and absorption of body forces as well as gravity. Table B1 summarizes the muscles including origin, insertion, and action that influence the SIJ. Laterally the tensor fascia lata, gluteus medius, and gluteus minimus can affect ilial motion due to their attachment sites. ${ }^{1,12,51,53}$ Medially the hip adductors such as adductor magnus, adductor brevis, adductor longus, gracilis, and pectineus can cause motion due to their attachments on or near the pubic symphysis. ${ }^{1,12,51,53}$ Sartorius can affect iliosacral movement as well as knee and hip movement. ${ }^{12}$

One of the most important structure is the thoracolumbar fascia., ${ }^{3,40,47,49}$ The thoracolumbar 
fascia has extensive attachments to the lumbar spinous processes, interspinous ligaments, medial sacral crest, lumbar transverse processes, intertransverse ligaments from the iliac crest to the twelfth rib, ilium, iliolumbar ligament, erector spinae, internal oblique, serratus posterior inferior, sacrotuberous ligament, anterior sacroiliac ligament, posterior iliac spine, and sacral crest. ${ }^{12}$ Supported by the transverse abdominus and multifidus muscles, ${ }^{40}$ this structure increases intra abdominal pressure, creates divergent force vectors, acts as a connection for musculature, and provides "hydraulic amplification created in the lumbar paraspinals" to provide SIJ stability. ${ }^{47}$ The superficial portion of the thoracolumbar fascia assists in force transmission from the lower extremity across the pelvis to the contralateral latissimus dorsi. ${ }^{12,49}$ Posterior muscles that act on the pelvic girdle include the the latissimus dorsi, erector spinae, quadratus lumborum, hip external rotators, multifidus, hamstrings, piriformis, gluteus maximus, transverse abdominus, internal oblique, and diaphragm. ${ }^{1,12,51,53}$ Hip extensors can affect sacral motion due to the attachment on the sacrotuberous ligament. ${ }^{12}$ Anterior muscles that act on the pelvic girdle include the abdominals, iliopsoas, and rectus femoris. ${ }^{12,51,53}$ Much like sartorius, rectus femoris can affect iliosacral movement as well as knee and hip movement. ${ }^{12,51}$ Iliopsoas attaches on the ilium, sacrum, and lower lumbar segments to affect the function of both the lumbar spine as well as the pelvis. ${ }^{12}$ This muscle also decreases shear force on the SIJ by loading the femur against the acetabulum. ${ }^{51}$

Neurovascular: Neurological information is provided by extensive innervation of nerves, mechanoreceptors, and nociceptors. ${ }^{11,12,14,49,51}$ Examples of mechanoreceptors are Golgi tendon organs (GTOs) and groups I-II proprioceptive nerve endings that are both myelinated and unmyelinated ${ }^{11,12,14}$ Mechanoreceptors are stimulated to either inhibit or activate muscles. ${ }^{51}$ While being located in the pelvis, many nerves innervate the lower limb rather than pelvic structures. Table B2 summarizes the nerves as well as origin and distribution. Due to the extensive nerve innervations, 
Table B1. Muscles 1,11,12,51,53,56

\begin{tabular}{|c|c|c|c|}
\hline Muscle & Origin & Insertion & Action \\
\hline Multifidus & $\begin{array}{l}\text { Posterior sacrum, PSIS, } \\
\text { erector spinae, sacroiliac } \\
\text { ligament, lumbar vertebra, } \\
\text { transverse processes T1-T3 } \\
\text { and articular processes C4- } \\
\text { C7 }\end{array}$ & $\begin{array}{l}\text { Spinous processes of } \\
\text { vertebra }\end{array}$ & Stabilization of vertebra \\
\hline Erector Spinae & $\begin{array}{l}\text { Posterior iliac crest, } \\
\text { posterior sacrum, sacroiliac } \\
\text { ligament, sacral and inferior } \\
\text { lumbar spinous processes, } \\
\text { supraspinous ligament }\end{array}$ & $\begin{array}{l}\text { Transverse } \\
\text { processes,spinous } \\
\text { processes ribs, mastoid } \\
\text { process, }\end{array}$ & $\begin{array}{l}\text { Extension, lateral flexion of } \\
\text { vertebral column }\end{array}$ \\
\hline Quadratus Lumborum & $\begin{array}{l}\text { Medial half of inferior } \\
\text { border of } 12^{\text {th }} \text { ribs and } \\
\text { lumbar transverse processes }\end{array}$ & $\begin{array}{l}\text { Iliolumbar ligament and } \\
\text { iliac cret }\end{array}$ & $\begin{array}{l}\text { Extension, Lateral flexion } \\
\text { of vertebral column }\end{array}$ \\
\hline Pectineus & Superior ramus of pubis & $\begin{array}{l}\text { Femur, Inferior to lesser } \\
\text { trochanter }\end{array}$ & $\begin{array}{l}\text { Adduction, medial rotation, } \\
\text { and flexion of thigh }\end{array}$ \\
\hline Psoas & $\begin{array}{l}\text { T12-L1 and transverse } \\
\text { processes of lumbar } \\
\text { vertebra }\end{array}$ & $\begin{array}{l}\text { Lesser trochanter of } \\
\text { femur }\end{array}$ & $\begin{array}{l}\text { Flexion and stabilization of } \\
\text { thigh at hip joint }\end{array}$ \\
\hline Iliacus & $\begin{array}{l}\text { Iliac crest and fossa, } \\
\text { sacrum, anterior sacroiliac } \\
\text { ligaments }\end{array}$ & $\begin{array}{l}\text { Psoas major tendons, } \\
\text { lesser trochanter of femur }\end{array}$ & $\begin{array}{l}\text { Flexion and stabilizion of } \\
\text { thigh at hip joint }\end{array}$ \\
\hline Sartorius & ASIS & $\begin{array}{l}\text { Superior medial surface } \\
\text { of tibia }\end{array}$ & $\begin{array}{l}\text { Flexion, abduction, and } \\
\text { lateral rotation of thigh at } \\
\text { hip; flexion of knee }\end{array}$ \\
\hline Rectus femoris & $\begin{array}{l}\text { ASIS and ilium proximal to } \\
\text { acetabulum }\end{array}$ & Patellar ligament & $\begin{array}{l}\text { Extension of knee, } \\
\text { stabilization and flexion of } \\
\text { hip }\end{array}$ \\
\hline Adductor longus & Inferior pubic crest & Linea aspera of femur & Adduction of thigh \\
\hline Adductor brevis & Inferior ramus of pubis & Linea aspera of femur & Adduction of thigh \\
\hline Adductor magnus & $\begin{array}{l}\text { Inferior ramus of pubis, } \\
\text { inschial tuberosity }\end{array}$ & $\begin{array}{l}\text { Femur via gluteal } \\
\text { tuberosity, linea aspera, } \\
\text { and adductor tubercle }\end{array}$ & $\begin{array}{l}\text { Adduction, flexion, and } \\
\text { extension of thigh }\end{array}$ \\
\hline Gracilis & $\begin{array}{l}\text { Body and inferior ramus of } \\
\text { pubis }\end{array}$ & Superior-medial tibia & $\begin{array}{l}\text { Adduction of thigh and } \\
\text { flexion of leg }\end{array}$ \\
\hline Gluteus maximus & $\begin{array}{l}\text { Ilium, sacrum, coccyx, and } \\
\text { sacrotuberous ligament }\end{array}$ & Iliotibial tract & $\begin{array}{l}\text { Extension, lateral rotation, } \\
\text { and stabilization of thigh }\end{array}$ \\
\hline Gluteus medius & Ilium & $\begin{array}{l}\text { Greater trochanter of } \\
\text { femur }\end{array}$ & $\begin{array}{l}\text { Abduction, medial rotation, } \\
\text { and stabilization of thigh }\end{array}$ \\
\hline Gluteus minimus & Ilium & $\begin{array}{l}\text { Greater trochanter of } \\
\text { femur }\end{array}$ & $\begin{array}{l}\text { Abduction, medial rotation, } \\
\text { and stabilization of thigh }\end{array}$ \\
\hline Tensor fascia lata & ASIS and iliac crest & Iliotibial tract & $\begin{array}{l}\text { Abduction, medial rotation, } \\
\text { and stabilization of thigh }\end{array}$ \\
\hline Piriformis & $\begin{array}{l}\text { ASIS, sacrotuberous } \\
\text { ligament }\end{array}$ & $\begin{array}{l}\text { Greatr trochanter of } \\
\text { femur }\end{array}$ & $\begin{array}{l}\text { Lateral rotation of the } \\
\text { extended thigh, abduction of } \\
\text { the flexed thigh, hold } \\
\text { femoral head in acetabulum }\end{array}$ \\
\hline Semitendinosus & Ischial tuberosity & Tibia & $\begin{array}{l}\text { Extension of thigh, flexion } \\
\text { of leg }\end{array}$ \\
\hline
\end{tabular}




\begin{tabular}{|c|c|c|c|}
\hline Semimembranosus & Ischial tuberosity & Tibia & $\begin{array}{l}\text { Extension of thigh, flexion } \\
\text { of leg }\end{array}$ \\
\hline Biceps femoris & $\begin{array}{l}\text { Ischial tuberosity, } \\
\text { sacrotuberous ligament, and } \\
\text { femur }\end{array}$ & Fibula & $\begin{array}{l}\text { Flexsion of leg, extension of } \\
\text { thigh }\end{array}$ \\
\hline Latissimus dorsi & $\begin{array}{l}\text { Iliac crest, thoracic } \\
\text { vertebra, interior } 3 \text { or } 4 \text { ribs }\end{array}$ & Humerus & $\begin{array}{l}\text { Extension, adductsion, and } \\
\text { medial rotation of humerus, } \\
\text { raises body towards arms }\end{array}$ \\
\hline Rectus abdominus & Pubic symphysis and crest & $\begin{array}{l}\text { Xiphoid process and } 5^{\text {th }}- \\
7^{\text {th }} \text { costal cartilages }\end{array}$ & $\begin{array}{l}\text { Flexion of trunk, } \\
\text { stabilization and control of } \\
\text { pelvic tilt }\end{array}$ \\
\hline Transverse abdominus & $\begin{array}{l}\text { Costal cartiliages, iliac } \\
\text { crest, thoracolumbar fascia, } \\
\text { inguinal ligament }\end{array}$ & Pubic crest, linea alba & $\begin{array}{l}\text { Compresssion and support } \\
\text { of abdominal viscera }\end{array}$ \\
\hline Internal oblique & $\begin{array}{l}\text { Iliac crest, thoracolumbar } \\
\text { fascia, inguinal ligament }\end{array}$ & $10-12$ th ribs, linea alba & $\begin{array}{l}\text { Compression and support } \\
\text { of viscera, flexion and } \\
\text { rotation of trunk }\end{array}$ \\
\hline External oblique & $5^{\text {th }}-12^{\text {th }}$ ribs & Pubic tubercle, iliac crest & \\
\hline
\end{tabular}

SIJ pain can present many different ways. The pelvis itself is innervated by sacral and coccygeal nerves such as the sciatic, pudendal, superior gluteal, and inferior gluteal nerves, all of which arise from either the lumbar or sacral spinal nerves. ${ }^{10,58,59}$

The pelvis has an extensive network of blood vessels which supply the internal pelvic structures. Most of the arteries of the pelvis originate from the posterior or anterior divisions of the internal iliac artery. These arteries supply the structures housed inside the pelvis as well as muscles surrounding the pelvis. Table B3 summarizes each artery, including origin and distribution. The most noted circulatory structures are the the coccygeal branches of the inferior gluteal artery which pierces the sacrotuberous ligament. ${ }^{57}$ The plexus of Batson, consisting of arteries and veins, also vascularizes the pelvis. ${ }^{47}$ The veins around the pelvis drain into the internal iliac veins and superior rectal vein to either the inferior mesenteric vein or lateral sacral vein to the internal vertebral venous plexus. ${ }^{58}$ The internal iliac veins and external iliac veins merge to form the common iliac vein. The common iliac vein is where the iliolumbar veins drain. ${ }^{58}$ 
Table B2. Nerve Innervations 13,1011,58,59

\begin{tabular}{lcl}
\hline Nerve & Origin & Distribution \\
\hline Sciatic & L4-S3 & Hip, knee flexors, leg, foot muscles \\
Superior gluteal & L4-S1 & Gluteus medius and minimus muscles \\
Nerve to quadratus femoris and & L4-S1 & $\begin{array}{l}\text { Quadratus femoris and inferior } \\
\text { gemellus muscles }\end{array}$ \\
inferior gemellus & & Gluteus maximus muscle \\
Inferior gluteal & L5-S2 & $\begin{array}{l}\text { Obturator internus and superior } \\
\text { Gemellus muscles }\end{array}$ \\
Nerve to obturator internus and & L5-S1 & Piriformis muscle \\
superior gemellus & & $\begin{array}{l}\text { Buttock and superior medial and } \\
\text { posterior thigh }\end{array}$ \\
Nerve to piriformis & S1, S2 & Medial buttock \\
Posterior femoral cutaneous & S2, S3 & Genitalia, perineal muscles, external \\
urethral sphincter, external anal
\end{tabular}

Table B3. Blood Vessels ${ }^{58,59}$

\begin{tabular}{|c|c|c|}
\hline Artery & Origin & Distribution \\
\hline Iliolumbar & $\begin{array}{l}\text { Posterior division of internal iliac } \\
\text { artery }\end{array}$ & $\begin{array}{l}\text { Psoas, iliacus, quadratus lumborum } \\
\text { muscles }\end{array}$ \\
\hline Internal iliac & Common iliac artery & $\begin{array}{l}\text { Pelvic organs, gluteal muscles, } \\
\text { perineum }\end{array}$ \\
\hline Anterior division of internal iliac & Internal iliac artery & $\begin{array}{l}\text { Pelvic viscera, muscles of superior } \\
\text { medial thigh, perineum }\end{array}$ \\
\hline Posterior division of internal iliac & Internal iliac artery & Pelvic wall and gluteal region \\
\hline Obturator & $\begin{array}{l}\text { Anterior division of internal iliac } \\
\text { artery }\end{array}$ & $\begin{array}{l}\text { Pelvic muscles, muscles of medial } \\
\text { compartment of thigh }\end{array}$ \\
\hline Superior gluteal & $\begin{array}{l}\text { Posterior division of internal iliac } \\
\text { artery }\end{array}$ & Piriformis, gluteals, tensor fascia lata \\
\hline Median sacral & Posterior aspect of abdominal aorta & $\begin{array}{l}\text { Inferior lumbar vertebrae, sacrum, ad } \\
\text { coccyx }\end{array}$ \\
\hline Lateral sacral & $\begin{array}{l}\text { Posterior division of internal iliac } \\
\text { artery }\end{array}$ & $\begin{array}{l}\text { Piriformis, erector spinae, tensor } \\
\text { fascia lata muscles }\end{array}$ \\
\hline Umbilical & $\begin{array}{l}\text { Anterior division of internal iliac } \\
\text { artery }\end{array}$ & Superior aspect of urinary bladder \\
\hline Internal pudendal & $\begin{array}{l}\text { Anterior division of internal iliac } \\
\text { artery }\end{array}$ & Main artery of perineum \\
\hline Inferior gluteal & $\begin{array}{l}\text { Anterior division of internal iliac } \\
\text { artery }\end{array}$ & $\begin{array}{l}\text { Pelvic diaphragm, piriformis, } \\
\text { quadratus femoris, hamstrings, } \\
\text { gluteus maximus, sciatic nerve }\end{array}$ \\
\hline
\end{tabular}


Biomechanics

Kinematics: The SIJ rotates around three axes $(\mathrm{X}, \mathrm{Y}$, and $\mathrm{Z})$ with the origin lying halfway between the left and right PSIS. ${ }^{1,2,6,7,12,13}$ Six degrees of freedom, three angular and three linear, have been identified. ${ }^{11-13}$ Only a very small amount of motion (estimated to be about 2.5 degrees) occurs. ${ }^{12,6,7}$ Movement can occur between the sacrum and ilium, or around the pubic symphysis. ${ }^{37}$ Sacral motion on the ilium occurs around an oblique axis while anterior and posterior rotation of the ilium on the sacrum occurs around a transverse axis in the sagittal plane. ${ }^{53,55}$ The ilia provide five degrees of inflare and five degrees of outflare motion in the transverse plane. ${ }^{55}$ During inflare, the ASIS move medially while the PSIS move laterally and vice versa for outflare. ${ }^{55}$ There is typically five degrees of posterior rotation and five degrees of anterior rotation. ${ }^{55}$ Anterior rotation of the innominates occurs with hip extension while posterior rotation of the innominates occurs with hip flexion..$^{12,1437,53,55}$ During anterior rotation, the ASIS will become lower and the PSIS will become higher. ${ }^{37}$ Due to the link between the innominates and sacrum, anterior rotation (nutation relative to the base) of the sacrum occurs with posterior rotation of the innominates and vice versa. This sacral flexion(nutation) can also occur with trunk extension while sacral extension(counternutation) occurs with trunk flexion. ${ }^{3,11,12,14,55}$ Counternutation of the sacrum is thought to be the less stable, open pack position for the SIJ., 3,6, 12,14 Kinetics: As mentioned, the SIJ rotates around three axes; however, only a very small amount of motion occurs, therefore a lot of intrapelvic motion is needed to transmit forces. ${ }^{1,2,6,7}$ The SIJ is vulnerable to axial compression and axial torsion overloading. ${ }^{3}$ The primary function of the SIJ is stability through the transmission and dissipation of forces created by the body as well as gravity.,6,7,12 This load transfer is achieved through a self-bracing mechanism, also known as the close-pack position. In a closed pack position, neuromuscular activation as well as tensioning of the fascia and ligaments such as the interosseous and short dorsal ligaments cause compressive forces to act on the joint surface. ${ }^{6,7,15,40}$ When an individual moves from supine to sitting or standing, the ilia rotate backwards 
and the iliac crest move inward. ${ }^{11,60}$ The self-braced, closed pack position of the SIJ is during nutation of the sacrum or posterior rotation of the innominate. ${ }^{6,715}$ This occurs when sitting or standing since one's center of gravity falls on the posterior pelvis, creating a pelvic tilt. ${ }^{6,7,12,53}$ Counternutation of the sacrum and anterior rotation of the innominate is a less stable position. ${ }^{6,7,12}$

During the gait cycle, the ilium rotate posteriorly during the swing phase. At midswing, the hip is flexed and there is posterior rotation of the innominate. As the leg accelerates through the swing phase, tension accumulates on the oblique axis, causing the sacrum to lock and increase the shearing force of the pelvis. This posterior rotation converts to anterior rotation right after the loading response while the sacrum rotates forward. ${ }^{11}$ During these movements, there is a shearing force on the SIJ due to a deceleration moment on the innominates, as well as the open pack position. ${ }^{6,7,12,15,53}$ At heel strike, the hip internally rotates, causing an inflare of the ilium. There is also a slight posterior rotation that accompanies this. Once the foot is flat, there is counternutation of the sacrum. At midstance, the hip externally rotates, causing an outflare of the ilium. At this point, the sacrum rotates forward along a diagonal axis. At heel off, the hip extends and the innominate anteriorly rotates. At toe off, the center of gravity shifts forward and the innominate anteriorly rotates. ${ }^{12,53}$ Running increases the anterior pelvic tilt during terminal stance through toe- off to increase the extension of the lower extremity. ${ }^{61}$ When running as opposed to walking, axial rotation of the pelvis during the initial contact phase changes from rotating to the opposite side to rotating to the same side. This prevents a loss of speed. Since the double support phase is lost during running, the pelvis is no longer needed to increase stride length. ${ }^{61}$

Epidemiology

Low back pain (LBP) is estimated to occur at least once in 80 to 90 percent of the population. ${ }^{5,12}$ Within a year, seven percent of adults will seek medical attention for this complaint and 
$\$ 5$ billion to $\$ 20$ billion annually will be spent in health care to directly treat LBP. ${ }^{5}$ The SIJ was described as a source of LBP for the first time in 1905 by Goldwaith and Osgood. ${ }^{20,62}$ Before 1934, SIJ dysfunction was considered the most common cause of LBP. In a study by Weiner et al. ${ }^{63} 83.6$ percent of patients complaining of chronic low back pain also had findings indicative of SIJ dysfunction. Some studies $^{44,46,51,64}$ estimated the prevalence of SIJ dysfunction to be between 13 and 30 percent, with 19.3 to 47.9 percent of SIJ dysfunction being linked to LBP. Another study ${ }^{17}$ reported ranges from .4 to 98 percent of LBP as being attributed to SIJ dysfunction.

Two percent of United States workers are affected annually. ${ }^{10}$ A study by Toussaint et al. ${ }^{65}$ found a 29 percent incidence of sacroiliac joint dysfunction in construction workers who had positive ipsilateral results in the spine test, the standing flexion test, or the iliac springing test in side position. They also found a 6.3 percent incidence of sacroiliac joint dysfunction found by positive results for the spine test and the standing flexion test and a positive finding either for the iliac compression test or the iliac springing test. On the day of the study, 92.1 percent of participants had an asymptomatic sacroiliac joint dysfunction while 7.9 percent of participants had low back pain due to a sacroiliac joint dysfunction. Oftentimes, females will experience SIJ dysfunction more often than males since females have a lower SIJ to sacrum ratio, making it more mobile as compared to males. ${ }^{66}$ Furthermore, 20 to 80 percent of females will have SIJ pain during pregnancy. ${ }^{4}$ Sacroiliac joint dysfunction is present in both active individuals such as rowers ${ }^{67,68}$ marathon runners ${ }^{69}$ as well as inactive individuals with desk jobs. $^{70}$ The incidence of SIJ dysfunction in fit college students was 19.3 percent. ${ }^{12,16}$

Etiology

Sacroiliac joint dysfunction can exist as either an ilial lesion consisting of an anterior rotation, posterior rotation, inflare, outflare, upslip, or down slip; or as a sacral lesion consisting of a right rotation, left rotation, flexion or extension. ${ }^{55}$ Sacroiliac joint dysfunction can be caused by direct and 
indirect factors. Commonly reported mechanisms of SIJ dysfunction are poor muscular support during trunk flexion, ${ }^{4,71}$ hard missteps down on one foot, ${ }^{4,12,16,53,71,72}$ being rear-ended in a motor vehicle accident, ${ }^{4,40,62,71}$ or falling on the buttocks. ${ }^{3,4,12,16,40,53,62,71}$ This type of injury causes a combination of axial loading with abrupt rotation to occur. ${ }^{2,51,53}$ Pregnancy also increases the chance that a woman will experience SIJ dysfunction since there is an increased lordotic curve, weight gain, and release of hormones that can potentially contribute to the laxity of the ligaments around the SIJ. 2,9,10,12,40,47,62,66,71,73 Sometimes, the mechanism of injury is unknown. ${ }^{12}$ Unsupported sitting, kyphotic postures, and asymmetrical loading of the lower extremities could be causes of a SIJ dysfunction., ${ }^{42,40,71,74}$

From a sport standpoint, SIJ dysfunction can occur from cumulative shear or torsional forces during sports such as skating, gymnastics, golf, rowing, and bowling;, ${ }^{4,47,62,67}$ by running on the same side of a crowned road or on a banked track, which could possibly create a leg length discrepancy, ${ }^{37,41,69,76}$ or in sports with unilateral loading such as baseball or soccer. ${ }^{10}$ Risk factors such as a leg length discrepancy, ${ }^{2,16,37-42}$ gait abnormalities, ${ }^{2,37}$ prolonged exercise, ${ }^{2}$ muscle imbalances,${ }^{53}$ muscle strains ${ }^{53}$ hypermobility, ${ }^{8,19,38,47,53}$ hypomobility, ${ }^{8,19,40,47,53}$ and scoliosis ${ }^{2,16}$ can increase the chances of an individual acquiring a SIJ dysfunction.

\section{Signs and Symptoms}

Those with SIJ dysfunction will present with a wide array of signs and symptoms. Pain characteristics and locations can vary. When taking the subjective portion of an examination, dysfunction questionnaires can be helpful. Low back pain disability, SIJ dysfunction, medical history, and medication questionnaires can be completed. The patient should report date of onset, chief complaint with pain range and activities that causes irritation, sleep limitations, and answer questions about function. ${ }^{40}$ Function questions should include aggravating or limiting factors in activities of daily living including how much or how long he or she can perform the activity and perceived level of 
function. ${ }^{40}$

Patients will report either bilateral or unilateral pain in the lumbar spine, SIJ, and buttocks. ${ }^{10,12,14,47.53 .59 .66 .72 .76-78}$ This pain could radiate to the iliac crest, thigh, groin, inguinal ligament, leg, foot, or abdomen. ${ }^{10,14,47,53,59,66,71,76-79}$ Patients could possibly report an increase in pain when walking, running, sitting on the affected side, lying on the affected side, and touching one's toes while keeping the legs straight. ${ }^{16,53,71}$ Common complaints could be feelings of numbness, popping, catching or clicking; as well as weakness or fatigue in the lumbo-sacral region. ${ }^{10,12,47,53}$

A certified athletic trainer (ATC) evaluating a patient for SIJ dysfunction will elicit tenderness with palpation over the SIJ, PSIS, and lumbar spine., ${ }^{4,12,40,45}$ Sometimes palpable muscle spasms around the lumbar spine are also present. When performing an evaluation, the ATC should evaluate posture, gait, and have the patient perform functional tests such as squatting and balancing. ${ }^{38,49,80,81}$ Gait and function testing will sometimes reveal limited stride length on one side, excessive foot pronation on one side, restricted ankle dorsiflexion with squatting, and Trendelenberg during the gait cycle or balancing on a single leg. ${ }^{40}$ The ATC should perform passive range of motion (PROM) of the hip for flexion, extension, medial rotation, lateral rotation, abduction, adduction, flexion with a straight leg raise, and with the FABER position in order to note quality, end feel, and assess muscle length ${ }^{40,80,81}$ Many times, the ATC will note limited flexion, extension, medial rotation, and a limited FABER. ${ }^{40}$ Active trunk range of motion performed standing and seated should include flexion, extension, side bending and rotation. The ATC should also evaluate the patient's ability to transfer weight as well as the ability to perform repeated movements. Range of motion assessment will show a notable decrease in trunk range of motion and function as well as hip range of motion and function. ${ }^{12,38,47,70}$ The ATC should perform manual muscle testing of the hip flexors, quadriceps, gluteus medius, gluteus maximus, hamstring, transversus abdominus, and lower trunk rotators. This testing could demonstrate weakness of the gluteal muscles, abdominals, multifidus, hamstrings, and hip flexors. ${ }^{38}$ 


\section{Sacroiliac Joint Testing}

The focus of clinical assessment procedures for pelvic girdle function has shifted in the last ten years from SIJ mobility testing to functional assessment procedures. ${ }^{6,7}$ The diagnosis of SIJ pain is made through a thorough history and physical evaluation; however, studies have demonstrated that neither of these consistently identify SIJ dysfunction/pain ${ }^{2,17}$ There are two types of tests used to assess the SIJ including motion palpation to assess the movement or location of relevant landmarks, and the pain provocation that attempts to reproduce symptoms.

Palpation and mobility: Many tests exist to assess SIJ mobility. Motion palpation/mobility tests can be separated into dynamic and static tests. Dynamic tests such as standing flexion, sitting flexion, Gillet, and supine-to-sit examine hypomobility or motion asymmetry of the SIJ. ${ }^{25}$ Other dynamic tests include the flexion-adduction of the hip, hip internal rotation, lateroflexion, sacral base position with trunk flexion and extension, active straight leg raise, thigh thrust SI motion, unilateral hip rotation, and prone knee flexion. Static tests include iliac crest tissue tension, spine, supine ASIS symmetry, neutral zone analysis, and sitting PSIS tests. Motion palpation tests have been reported to have very low reliability. ${ }^{17}$ One of the explanations for this has been identified as any abnormal tissue tension around bony landmarks which create false results during palpation. ${ }^{1}$ Another topic of debate is whether or not sitting flexion tests detect hypomobility of the sacrum on the ilium while standing flexion detects hypomobility of the ilium on the sacrum. ${ }^{25}$

The Stork stand test is also referred to as the Gillet or March test ${ }^{1,4,6,7,21,25,27,28}$ During this test, the evaluator palpates certain landmarks while the patient slowly raises the leg into maximal hip flexion with the knee flexed to 90 degrees. This test has been described several different ways in the literature, causing a lack of standardization among evaluators and creating issues with reliability. Despite the disparities between the application of the test, it is accepted that this test assesses the ability of the patient to maintain a stable alignment of the innominate bone relative to the sacrum during load 
transfer thereby identifying any sacral restriction. ${ }^{1,4,6,7,21,25,27,28}$ While the motion performed by the patient is the same, there is debate about the landmarks that are palpated. Hertzog et al. ${ }^{27}$ described the landmarks as bilateral palpation of the PSISs with the motion followed by palpation of the PSIS and second sacral tubercle with the motion. Most studies ${ }^{6,7,21,28}$ describe the palpation of the landmarks as solely the PSIS and second sacral tubercle. Another study ${ }^{29}$ identified several palpations that need to be preformed while the patient is performing the motion including L5 and the PSIS, S1 and the PSIS, S3 and the PSIS, and the hiatus sacralis and caudolateral to the hiatus sacralis underneath the ischial spine. Despite these differences, general consensus is that a negative result indicates downward movement of the the PSIS on the side of the flexed leg while with a positive test the PSIS either does not move downward or moves upward relative to the other palpation landmark. ${ }^{1,6,7,21,25,27}$ This test is more reliable if only negative or positive results were recorded instead of attempting to identify the discrepancy. ${ }^{6,7}$ Tong et al. ${ }^{21}$ believed this test to have the best interexaminer reliablilty while Cattley et al. ${ }^{1}$ considered this test to be invalid and not reliable because the SIJ is engaged bilaterally when balancing on one leg while lifting the other. They suggested a modification to this test in which the patient keeps the foot on the ground and lets the hip drop rather than lifting the knee to the chest.

Seated and standing forward flexion tests are often employed when assessing the SIJ. Several authors $^{1,21,25}$ describe the seated or sitting forward flexion test. This test is used to determine the side of the dysfunction of the sacrum moving on the innominate bone. It is performed with the patient seated and the evaluator behind the subject, palpating the PSIS. As the patient flexes their trunk forward, the PSIS should move up. If one side moves higher than the other by more than $1 \mathrm{~cm}$ it is a positive test. Conversely, studies ${ }^{20-24}$ describe the standing forward flexion test as assessing the movement of the innominate on the sacrum. The evaluator sits behind the patient with the thumbs on both PSISs, while the patient bends forward slowly as far as possible. Ideally, both PSIS should move up equally. ${ }^{7,20,22}$ The test is positive if one thumb starts to move before the other and if at the end of the range of motion 
one thumb is higher than the other by more than $1 \mathrm{~cm}$. While standing, one can evaluate sacral base position with trunk flexion and trunk extension. ${ }^{21}$ This is performed with the patient standing and the evaluator seated behind them. The sacral base is palpated while the patient flexes and extends the trunk. If one side of the sacral base is anterior or posterior to the other side, then the test is positive.

The active straight leg raise test is hypothesized to examine the transfer of load through the trunk and lower limb region. ${ }^{6,7,82}$ When performing this test, the patient is instructed to lay supine and lift one leg off the table. If there is SIJ instability, the patient will complain of heaviness in the leg. This test is then repeated with compression applied to the ilia to see if there is improvement. A positive test is indicated when the pelvis fails to remain in neutral with patient reported difficulty or inability to elevate a straight leg while supine. ${ }^{6,782}$ Symptomatic patients will report pain directly over the SIJ without any referred or radiating pain, indicating that ligamentous structures as well as the SIJ are involved.

Supine ASIS symmetry as well as the supine-to-sit test are two tests commonly performed with the patient supine. Both require that the patient performs a bridge to clear the hips. After this traction is usually applied. The supine ASIS symmetry test assesses the level of the ASIS bilaterally. ${ }^{21}$ If the ASIS on the side of dysfunction is higher or lower than the other one by one $\mathrm{cm}$ or more, the test is positive. Typically this test is performed in conjunction with the stork test and standing flexion test to increase the reliability. ${ }^{21}$ The supine-to-long sitting requires that the level of the malleoli are compared bilaterally in two positions: laying down and in a long sit position. ${ }^{1,20,21,23,25}$ A negative test would be if there was no difference between and no change in malleoi heights in either position. A positive test would be if there were differences, which would indicate an innominate rotation. Much like the supine-to-sit test, the prone knee flexion test assesses leg length differences. For this test, the patient lies in a prone position with the knees flexed to 90 degrees and then with the knees extended. The leg length is assessed in both of these positions. A positive test would be a shorter leg with the knees 
extended, indicating a posterior rotation..$^{20,42}$

Pain provocation: Compared to mobility tests, the reliability of pain provocation tests have ranged from poor to excellent. ${ }^{17}$ Examples of pain provocation tests are FABER, Gaenslens, posterior shear, resisted abduction, compression/distraction, Yeoman's, cranial shear, pubic symphysis springing, sacral sulcus tenderness, sacral thrust and resisted hip external rotation tests. Slipman et al. ${ }^{83}$ found that neither a history nor positive pain provocation tests can truly confirm the presence of SIJ dysfunction since many disorders mimic SIJ dysfunction. Force distribution is a key component to any pain

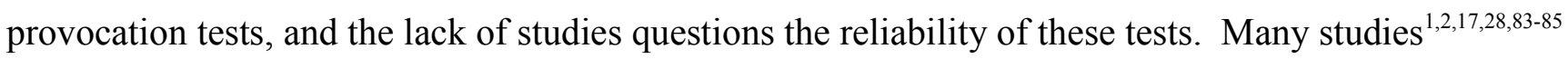
have described pain provocation tests; however, there are very few studies examining how the evaluator distributed the forces being used while performing these tests. A study by Levin et al. ${ }^{86}$ sought to answer this question using force plates with the SI compression and distraction test. They found an inconsistency of forces being applied by evaluators. Gaenslens, Patrick/FABER, and posterior shear are the most reliable tests since clinical reliability has been reported to be greater than 80 percent. Patrick/FABER, posterior shear and resisted abduction together have been found to have sensitivities ranging from 70 to 80 percent and a 100 percent specificity. ${ }^{84}$

Patrick/FABER is performed with the patient supine. ${ }^{1,2,17,84}$ The ipsilateral hip and knee are brought into flexion, and the heel is placed against the knee of the other leg. The evaluator then applies pressure to the contralateral ASIS to keep the low back in neutral as well as applies pressure to the ipsilateral knee to stress the anterior SI ligament and hip joint. Broadhurst and Bond ${ }^{84}$ found this test to have 77 percent sensitivity and 100 percent specificity. Some studies ${ }^{1,28,83,85}$ consider this test invalid and unreliable. When examining the literature, there is a notable lack of standardization when performing the test, which could contribute to the validity and reliability of the test. FABER is described in many ways. At times the description is flexion, abduction, and external rotation of the hip. $^{28,84}$ Another study ${ }^{22}$ stated that it is performed supine with one leg flexed so the ipsilateral heel is 
next to the opposite knee while the patient presses the flexed knee outward and then the evaluator continues this motion. In some cases the patient is positioned supine with one leg flexed so the heel is on the opposite knee and movement is passively reiforced by the ealuator pressing on the flexed knee. ${ }^{85}$

Gaenslen's test is performed with the patient in a supine position with one hip and knee flexed and the other hip extended while pressure is applied ${ }^{1-4,28,45}$ This test stresses both SIJ simultaneously. ${ }^{4}$ Two studies ${ }^{28,45}$ found this test to be reliable.

Thigh thrust/ posterior shear test positions the patient supine with the hip flexed to 90 degrees and the knee flexed. ${ }^{1,84}$ A posterior shearing stress is applied along the line of the femur. This maneuver causes posterior shear forces on the ilium and causes SIJ pain. ${ }^{4}$ Broadhurst and Bond ${ }^{84}$ found this test to have 80 percent sensitivity and 100 percent specificity. Other studies ${ }^{28,45}$ have also found this test to be both valid and reliable.

During the resisted abduction test the patient is supine with the leg fully extended and abducted to 30 degrees. ${ }^{1,4}$ The evaluator pushes medially against the ipsilateral ankle as the subject pushes laterally. ${ }^{1}$ Broadhurst and Bond ${ }^{84}$ found this to have 87 percent sensitivity and 100 percent specificity. Compression and distraction are two most commonly used tests. ${ }^{1,3,17}$ The compression test has the patient positioned sidelying facing away from the examiner while downward pressure is applied to the iliac crest. This test stretches the posterior SI ligament or compresses the anterior SIJ. ${ }^{17}$ During the distraction test the patient is supine while posterior-lateral pressure is applied to the ASIS. ${ }^{1,3,17}$ This test stretches the anterior SI ligament. ${ }^{17}$ The sacral thrust/compression test places the patient in a prone position while a thrust is applied to the sacrum in an anterior direction. This test is considered to be invalid and unreliable. ${ }^{1,28,45,83,85}$ 


\section{SIJ Reliability Studies}

In recent years, the term evidence based practice has been used to describe the rationale for various treatments and assessment tools. Sacroiliac joint testing, like many of the other orthopedic assessment tools and tests used in athletic training, has been studied to determine reliability and validity. In this case, the evidence leads to conflicting results about which tests should be used in everyday practice. Table B4 summarizes some of the studies performed on SIJ testing, including tests used, the participants, the general procedure, and the results including the statistics used.

Some of these studies examined only an individual SIJ test. Both Herzog et al. ${ }^{27}$ and Hungerford et al. ${ }^{15}$ focused on the Gillet or Stork stand test. The participants in these studies varied. Herzog et al. ${ }^{27}$ used chiropractors whereas Hungerford et al. ${ }^{15}$ used physical therapists; however, neither groups participated in a training or practice session beforehand. The palpation landmarks and general description of the test were the same; however the rating scales were different. Hungerford et al. ${ }^{15}$ found that when physical therapists used a two point scale to identify if a dysfunction was present, the kappa scores were .67 for the left side and .77 for the right side; whereas using a three point scale kappa scores were lower (.59 on the left and .59 on the right). Herzog et al. ${ }^{27}$ did not use Cohen's kappa coefficient for reliability. Percent agreement was used instead. In this study, the examiners rated the joint fixation as mild, moderate, or complete. The examiners were first compared statistically as one group, and then were split into a high expertise group and a low expertise group. In the first session, there was an overall 78 percent agreement for severe patients and nonsevere patients while in the second session there was a 56 agreement for severe patients and a 54 percent agreement for the nonsevere patients. When combining these two sessions to compare high and low expertise, the percent agreement on SIJ fixations was 72 percent with a 78 percent agreement on the correct side for low expertise chiropractors while high expertise chiropractors had 64 percent agreement on SIJ fixation with a 67 percent agreement on the correct side. 
Unlike Hungerford et al. ${ }^{15}$ and Herzog et al., ${ }^{27}$ Schneider et al. ${ }^{42}$ and Vincent-Smith and Gibbons $^{30}$ performed studies on two other SIJ tests; the prone leg length analysis procedure and the standing flexion test. Schneider et al. ${ }^{42}$ examined the interexaminer reliability of the prone leg length analysis procedure. In this study, two chiropractors were used as examiners. Prior to the testing date, the two chiropractors met with the authors for training and practice sessions. Upon testing, the examiners were told to report the side of the short leg with the knees extended, the amount of leg length difference, if there was any change with head rotation, and whether or not the short leg became longer with knee flexion. Cohen's kappa coefficient was used in this study. The authors found kappa values of $.65, .28, .04$, and -.195 with identification of the short leg with the knee extended, reported leg length difference, head rotation left, and head rotation right, respectively. Unlike previously discussed studies, Vincent-Smith and Gibbons ${ }^{30}$ used physical therapy students as the examiners in their study of the standing flexion test. Subject positioning, examiner positioning, and the instructions were all standardized without a practice or training session prior to data collection. They found an interexaminer reliability kappa value of .052 and an intraexaminer reliability kappa of .46.

Other studies examined a group of tests, sometimes as a test regimen and other times as only a means to compare the tests to each another. Three studies ${ }^{21,23,26}$ examined motion and palpation tests. Freburger and Riddle ${ }^{26}$ determined the reliability of using handheld calipers and an inclinometer with SIJ dysfunction subjects. In this case, the examiners were physical therapists who received instructions prior to the testing day. For this study, both the ICC and Cohen's kappa were low at .27 and .18, respectively. Riddle and Freburger ${ }^{23}$ published another study in 2002 that examined the standing flexion, prone knee flexion, supine to long sitting, and sitting PSIS tests. The physical therapists used as examiners were given a written description on the procedures complete with pictures. Prior to testing, they were allowed to practice until they felt comfortable. In this case, Riddle and Freburger also found low kappa scores ranging from .11 to .23. Both of these studies indicate that these SIJ tests 
are uncertain in terms of reliability.

Tong et $\mathrm{al}^{21}$ used physicians at spine centers as the examiners in their study. The physicians and subjects participated in this study over the course of a year. Interexaminer reliability of three different methods for SIJ dysfunction evaluation using the same tests: seated flexion, standing stork, standing flexion, sacral base position with trunk flexion and extension, supine ASIS symmetry, and supine medial malleolus symmetry were compared. The first method "used the examination that had the best interexaminer reliability to determine the diagnoses for the sacral and innominate bone positions." The second method "required that at least one palpatory examination reveal dysfunction for a variable to be considered abnormal." The third method "required that all of the palpatory examinations reveal dysfunction for a variable to be considered abnormal." The kappa statistics for each individual test were as follows: seated flexion $(\mathrm{k}=.11)$, standing stork $(\mathrm{k}=.50)$, standing flexion $(\mathrm{k}=.30)$, sacral base with trunk flexion $(\mathrm{k}=.47)$, sacral base with trunk extension $(\mathrm{k}=.26)$, ASIS symmetry $(\mathrm{k}=.29)$, and medial malleolus symmetry $(\mathrm{k}=.49)$. For method one, kappas were higher with sacral position $(\mathrm{k}=.47)$, innominate bone position $(\mathrm{k}=.08)$, and side of dysfunction $(\mathrm{k}=.32)$. Method two yielded kappa scores of $.09, .04$, and .16 respectively while method three yielded kappa scores of $.16, .1$, and -.33 , respectively. From this, the authors determined that method one had the highest interexaminer reliability and should be used clinically.

Two studies, Robinson et al. ${ }^{17}$ and Kokmeyer et al., ${ }^{46}$ examined SIJ pain provocation tests to determine if they were reliable. Robinson et al. ${ }^{17}$ used the compression, distraction, $\mathrm{P} 4$, Patrick, bilateral internal hip rotation, and unilateral internal hip rotation, joint-play, and Drop tests in their study. The physiotherapists did not undergo a training session prior to the study. They were blinded to the patient's diagnosis as well as each other. A one hour break took place between the two examinations. In this study, kappa scores for the individual pain provocation tests ranged between .43 and .84 while the joint play test had a kappa score of -.06. Kokmeyer et al. ${ }^{46}$ examined the distraction, 
compression, thigh thrust, Gaenslen, and Patrick tests using two final year physical therapy students.

They wanted to determine if a regimen of these five tests would be reliable in diagnosing SIJ pain. The examiners used the tests as described by Magee. The weighted kappa in this study was .70. From this they determined that "a multitest regimen of five sacroiliac joint pain provocation tests is a reliable method to evaluate SIJ dysfunction.

Table B4. SIJ Reliability studies

\begin{tabular}{|c|c|c|c|c|c|}
\hline Authors & SIJ tests examined & \#participants & $\begin{array}{l}\text { Admission } \\
\text { criteria }\end{array}$ & Procedure & Results \\
\hline $\begin{array}{l}\text { Herzog et al } \\
1989\end{array}$ & Gillet test & $\begin{array}{l}11 \text { subjects } \\
10 \text { chiropractors }\end{array}$ & $\begin{array}{l}\text { Subjects: } \\
\text { Referral from } \\
\text { chiropractor and } \\
\text { identified as } \\
\text { having SIJ } \\
\text { problems } \\
\text { Chiropractors: } \\
\text { volunteer }\end{array}$ & $\begin{array}{l}\text { Examiner palpated } \\
\text { BL PSIS while } \\
\text { subject raised flexed } \\
\text { knee. Examiner then } \\
\text { palpated second } \\
\text { sacral tubercle and } \\
\text { PSIS while subject } \\
\text { raised flexed knee on } \\
\text { right. It was then } \\
\text { performed on the left. } \\
\text { The examiner then } \\
\text { rated the fixation as } \\
\text { mild, moderate, or } \\
\text { complete }\end{array}$ & $\begin{array}{l}\text { Significant } \\
\text { intraexaminer } \\
\text { reliability for all } 3 \\
\text { sessions } \\
\text { Significant } \\
\text { interexaminer } \\
\text { reliability for only } \\
\text { sessions } 1 \text { and } 3 \\
\text { Chiropractors with } \\
\text { more experience } \\
\text { had higher } \\
\text { intraexaminer } \\
\text { scores } \\
\text { Statistics used: } \\
\text { percent agreement }\end{array}$ \\
\hline $\begin{array}{l}\text { Hungerford et } \\
\text { al } 2007\end{array}$ & $\begin{array}{l}\text { Stork test on the } \\
\text { support side }\end{array}$ & $\begin{array}{l}33 \text { subjects } \\
3 \text { physical } \\
\text { therapists }\end{array}$ & $\begin{array}{l}\text { Subjects: } \\
\text { Volunteers at } \\
\text { least } 18 \text { yrs old } \\
\text { Physical } \\
\text { Therapists: } \\
\text { experience and } \\
\text { frequent use of } \\
\text { stork test }\end{array}$ & $\begin{array}{l}\text { The examiner placed } \\
\text { the right thumb on the } \\
\text { right PSIS and the left } \\
\text { thumb on the second } \\
\text { sacral spinous } \\
\text { process. The subject } \\
\text { then raised the } \\
\text { contralateral leg to } \\
90-90 \text {. This was } \\
\text { performed } 3 \text { times } \\
\text { and then performed } \\
\text { on the other side. The } \\
\text { examiner then rated it } \\
\text { on a } 3 \text { point scale as } \\
\text { well as a } 2 \text { point scale }\end{array}$ & $\begin{array}{l}\text { Interrater reliability } \\
\text { for the } 3 \text { point scale } \\
\text { was moderate for } \\
\text { both sides whereas } \\
\text { the interrater } \\
\text { reliability was good } \\
\text { for the } 2 \text { point scale } \\
\text { Statistics used: } \\
\text { Cohen kappa } \\
\text { reliability } \\
\text { coefficient, and } \\
\text { percent agreement }\end{array}$ \\
\hline $\begin{array}{l}\text { Schneider et al } \\
2007\end{array}$ & $\begin{array}{l}\text { Prone leg length } \\
\text { analysis procedure }\end{array}$ & $\begin{array}{l}45 \text { subjects } \\
2 \text { chiropractors }\end{array}$ & $\begin{array}{l}\text { History of LBP, } \\
\text { between } 18 \text { and } \\
65 \text { yrs old, able } \\
\text { to tolerate prone } \\
\text { position }\end{array}$ & $\begin{array}{l}\text { Each participant } \\
\text { evaluated all subjects. } \\
\text { First, the observed the } \\
\text { leg length with knees } \\
\text { extended, then after } \\
\text { knees have been } \\
\text { flexed to } 90 \text { degrees, } \\
\text { and afterwards if the } \\
\text { leg length is judged to }\end{array}$ & $\begin{array}{l}\text { Good reliability in } \\
\text { identifying a leg } \\
\text { length difference } \\
\text { but poor reliability } \\
\text { when identifying } \\
\text { how much. The } \\
\text { head rotation step } \\
\text { was also unreliable }\end{array}$ \\
\hline
\end{tabular}


Vincent-Smith Standing flexion and Gibbons

1999
14 student subjects Subjects all had to be around the same height and weight, have no LBP or low limb pain, and no previous pelvic or lower limb surgery

Osteopathic students: 4-5 yrs experience using standing flexion test

\section{3 subjects}

23 physical therapists were examiners
Kokmeyer et al 1)Distraction test 2002 2)compression test 3)thigh thrust 4)Gaenslen 5)Patrick
78 subjects

2 final year physical therapy students be less than .25

inches the patient rotates their head to see if rotation causes a change

The test was performed to the methodology chosen. The examiners reported positive right, positive left, or negative

$\begin{array}{ll}\begin{array}{l}\text { Subject were } \\ \text { included if SIJ } \\ \text { examination }\end{array} & \begin{array}{l}\text { The examiner } \\ \text { identified the ASIS } \\ \text { and PSIS landmarks } \\ \text { bould be }\end{array} \\ \begin{array}{l}\text { bycluded in the } \\ \text { normal }\end{array} & \begin{array}{l}\text { adhesive dot on the } \\ \text { location. }\end{array} \\ \begin{array}{l}\text { assessment and } \\ \text { Inclinometers were }\end{array} \\ \begin{array}{ll}\text { if there was no } \\ \text { radiographic }\end{array} & \begin{array}{l}\text { used to record the } \\ \text { angles between the }\end{array} \\ \text { evidence of } & \begin{array}{l}\text { landmarks. A retest } \\ \text { examiner then }\end{array} \\ \text { scoliosis or leg } & \begin{array}{l}\text { performed the same } \\ \text { length }\end{array} \\ \text { discrepancies } & \text { procedure }\end{array}$

None specified MicroFet 2 as well as Two trials for each test. The MicroFet 2 and feedback ensured that 250 to $300 \mathrm{~N}$ of forces was used when applying pressure for the tests. Each test was held 5 seconds. Subjects indicated ye or no if the test was painful

Subjects must be The physical between 18 and 65 , be referred or treated for LBP, have unilateral or bilateral low back pain, be a new patient, positive side and asymmetry if present. The retest therapist then had the subject rate their pain and
Statistics used:

cohen kappa

reliability

coefficient, percent agreement, confidence interval, prevalence index, bias index

The standing flexion test has insignificant reliability.

Statistics used: percentage agreement, Cohen's unweighted kappa agreement coefficient, and standard error

There was low reliability of the measurement of the difference between the angles of inclination of the innominates.

Measurements of SIJ alignment are unreliable

Statistics used: ICC, kappa, standard error of measurement,

A battery of tests produce better reliability than a single test alone

Statistics used: weighted kappa, bias index, prevalence index, and prevalence adjusted and bias adjusted kappa

The authors considered the reliability of the tests too low for clinical use
Statistics used: percent agreement, cohen kappa 


\begin{tabular}{|c|c|c|c|c|c|}
\hline $\begin{array}{l}\text { Robinson et al } \\
2005\end{array}$ & $\begin{array}{l}\text { 1) compression } \\
\text { 2)distraction } \\
\text { 3) P4 } \\
\text { 4)Patrick } \\
\text { 5)BL IR hip and } \\
\text { unilateral IR hip } \\
\text { 6) joint-play } \\
\text { 7)Drop }\end{array}$ & $\begin{array}{l}61 \text { subjects } \\
\text { physiotherapists }\end{array}$ & $18-50$ years old & $\begin{array}{l}\text { Each participant was } \\
\text { examined by } 2 \\
\text { physiotherapists, with } \\
\text { a break of } 1 \mathrm{~h} \\
\text { between each exam. } \\
\text { Both examiners } \\
\text { performed all the } \\
\text { listed tests. The } \\
\text { results were } \\
\text { appropriately } \\
\text { recorded }\end{array}$ & $\begin{array}{l}\text { Reliability of pain } \\
\text { provocation tests is } \\
\text { acceptable while } \\
\text { the palpation test } \\
\text { had poor reliability } \\
\text { Statistics used: } \\
\text { percent agreement, } \\
\text { cohen kappa } \\
\text { coefficient, } \\
\text { confidence interval }\end{array}$ \\
\hline Tong et al 2006 & $\begin{array}{l}\text { 1) seated flexion } \\
\text { 2) standing stork } \\
\text { 3) standing flexion } \\
\text { 4) sacral base } \\
\text { position with trunk } \\
\text { flexion and } \\
\text { extension } \\
\text { 5) supine ASIS } \\
\text { symmetry } \\
\text { 6) supine medial } \\
\text { malleolus } \\
\text { symmetry }\end{array}$ & $\begin{array}{l}24 \text { subjects } \\
2 \text { physicians }\end{array}$ & $\begin{array}{l}\text { Chief complaint } \\
\text { of LBP }\end{array}$ & $\begin{array}{l}\text { Three different } \\
\text { methods were used. } \\
\text { Method lused the } \\
\text { examination with the } \\
\text { best interrater } \\
\text { reliability. Method } 2 \\
\text { required that at least } \\
\text { one dysfunction was } \\
\text { found during } \\
\text { palpation. Method } 3 \\
\text { required that all } \\
\text { palpation tests } \\
\text { reveiled a dysfunction }\end{array}$ & $\begin{array}{l}\text { Interrater reliability } \\
\text { was highest for } \\
\text { Method } 1 \\
\text { Statistics used: } \\
\text { cohen's kappa } \\
\text { coefficient }\end{array}$ \\
\hline
\end{tabular}

\section{Kappa Statistic}

have discomfort performed the same in the buttocks

tests

area, be able to

reach at least the

patella with their fingers coefficient, observed portion positive agreement

Reliability of pain provocation tests is on test Statistics used: percent agreement, Interrater reliability was highest for

Stistics used: cohen's kappa coefficient

In this study, Cohen's kappa statistic will be used for interexaminer and intraexaminer

reliability. Cohen's kappa is the amount of agreement between two or more examiners rating a certain amount of subjects after the chance of agreement has been removed. ${ }^{31,32}$

It is particularly useful when one examiner has a tendency to use a specific category more often than any other category. ${ }^{33}$ The equation for Cohen's kappa is: ${ }^{32}$

$$
\kappa=\left(p_{o}-p_{c}\right) /\left(1-p_{c}\right)
$$

$\mathrm{p}_{\mathrm{o}}$ is the observed proportion(percentage) of agreement $=(1 / \mathrm{n}) \sum_{\mathrm{i}} \mathrm{n}_{\mathrm{ji}}$ (Observed 
the total possible data. ${ }^{31-33}$ Agreement can be positive or negative and shows which type of answer is most likely. ${ }^{23}$ )

$\mathrm{p}_{\mathrm{c}}$ is the chance of proportion (percentage) of agreement $=\left(1 / \mathrm{n}^{2}\right) \Sigma_{\mathrm{i}} \mathrm{n}_{\mathrm{i}} \cdot \mathrm{n}_{\cdot \mathrm{j}}$

$\mathrm{n}_{\mathrm{ij}}$ is the observed frequency in the $\mathrm{i}$, jth cell, also known as the number of subjects assigned rating $\mathrm{i}$ by Rater 1 and rating $\mathrm{j}$ by Rater 2 .

$\mathrm{n}_{\mathrm{i}}$. is the marginal row frequencies $=\Sigma_{\mathrm{j}} \mathrm{n}_{\mathrm{ij}}$

$\mathrm{n}_{\cdot \mathrm{j}}$ is the marginal column frequencies $=\Sigma_{\mathrm{i}} \mathrm{n}_{\mathrm{ij}}$

To use kappa, three assumptions must be met including the objects or subjects to be rated are independent of one another, the raters operate independent of one another, and the categories are mutually exclusive and complete. ${ }^{31-33}$ Kappa scores range from -1 to 1 with scores closer to one indicating better reliability. ${ }^{15,30,32,34}$ Positive scores signify agreement better than chance while a negative value is worse than chance. Zero means that the agreement is no better than chance. ${ }^{30}$ Using the Landis and Koch scale, ${ }^{6,30,32-35}$ kappa scores are poor if $\mathrm{k}<0$, slightly agree if $\mathrm{k}$ is between 0 and . 20, fair if $\mathrm{k}$ is between .21 and .40 , moderate if $\mathrm{k}$ is between .41 and .60 , substantial if $\mathrm{k}$ is between .61 and .80 , and perfect if between .81 and $1 .^{15,33,34,36}$

Typically if the results of a study had nominal data, unweighted kappa will be used, whereas if the data is ordinal then a weighted kappa should be used..$^{32,34,38}$ For unweighted kappa scores, all disagreements are equally serious whereas weighted kappa scores are rank-interval and can indicate values of differences between disagreements using units of measurements. ${ }^{32}$ When kappa scores are expected to be skewed, maximum kappa and kappa/kappa maximum can be calculated. ${ }^{23}$ The maximum kappa is typically calculated with low kappa scores and is the best agreement that can occur without chance in the present distribution. ${ }^{31,33}$ Maximum kappa is the best reliability that could be reached. ${ }^{33}$ This will be helpful if the kappa score is low while observed proportion(percentage) of agreement is high. Maximum kappa is calculated as follows: 


\section{$\mathrm{Kmax}=(\mathrm{Pm}-\mathrm{Pc}) /(1-\mathrm{Pc})$}

$\mathrm{Pm}$ is a percentage taken from the lowest pair of marginal data from row and column totals while Pc is the "proportion of units for which agreement is expected by chance. ${ }^{31,33}$ It is found by multiplying each row and column total together and then summing the results.

Kappa/kappa maximum is the proportion of the maximum kappa coefficient that kappa was able to reach. When this proportion is high, the two examiners could agree well, and chance is not a factor. By taking the difference between kappa and kappa maximum, the amount of disagreement truly present can be found..$^{31,33}$

Summary

The sacroiliac joint is a complex structure used primarily for stability and transferring loads. Force closure provided by muscles and ligaments and form closure provided by the bony anatomy of the pelvis are important in pelvic stability. The various ligamentous and muscular structures interacting with the pelvis and therefore the SIJ maximize pelvic stability while minimizing SIJ movement. These two closures provide stability with forces at 90 degree angles but are unable to protect the SIJ from shear forces. Despite the small amount of movement, force transmission is achieved through motion between the two innominates.

Athletes and non-athletes who participate in activities requiring repetitive, unidirectional pelvic shear and torsional forces are at an increase risk of SIJ dysfunction. Aside from the biomechanics required from sports that could lead to a SIJ dysfunction, activities of daily living and minor episodes such as missteps down, poor posture and unsupported sitting can be mechanisms. A majority of the population will experience back pain during the course of their lives, and millions of days will be lost, and millions more will be spent in treating LBP and associated SIJ dysfunction. 
SIJ testing encompasses both palpation, mobility, and pain provocation testing. There are many tests that assess palpation and mobility, ranging from the stork stand, to sacral base position with trunk flexion and extension to supine ASIS symmetry. Most motion palpation tests have been reported to have very low reliability while pain provocation tests have had a reliability ranging from poor to excellent. Pain provocation tests ranging from FABER to sacral thrust stress the SIJ in an attempt to elicit pain. Reliability studies that examine SIJ testing procedure often employ physicians, chiropractors, or physical therapists as the examiners. Because of this, intratester reliability is typically higher than intertester reliability. Despite the individuals participating in the studies, motion palpation and pain provocation tests appear questionable with respect to their validity, sensitivity, specificity, and reliability. 
APPENDIX C

ADDITIONAL METHODS

Table C1. Informed Consent.

\section{CONSENT AND INFORMATION FORM}

\section{Reliability of Sacroiliac Joint Tests in Experienced and Inexperienced Examiners Introduction}

You, , have been invited to participate in this research study, which has been explained to me by Danielle Lueck, ATC. She is conducting research under the supervision of Michelle A. Sandrey, PhD, ATC to fulfill the requirements for a masters thesis for Athletic Training in the College of Physical Activity and Sports Sciences at West Virginia University.

\section{Purposes of the Study}

The purposes of the study are to evaluate 1) whether or not experienced examiners have a higher reliability of sacroiliac joint testing than inexperienced examiners and 2) how reliable is this measurement over time. This study will include 50 subjects, four examiners, and four recorders.

\section{Description of this Study}

This study will be conducted at HealthWorks Rehab and Fitness at 943 Maple Drive, Morgantown, WV 26505.

\section{Orientation Procedures}

Examiners: At an orientation meeting, you will be explained the purpose of this study. You will also be given an informed consent form explaining your rights as a research subject. It will be explained that it is important that you are present for all meetings and for their entirety after the orientation meeting.

Recorders: At an orientation meeting, you will be explained the purpose of this study. You will also be given an informed consent form explaining your rights as a research subject and a copy of the data sheet that you will be recording onto. It will be explained that it is important that you are present for both meetings and for their entirety after the orientation meeting.

Subjects: At an orientation meeting, you will be explained the purpose of this study. you will also be given an informed consent form and a demographic/injury history questionnaire explaining you rights as a research subject. If you are an eligible subject, you will sign up for a time slot on the day that the study will take place. You will be asked for your full cooperation and that you show up on time your time slot.

Version Date Time




\section{Reliability of Sacroiliac Joint Tests in Experienced and Inexperienced Examiners}

Interventions

Examiners: You will be required to come to one practice and one testing meeting to complete the required testing procedure. The practice meeting will take place at HealthWorks Rehab. and Fitness 45-60 minutes prior to testing. The test meeting will take place at HealthWorks Rehab and Fitness. There will be three other examiners participating in this study. At your practice session, you will practice the battery of sacroiliac joint tests. You will be allowed to practice this method until you are comfortable during this practice meeting. You understand that this practice meeting may last up to an hour. You will perform the Stork stand/Gillet test, standing flexion test, seated flexion test, and supine-to-sit test on each subject that enters the examination room. You will indicate a positive test by telling the recorder "yes" or a negative test by telling the recorder "no."

Recorders: You will be required to come to one meeting to complete the required testing procedure. You will show up at least 15 minutes prior to each meeting at HealthWorks Rehab and Fitness and will be allowed to leave after the last subjects have been evaluated. You will perform the same duties at each meeting. You will be given a pen and clipboard with data recording sheets to record all data for one examiner. Three other recorders will be participating in this study. No examiner's names will be used on the sheet, but corresponding numbers to each examiner that will be randomly chosen prior to the meeting. You will rotate from table to table with the examiner that you are assigned to. After each measurement, you will record the examiner's result by circling the indicated response. After each data sheet is complete, you will place the used data sheet in a designated folder that will be given to the principal investigator at the end of the meeting. You understand that this meetings may last up to five hours.

Subjects: You will show up for your allotted time slot at HealthWorks Rehab and Fitness. There will be three or four other subjects showing up at the same time as you do to be tested. You will warmup prior to testing. You will be brought to the treatment area and asked to remain standing. You will follow the directions given to you by the examiner. The first two tests will require you to stand feet shoulder width apart with weight equally distributed on both legs. The stork stand test will require that you assume a single leg stance with your hip and knee flexed to 90 degrees. The standing flexion test will require that you slowly bend forward as far as possible and then stand up straight. The seated flexion test will require that you sit on the treatment table with your legs shoulder width apart, hanging off the table. You will slowly bend forward as far as possible and then sit upright. The supine-to-sit test will require that you lie on your back on the treatment table. You will then perform a bridge to clear your hips away from the table. You will straighten my legs and allow the examiner to apply traction on both of your legs. When directed to by the examiner, you will sit up without shifting your hips and pelvis.

\section{Risks and Discomforts}

There are no known or expected risks or discomforts from participating in this study. If any injury should occur during the participation of this study, you understand that Danielle Lueck, ATC will provide first aid and make any necessary medical referrals. The four tests used are performed in the clinical setting on a daily basis.

$\overline{\text { Version }} \quad \overline{\text { Date }} \quad \overline{\text { Time }}$




\section{Reliability of Sacroiliac Joint Tests in Experienced and Inexperienced Examiners}

\section{Alternative}

You understand that you do not have to participate in this study.

\section{Benefits}

You understand that this study is not expected to be of direct benefit to you, but the knowledge gained may be of benefit to others.

\section{Financial Considerations}

I will receive no financial remuneration for completing this study.

\section{Contact Persons}

For more information about this research, you can contact Danielle Lueck, ATC at (414) 232.6431 or the principle investigator, Michelle A. Sandrey, PhD, ATC at (304) 293.3295 Ext. 5220 or at msandrey@mail.wvu.edu. For information regarding your rights as a research subject, you may contact the Executive Secretary of the Review Board at (304) 293.7073.

\section{Confidentiality}

You understand that any information about you obtained as a result of your participation in this research will be kept as confidential as legally possible. Identifying information on the informed consent form and demographic/history questionnaire will be kept confidential by assigning a code number to each informed consent form and demographic/injury history questionnaire. You understand that your research records and test results, just like hospital records, may be subpoenaed by court order or may be inspected by the study sponsor or federal regulatory authorities (including the FDA if applicable) without your additional consent. In any publications that result from this research, neither your name nor any information from which you might be identified will be published without your consent.

\section{Voluntary Participation}

Participation in this study is voluntary. You understand that you are free to withdraw your consent to participate in this study at any time and that such refusal to participate will not affect your future care, your employee status at West Virginia University or Healthworks Rehab and Fitness, or your class standing or grades. Refusal to participate or withdrawal will involve no penalty to you. You have been given the opportunity to ask questions about the research, and you have received answers concerning areas you did not understand. In the event new information becomes available that may affect your willingness to continue to participate in this study, this information will be given to you so you may make an informed decision about your participation. Upon signing this form, you will receive a copy.

You willingly consent to participate in this research.

$\overline{\text { Signature of Subject }} \frac{\text { Date }}{\text { Time }}$

$\overline{\text { Signature of Principle Investigator }} \frac{\text { Date }}{\text { Time }}$


Table C2. HIPAA form

\section{Reliability of Sacroiliac Joint Tests in Experienced and Inexperienced Examiners}

\section{Principal Investigator: \\ Department: \\ Tracking Number:}

Subject's Name:

ID Number:

We know that information about you and your health is private. We are dedicated to protecting the privacy of that information. Because of this promise, we must get your written authorization (permission) before we may use or disclose your protected health information or share it with others for research purposes. This form gives that permission. It also helps us make sure that you are correctly told how this information will be used or disclosed. Please read the information below carefully before signing this form. Please ask any questions you may have about this form or its uses. You can decide to sign or not to sign this authorization form. However, if you choose not to sign this authorization form, you will not be able to take part in the research study. Whatever choice you make about this research study, it will not have an effect on your access to medical care.

\section{USE AND DISCLOSURE COVERED BY THIS AUTHORIZATION}

DO NOT SIGN A BLANK FORM. You or your authorized representative should thoroughly read the information below before signing this form.

Who will disclose, receive, and/or use the information? This form will authorize the following person(s), class(es) of persons, and/or organization (s) to disclose, use, and receive the information*: WVU, Michelle A. Sandrey, PhD, ATC and Danielle E Lueck, BS, ATC

*If, during the course of the research, one of the companies or institutions listed above merges with, or is purchased by, another company or institution, this authorization to use or disclose protected health information in the research will extend to the success or company or institution.

What information will be used or disclosed?

A self-report demographic history that includes information on height, weight, and past medical history of any lower limb or back injury.

\section{SPECIFIC UNDERSTANDINGS}

By signing this research authorization form, you give permission for the use and/or disclosure of your protected health information described above. The purpose for the uses and disclosures you are authorizing is to carry out the research study explained to you during the informed consent process. It is also to ensure that the information relating to the research is available to all parties who may need it for research purposes. Your protected health information may be used as necessary for your researchrelated treatment or to collect payment for your research related treatment (when applicable). It may also be used to run the business operations of the institution.

This information may be redisclosed or used for other purposes if a recipient described in this form is 
not required by law to protect the privacy of the information. You have a right to refuse to sign this authorization. Your health care outside the study, the payment for your health care, and your health care benefits will NOT be affected if you do not sign this form. However you will NOT be able to take part in the research study described in this authorization if you do not sign this form.

If you sign this authorization, you will have the right to cancel it at any time, except to the extent that UHA or UHA Affiliated, WVU, WVU Hospitals has already taken action based upon your authorization or needs the information to complete analysis and reports of data for this research study. To cancel this authorization, please write to the Principal Investigator, Michelle A. Sandrey, at: Mailbox \#:PO Box 6116.

You will be allowed to see or copy the information described on this form as long as the research is in progress, but you have a right to see and copy the information upon completion of the research in accordance with hospital policies.

The members and staff of any Institutional Review Board (IRB) that oversees this research study. The Principal Investigator: Michelle A. Sandrey, Phd, ATC, Members of UHA or UHA Affiliated, WVU, WVU Hospitals, administrative staff responsible for administering clinical trials and other research activities, including the Clinical Trials, Office/Office of Research and other -research activities, including the Clinical Trials, Office/Office of Research and Sponsored Programs.

You have a right to receive a copy of this form after you have signed it.

Expiration Date: None

THE SUBJECT OR HIS/HER AUTHORIZED REPRESENTATIVE MUST BE PROVIDED WITH A COPY OF THIS FORM AFTER IT HAS BEEN SIGNED.

\section{SIGNATURE}

I have read this form and all of my questions about this form have been answered. By signing below, I acknowledge that I have read and accept all of the above.

$\overline{\text { Signature of Subject or Authorized Representative }} \quad$ Date

Print Name of Subject or Authorized Representative

Print Name of Individual Explaining this Research Authorization Form 


\section{CONTACT INFORMATION}

The contact information of the subject or authorized representative who signed this form should be filled in below.

Address:

Telephone

Daytime:

Evening:

Table C3. Demographic/Injury History Questionnaire.

Name:

Age:

Gender: Male/Female

Year in School: Freshman/Sophomore/Junior/Senior/Graduate Student

1. Do you participate in any physical/sport activity? Yes/No

If yes, explain:

2. Have you had any low back pain in the last two weeks? Yes/No

If yes, explain:

3. Have you ever had surgery on your lower extremity in the past two years? Or have you ever had surgery on your low back or lower extremities? Yes/ No 
If yes, explain:

4. Have you had an injury to your low back or sacroiliac joint in the last six months? Yes/No If yes, explain:

5. Do you have any neurological disorders that would affect the lower body? Yes/No If yes, explain:

\section{C4. Volunteer Sign-up Sheet}

This study requires that you are available on one Saturday. If you are willing to participate in this study, please provide your name, phone number, and e-mail address.

\begin{tabular}{|l|l|l|}
\hline Name & Phone & E-mail \\
\hline & & \\
\hline & & \\
\hline & & \\
\hline & & \\
\hline & & \\
\hline
\end{tabular}


Table C5. Testing Availability

Please print your name.

\begin{tabular}{|c|c|c|}
\hline Timeslots & & \\
\hline \multirow[t]{2}{*}{11 AM- 11:35 AM } & 1. & 2. \\
\hline & 3. & 4. \\
\hline \multirow[t]{2}{*}{ 11:20 AM-11:55 AM } & 1. & 2. \\
\hline & 3. & 4. \\
\hline \multirow[t]{2}{*}{ 11:40 AM- 12:15 PM } & 1. & 2. \\
\hline & 3. & 4. \\
\hline \multirow[t]{2}{*}{ 12:00PM-12:35 PM } & 1. & 2. \\
\hline & 3. & 4. \\
\hline \multirow[t]{2}{*}{ 12:20 PM- 12:55 PM } & 1. & 2. \\
\hline & 3. & 4. \\
\hline \multicolumn{3}{|l|}{ BREAK } \\
\hline \multirow[t]{2}{*}{ 1:45PM-2:20 PM } & 1. & 2. \\
\hline & 3. & 4. \\
\hline \multirow[t]{2}{*}{ 2:05 PM- 2:40 PM } & 1. & 2. \\
\hline & 3. & 4. \\
\hline \multirow[t]{2}{*}{ 2:25 PM-3:00 PM } & 1. & 2. \\
\hline & 3. & 4. \\
\hline \multirow[t]{2}{*}{ 2:45PM-3:20PM } & 1. & 2. \\
\hline & 3. & 4. \\
\hline \multirow[t]{2}{*}{ 3:05PM-3:40 PM } & 1. & 2. \\
\hline & 3. & 4. \\
\hline \multirow[t]{2}{*}{ 3:25 PM-4:20PM } & 1. & 2. \\
\hline & 3. & 4. \\
\hline \multirow[t]{2}{*}{ 3:45 PM-4:20 PM } & 1. & 2. \\
\hline & 3. & 4. \\
\hline
\end{tabular}


Table C6. Recording Sheet for Sacroiliac Joint Testing.

Examiner:

Recorder:

Date:

\begin{tabular}{|c|c|c|c|c|c|c|c|c|c|c|}
\hline $\begin{array}{c}\text { Subject } \\
\#\end{array}$ & \multicolumn{2}{|c|}{$\begin{array}{c}\text { Supine-to- } \\
\text { Sit }\end{array}$} & \multicolumn{2}{|c|}{ March $L$} & \multicolumn{2}{|c|}{ March $R$} & \multicolumn{2}{|c|}{ Seated Flexion } & \multicolumn{2}{|c|}{ Standing Flexion } \\
\hline $11 \quad 1^{\text {st }}$ & $\mathrm{Y}$ & $\mathrm{N}$ & $\mathrm{Y}$ & $\mathrm{N}$ & $\mathrm{Y}$ & $\mathrm{N}$ & $\mathrm{Y}$ & $\mathrm{N}$ & Y & $\mathrm{N}$ \\
\hline $2^{\text {nd }}$ & $\mathrm{Y}$ & $\mathrm{N}$ & $Y$ & $\mathrm{~N}$ & $Y$ & $\mathrm{~N}$ & $\mathrm{Y}$ & $\mathrm{N}$ & Y & $\mathrm{N}$ \\
\hline $12 \quad 1^{\text {st }}$ & $\mathrm{Y}$ & $\mathrm{N}$ & $\mathrm{Y}$ & $\mathrm{N}$ & Y & $\mathrm{N}$ & $\mathrm{Y}$ & $\mathrm{N}$ & Y & $\mathrm{N}$ \\
\hline $2^{\text {nd }}$ & $\mathrm{Y}$ & $\mathrm{N}$ & $\mathrm{Y}$ & $\mathrm{N}$ & Y & $\mathrm{N}$ & $\mathrm{Y}$ & $\mathrm{N}$ & Y & $\mathrm{N}$ \\
\hline $13 \quad 1^{\text {st }}$ & $\mathrm{Y}$ & $\mathrm{N}$ & $\mathrm{Y}$ & $\mathrm{N}$ & Y & $\mathrm{N}$ & $\mathrm{Y}$ & $\mathrm{N}$ & Y & $\mathrm{N}$ \\
\hline $2^{\text {nd }}$ & $\mathrm{Y}$ & $\mathrm{N}$ & $\mathrm{Y}$ & $\mathrm{N}$ & Y & $\mathrm{N}$ & Y & $\mathrm{N}$ & Y & $\mathrm{N}$ \\
\hline $14 \quad 1^{\text {st }}$ & $\mathrm{Y}$ & $\mathrm{N}$ & Y & $\mathrm{N}$ & Y & $\mathrm{N}$ & $\mathrm{Y}$ & $\mathrm{N}$ & Y & $\mathrm{N}$ \\
\hline $2^{\text {nd }}$ & $\mathrm{Y}$ & $\mathrm{N}$ & Y & $\mathrm{N}$ & Y & $\mathrm{N}$ & Y & $\mathrm{N}$ & Y & $\mathrm{N}$ \\
\hline $21 \quad 1^{\text {st }}$ & $\mathrm{Y}$ & $\mathrm{N}$ & Y & $\mathrm{N}$ & Y & $\mathrm{N}$ & Y & $\mathrm{N}$ & Y & $\mathrm{N}$ \\
\hline $2^{\text {nd }}$ & $\mathrm{Y}$ & $\mathrm{N}$ & Y & $\mathrm{N}$ & Y & $\mathrm{N}$ & $\mathrm{Y}$ & $\mathrm{N}$ & Y & $\mathrm{N}$ \\
\hline $22 \quad 1^{\text {st }}$ & $\mathrm{Y}$ & $\mathrm{N}$ & $\mathrm{Y}$ & $\mathrm{N}$ & Y & $\mathrm{N}$ & $\mathrm{Y}$ & $\mathrm{N}$ & Y & $\mathrm{N}$ \\
\hline $2^{\text {nd }}$ & $\mathrm{Y}$ & $\mathrm{N}$ & Y & $\mathrm{N}$ & Y & $\mathrm{N}$ & $\mathrm{Y}$ & $\mathrm{N}$ & Y & $\mathrm{N}$ \\
\hline $23 \quad 1^{\text {st }}$ & Y & $\mathrm{N}$ & $\mathrm{Y}$ & $\mathrm{N}$ & Y & $\mathrm{N}$ & Y & $\mathrm{N}$ & Y & $\mathrm{N}$ \\
\hline $2^{\text {nd }}$ & $\mathrm{Y}$ & $\mathrm{N}$ & $\mathrm{Y}$ & $\mathrm{N}$ & Y & $\mathrm{N}$ & $\mathrm{Y}$ & $\mathrm{N}$ & Y & $\mathrm{N}$ \\
\hline
\end{tabular}

Figure C1. Procedure for the Standing Flexion Test. ${ }^{\text {7, 20, } 22}$ 


\section{$\underline{\text { Standing Flexion Test }}$}

1. The examiner instructed the subject to assume standing position feet shoulder width apart with his or her body weight equally distributed on both legs.

The examiner knelt with the subject's posterior hip at eye level.

2. The examiner palpated the right PSIS with his or her right thumb. The rest of the right hand contacted the right innominate bone.

The examiner will palpate the left PSIS with his or her right thumb. The rest of the left hand contacted the right innominate bone.

3. The examiner asked the subject to slowly bend forward as far as possible.

This movement was performed three times

4. As described in Van Deursen et al, the examiner reported a "yes" if one of the thumbs moves before the other thumb or if at the end of the movement one thumb is higher. A "no" will be reported if both sides move equally.
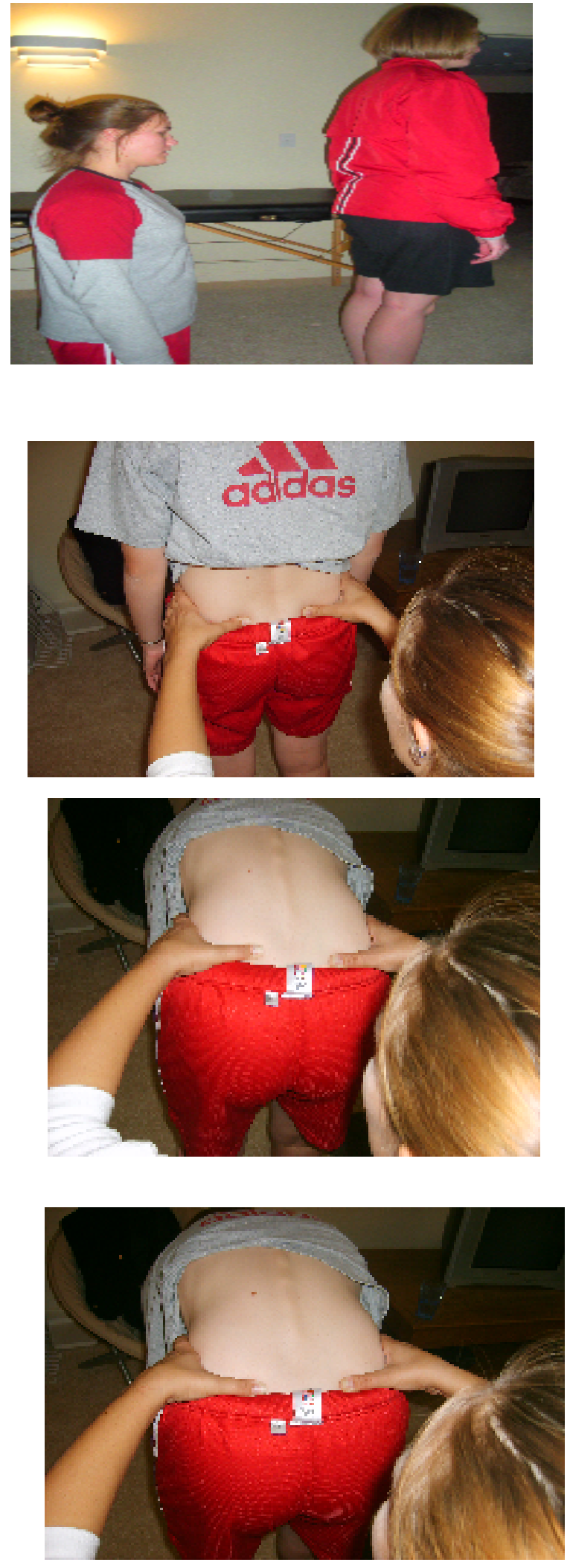
Figure C2. Procedure for the Seated Flexion Test. ${ }^{1,21,22}$

\section{Seated Flexion Test.}

1. The examiner instructed the subject to assume a seated position on the treatment table with his or her legs hanging off the table

The examiner knelt with the subject's posterior hip at eye level.

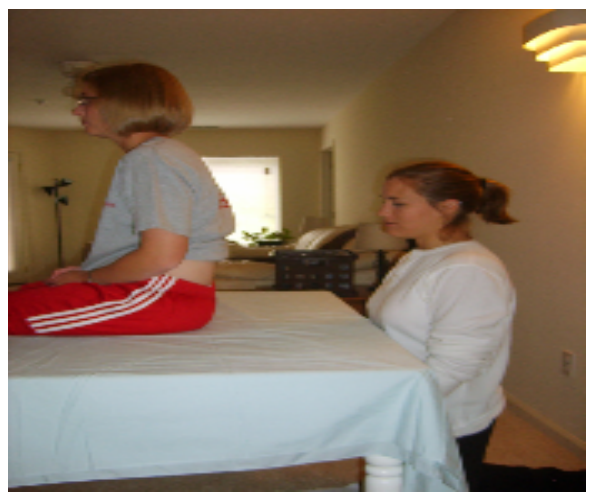

2. The examiner palpated the right PSIS with his or her right thumb. The rest of the right hand contacted the right innominate bone.

The examiner palpated the left PSIS with his or her right thumb. The rest of the left hand contacted the right innominate bone.

3. The examiner asked the subject to slowly bend forward as far as possible. This movement was performed three times
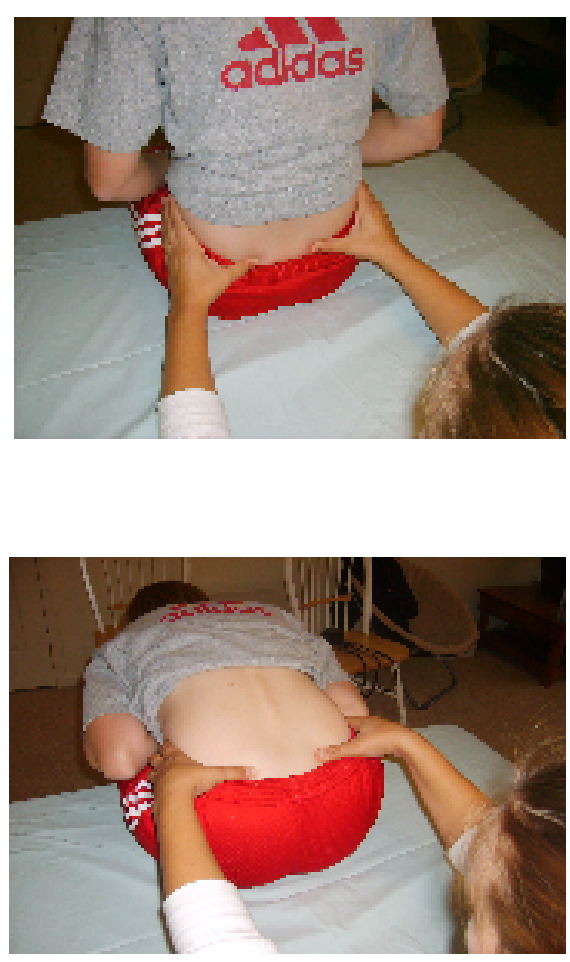

4. As described in Van Deursen et al, the examiner reported a "yes" if one of the thumbs moved before the other thumb or if at the end of the movement one thumb is higher. A "no" was reported if both sides move equally.

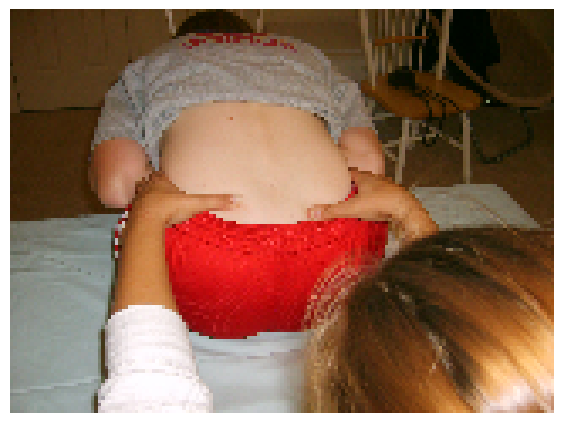


Figure C3. Procedures for the March/Gillet/Stork test ${ }^{15}$

\section{March Test}

1. The examiner instructed the subject to stand with feet shoulder width apart and to place equal weight on both legs.

The examiner knelt with the subject's posterior hip at eye level.

2. The examiner palpated the right PSIS with his or her right thumb. The rest of the right hand contacted the right innominate bone. The examiner palpated the S2 spinous process of the sacrum with the left thumb.

3. The examiner asked the subject to slowly raise the right leg into 90 degrees of hip flexion and 90 degrees of knee flexion and then return to a standing position. The examiner continued to palpate the right PSIS and innominate bone relative to the sacrum throughout this movement. This movement was performed three times.

4. The examiner reported to the recorder "yes" for a positive test if the PSIS moves cephalad (upwards in respect) to the sacrum or "no" for a negative test if the PSIS remained in the same position or moved caudally(downwards in respect) to the sacrum.

5. The same procedure was performed for the left side using the respective positioning and recording procedure.
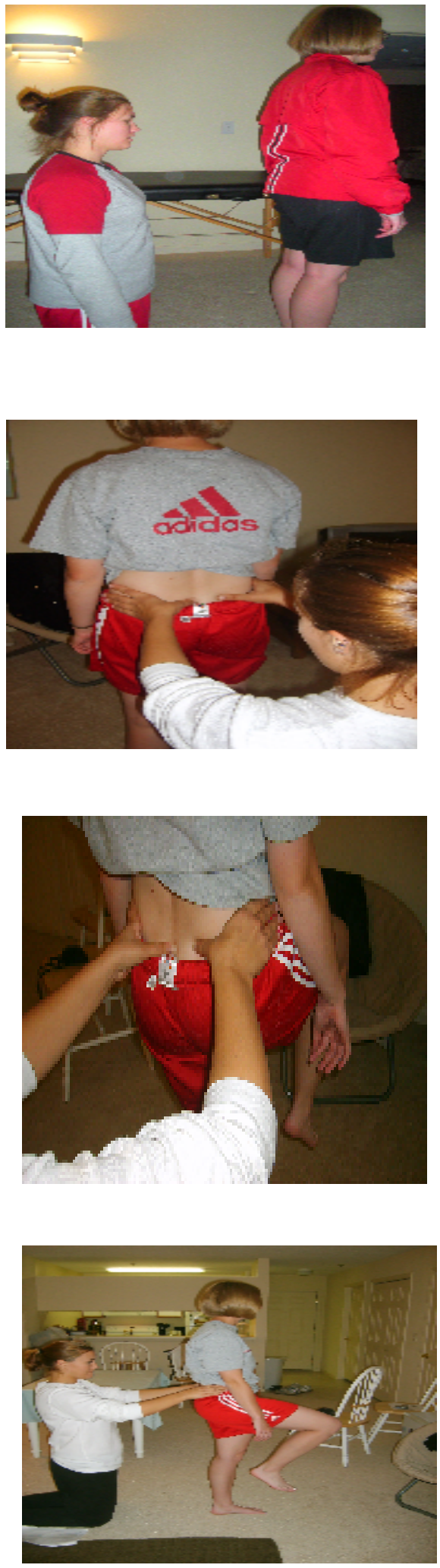
Figure C4. Procedure for the Supine-to-sit test.

\section{Supine-to-sit test.}

1. The patient laid supine and performed a bridge to clear his or her hips off of the table.

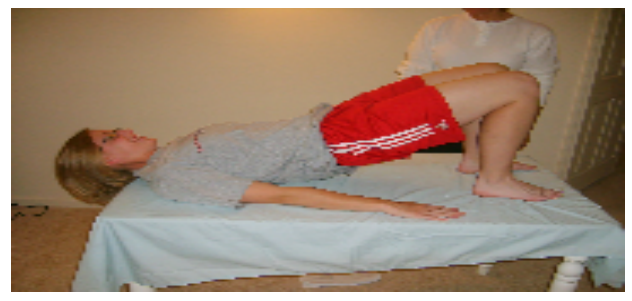

2. The examiner placed his or her hand around the ankle with his or her thumbs on the inferior aspect of the medial malleoli and applied traction.

3. The examiner compared the positions of the medial malleoli.

4. The subject then sat up without shifting his or her pelvis while the examiner maintained positioning on the malleoli.

5. The examiner then compared the positions of the medial malleoli again.

This was repeated three times.

6. If at any point during the evaluation the malleoli were not level with each other, the examiner reported a "yes" to the recorder, indicating a positive test. If the malleoli
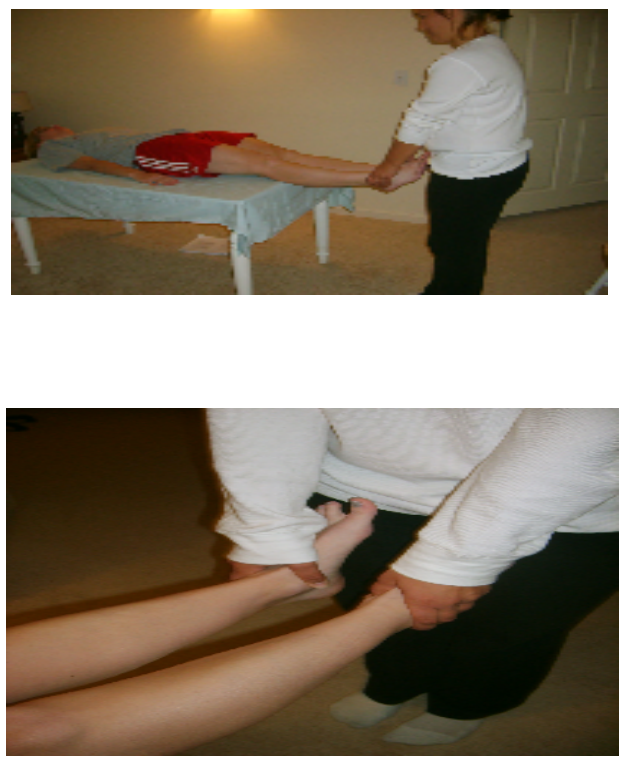
remain even with one another throughout the test, the examiner reported a "no" to the recorder.

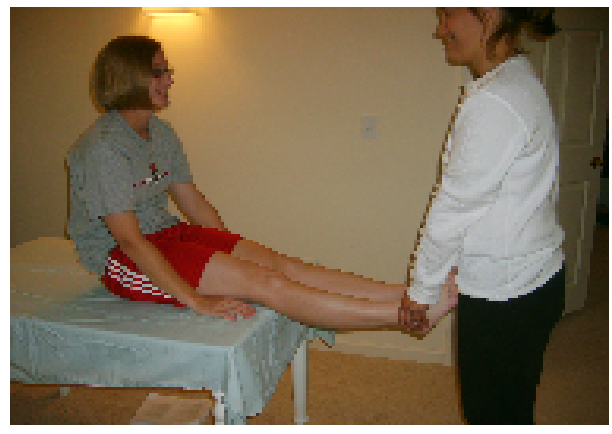


Figure C5. Subject Warm-up

1) Suggested Walk/elliptical/run/jog for 5 minutes

2) Perform the following stretches

(* indicates required stretch. The rest are suggested)

Hold 15s

Perform 2x

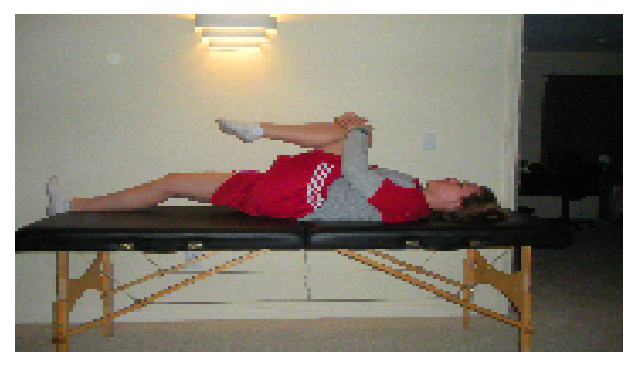

Glut

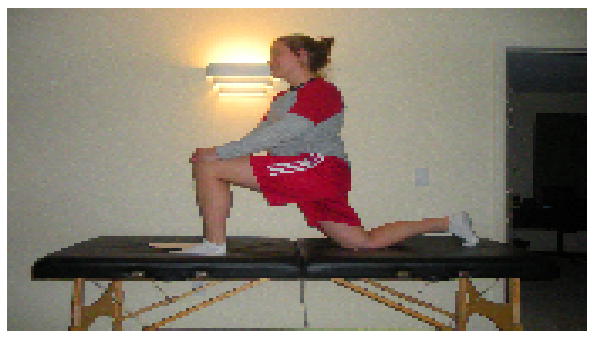

Hip Flexor

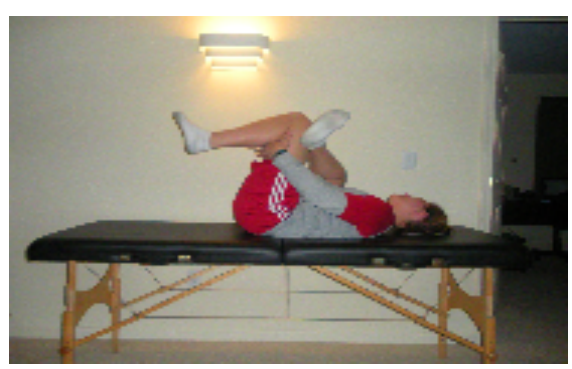

Piriformis

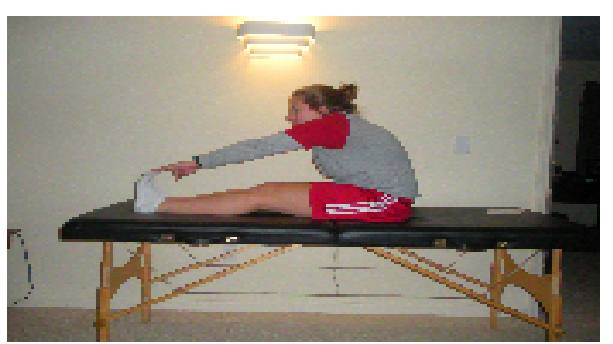

Hamstring*

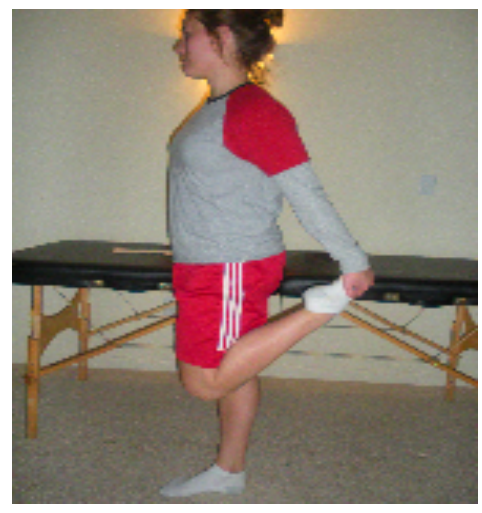

Quad 
3) Perform the Following Exercises

(* indicates required exercise. The rest are suggested)

*Pelvic Tilt: pull your hip towards your head while flattening your back. 2 sets 15 reps

Start

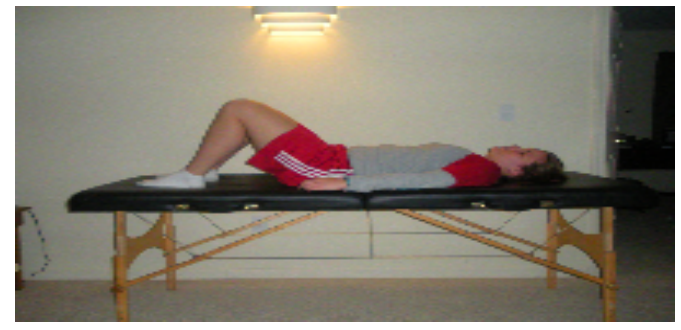

*Double Leg Fallout: 2 sets 15 reps

Start

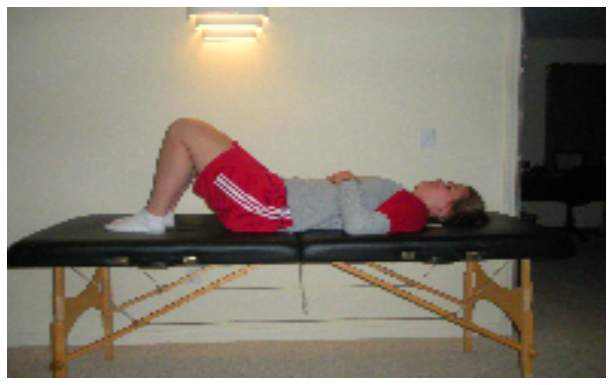

Double legs to chest:

6 reps. Hold 10 s each rep

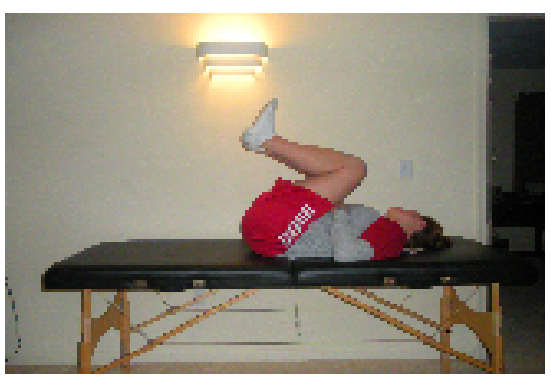

End

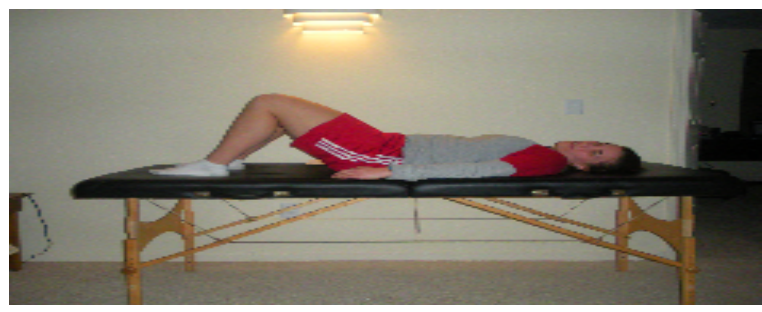

End

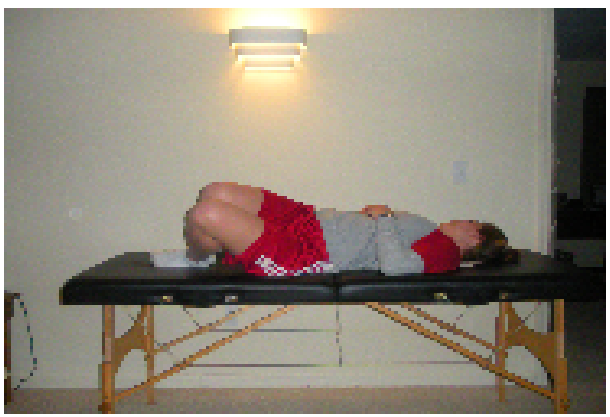

Single leg to chest:

6 reps. Hold $10 \mathrm{~s}$ each rep

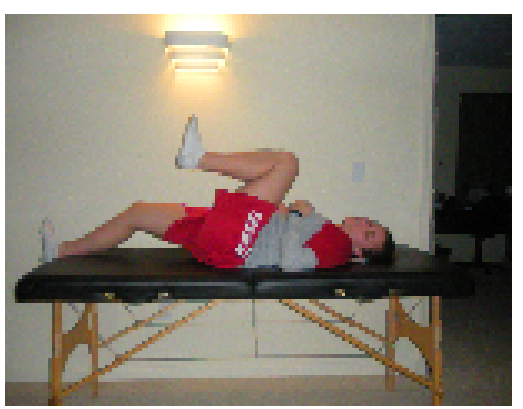




\section{APPENDIX D}

ADDITIONAL RESULTS

Table D1. Intrarater Reliability for the March Test $(n=31)$

\begin{tabular}{|c|c|c|c|c|c|}
\hline Examiner & $\begin{array}{l}\text { Agreement } \\
(\%)\end{array}$ & $\begin{array}{l}\text { Kappa } \\
(95 \% \mathrm{CI})\end{array}$ & P-value & $\kappa \max$ & $\kappa / \kappa \max$ \\
\hline I1 & 71 & .410 & $.022 *$ & .93 & .44 \\
\hline $\mathrm{I} 2$ & 84 & .351 & $.048 *$ & .87 & .40 \\
\hline E1 & 81 & .53 & $.003 *$ & 1 & .53 \\
\hline E2 & 100 & & & & \\
\hline
\end{tabular}

Key: I=Inexperienced; $\mathrm{E}=$ Experienced; * indicates significance at $\mathrm{p}=.05$

Table D2. Intrarater Distributions for the March Test

\begin{tabular}{lllll}
\hline & & yes & no & total \\
I1 Round 1 1 & yes & 13 & 5 & 18 \\
& no & 4 & 9 & 13 \\
& total & 17 & 14 & 31 \\
& & & \\
I2 Round 1 & I2 Round 2 & & & \\
& yes & 2 & 2 & 4 \\
& no & 3 & 24 & 27 \\
& total & 5 & 26 & 31 \\
& & & \\
E1 Round 1 & E1 Round 2 & & & \\
& yes & 6 & 3 & 9 \\
& no & 3 & 19 & 22 \\
& total & 9 & 22 & 31 \\
& E2 Round 2 & & & \\
E2 Round 1 & yes & & & 31 \\
& no & & 31 & 31 \\
& total & &
\end{tabular}

Key: I=Inexperienced; E=Experienced 
Table D3. Interrater Reliability for the March Test $(n=31)$

\begin{tabular}{|c|c|c|c|c|c|}
\hline Examiner & Agreement $(\%)$ & $\begin{array}{l}\text { Kappa } \\
(95 \% \text { CI })\end{array}$ & P-value & $\kappa \max$ & $\begin{array}{l}\kappa / \kappa \max \\
(\%)\end{array}$ \\
\hline \multicolumn{6}{|l|}{ Round 1 } \\
\hline$\overline{\mathrm{I} 1 \mathrm{xI} 2}$ & 42 & -.037 & .726 & .19 & -.19 \\
\hline I1XE1 & 65 & .335 & $.026^{*}$ & .46 & .73 \\
\hline I1xE2 & 42 & & & & \\
\hline $\mathrm{I} 2 \mathrm{xE} 1$ & 71 & .157 & .322 & .53 & .30 \\
\hline $\mathrm{I} 2 \mathrm{xE} 2$ & 87 & & & & \\
\hline E1xE2 & 71 & & & & \\
\hline \multicolumn{6}{|l|}{ Round 2} \\
\hline$\overline{\mathrm{I} 1 \mathrm{xI} 2}$ & 58 & -.090 & .467 & .27 & -.33 \\
\hline I1XE1 & 61 & .256 & .101 & .50 & .51 \\
\hline I1xE2 & 45 & & & & \\
\hline $\mathrm{I} 2 \mathrm{xE} 1$ & 68 & .099 & .555 & .64 & .15 \\
\hline $\mathrm{I} 2 \mathrm{xE} 2$ & 84 & & & & \\
\hline E1xE2 & 71 & & & & \\
\hline
\end{tabular}

Key: I=Inexperienced; E=Experienced; * indicates significance at $\mathrm{p}=.05$

Table D4. Interrater Distributions for the March Test

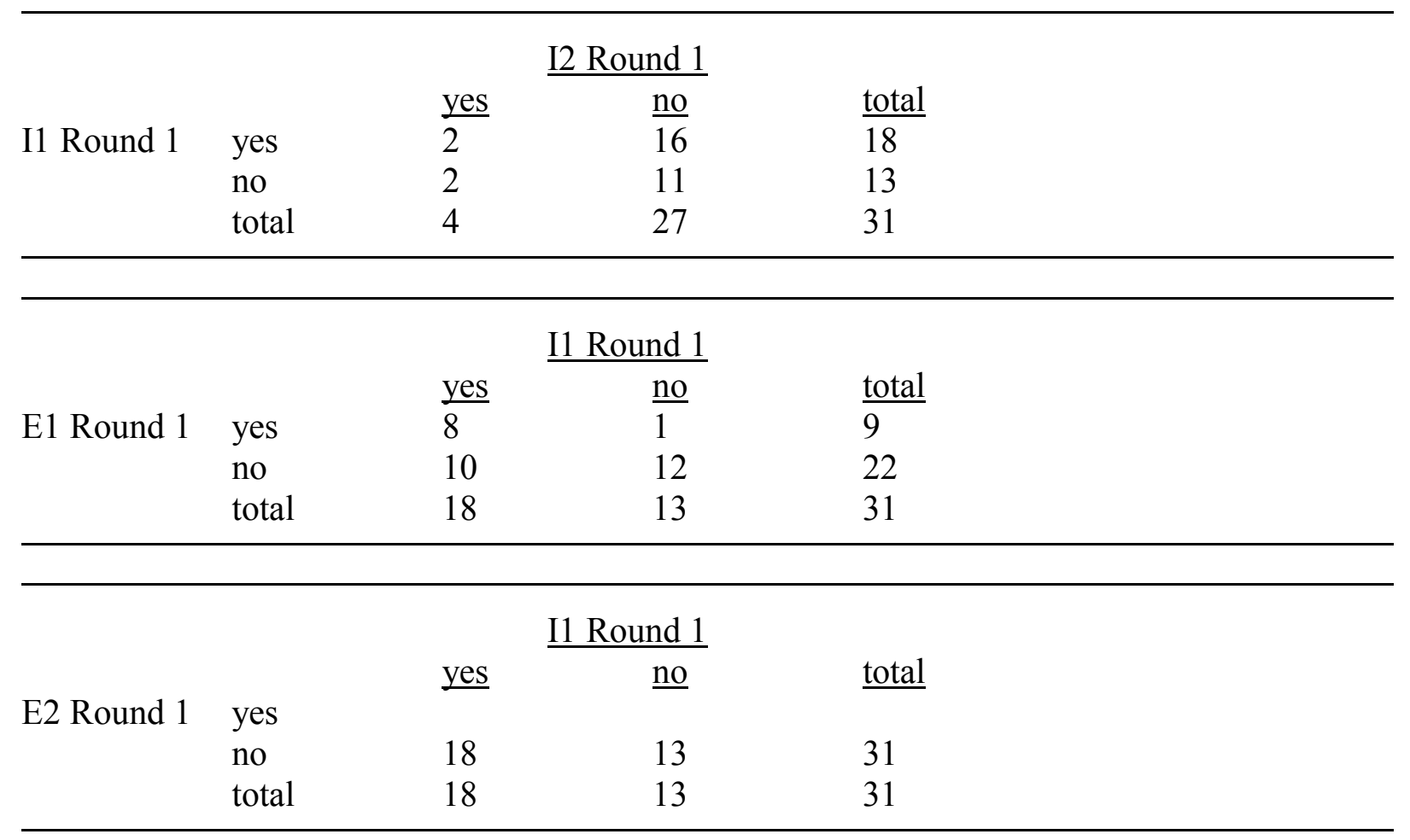




\begin{tabular}{|c|c|c|c|c|}
\hline & & & and 1 & \\
\hline & & yes & $\underline{\text { no }}$ & total \\
\hline E1 Round 1 & yes & 2 & $\overline{7}$ & $\overline{9}$ \\
\hline & no & 2 & 20 & 22 \\
\hline & total & 4 & 27 & 31 \\
\hline & & & and 1 & \\
\hline & & yes & $\underline{\text { no }}$ & $\underline{\text { total }}$ \\
\hline E2 Round 1 & yes & & & \\
\hline & no & 4 & 27 & 31 \\
\hline & total & 4 & 27 & 31 \\
\hline & & & und & \\
\hline & & yes & $\underline{\text { no }}$ & totall \\
\hline E1 Round 1 & yes & & 9 & 9 \\
\hline & no & & 22 & 22 \\
\hline & total & & 31 & 31 \\
\hline & & & and 2 & \\
\hline & & yes & $\underline{\text { no }}$ & total \\
\hline I1 Round 1 & yes & 2 & $\overline{15}$ & $\overline{17}$ \\
\hline & no & 3 & 11 & 14 \\
\hline & total & 5 & 26 & 31 \\
\hline & & & and 2 & \\
\hline & & yes & $\underline{\text { no }}$ & total \\
\hline E1 Round 1 & yes & 7 & 2 & 9 \\
\hline & no & 10 & 12 & 22 \\
\hline & total & 17 & 14 & 31 \\
\hline & & & und 2 & \\
\hline & & yes & $\underline{\text { no }}$ & total \\
\hline E2 Round 1 & yes & & & \\
\hline & no & 17 & 14 & 31 \\
\hline & total & 17 & 14 & 31 \\
\hline
\end{tabular}




\begin{tabular}{|c|c|c|c|c|}
\hline \multirow{5}{*}{ E1 Round 2} & \multicolumn{4}{|c|}{ I2 Round 2} \\
\hline & \multirow[b]{2}{*}{ yes } & yes & $\underline{\text { no }}$ & total \\
\hline & & 2 & $\overline{7}$ & 9 \\
\hline & \multirow{2}{*}{$\begin{array}{l}\text { no } \\
\text { total }\end{array}$} & 3 & 19 & 22 \\
\hline & & 5 & 26 & 31 \\
\hline \multirow{5}{*}{ E2 Round 2} & \multicolumn{4}{|c|}{ I2 Round 2} \\
\hline & \multirow{2}{*}{\multicolumn{4}{|c|}{$\underline{\text { total }}$}} \\
\hline & & & & \\
\hline & \multirow{2}{*}{$\begin{array}{l}\text { no } \\
\text { total }\end{array}$} & 5 & 26 & \multirow{2}{*}{$\begin{array}{l}31 \\
31\end{array}$} \\
\hline & & 5 & 26 & \\
\hline \multirow{5}{*}{ E1 Round 2} & \multicolumn{4}{|c|}{ E2 Round 2} \\
\hline & \multirow{2}{*}{\multicolumn{2}{|c|}{ yes }} & $\underline{\text { no }}$ & \multirow{2}{*}{$\frac{\text { total }}{9}$} \\
\hline & & & 9 & \\
\hline & \multicolumn{2}{|l|}{ no } & 22 & \\
\hline & \multicolumn{2}{|l|}{ total } & 31 & 31 \\
\hline
\end{tabular}

Key: I=Inexperienced; E=Experienced;

Table D5. Intrarater Reliability for the Standing Flexion Test ( $\mathrm{n}=31)$

\begin{tabular}{|c|c|c|c|c|c|}
\hline Examiner & $\begin{array}{l}\text { Agreement } \\
(\%)\end{array}$ & $\begin{array}{l}\text { Kappa } \\
(95 \% \mathrm{CI})\end{array}$ & P-value & $\kappa \max$ & $\kappa / \kappa m a x$ \\
\hline I1 & 87 & .587 & $.001 *$ & 1 & .44 \\
\hline $\mathrm{I} 2$ & 74 & .410 & $.023 *$ & 1 & .41 \\
\hline $\mathrm{E} 1$ & 81 & .557 & $.002 *$ & 1 & .53 \\
\hline E2 & 84 & .686 & $.00 *$ & .69 & .95 \\
\hline
\end{tabular}

Key: $\mathrm{I}=$ Inexperienced; $\mathrm{E}=$ Experienced; * indicates significance at $\mathrm{p}=.05$ 
Table D6. Intrarater Distributions for the Standing Flexion Test

\begin{tabular}{lllll}
\hline & & yes & no & total \\
I1 Round 1 & I1 Round 2 & & & \\
& yes & 4 & 2 & 6 \\
& no & 2 & 23 & 25 \\
& total & 6 & 25 & 31 \\
& I2 Round 2 & & & \\
I2 Round 1 & yes & 6 & 4 & 10 \\
& no & 4 & 17 & 21 \\
& total & 10 & 21 & 31 \\
& E1 Round 2 & & & \\
E1 Round 1 & yes & 7 & 3 & 10 \\
& no & 3 & 18 & 21 \\
& total & 10 & 21 & 31 \\
& E2 Round 2 & & & \\
E2 Round 1 & yes & 13 & 0 & 13 \\
& no & 5 & 13 & 18 \\
& total & 18 & 13 & 31 \\
\hline
\end{tabular}

Key: I=Inexperienced; E=Experienced

Table D7. Interrater Reliability for the Standing Flexion Test ( $\mathrm{n}=31)$

\begin{tabular}{llllll}
\hline Examiner & Agreement(\%) & $\begin{array}{l}\text { Kappa } \\
(95 \% \mathrm{CI})\end{array}$ & P-value & $\kappa m a x$ & $\begin{array}{l}\kappa / \kappa m a x \\
(\%)\end{array}$ \\
\hline Round 1 & & & & & \\
I1xI2 & 55 & -.154 & .363 & .67 & -.23 \\
I1XE1 & 68 & .176 & .301 & .67 & .26 \\
I1xE2 & 52 & -.074 & .634 & .50 & .15 \\
I2xE1 & 55 & -.033 & .853 & 1 & -.033 \\
I2xE2 & 71 & .384 & $.029 *$ & .79 & .49 \\
E1xE2 & 52 & -.220 & .160 & .79 & -.28 \\
& & & & & \\
Round 2 & & .011 & .95 & .67 & .02 \\
I1xI2 & 61 & .176 & .301 & .67 & .26 \\
I1XE1 & 68 & -.057 & .656 & .17 & -.34 \\
I1xE2 & 42 & -.033 & .853 & .30 & -.11 \\
I2xE1 & 55 & .268 & .088 & .51 & .525 \\
I2xE2 & 61 & -.026 & .880 & .51 & -.05 \\
E1xE2 & 35 & & & & \\
\hline
\end{tabular}

Key: I=Inexperienced; E=Experienced; * indicates significance at $\mathrm{p}=.05$ 
Table D8. Interrater Distributions for the Standing Flexion Test

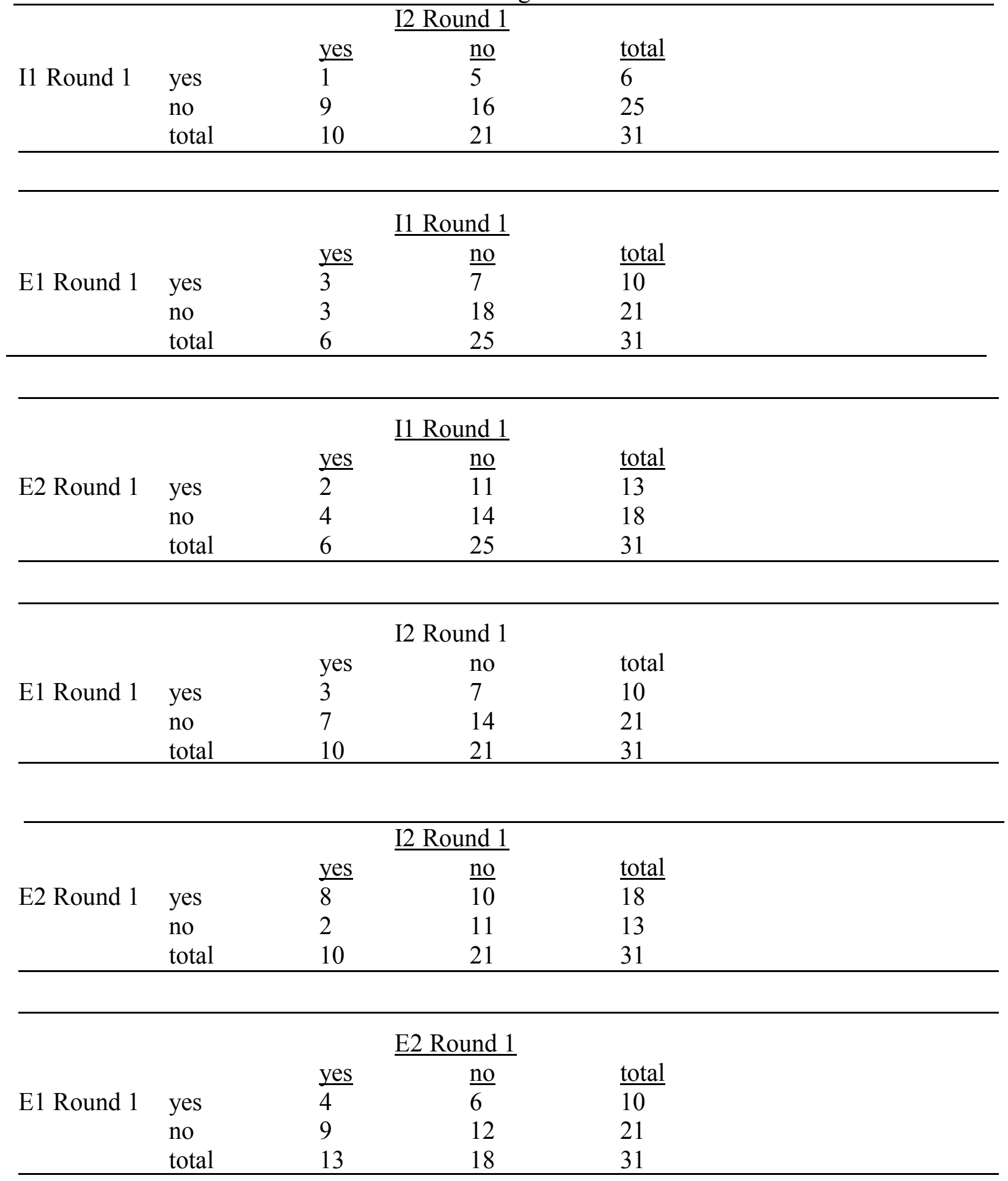




\begin{tabular}{|c|c|c|c|c|}
\hline & & & ind 2 & \\
\hline & & yes & $\underline{\text { no }}$ & total \\
\hline I1 Round 1 & yes & 2 & $\overline{4}$ & $\overline{6}$ \\
\hline & no & 8 & 17 & 25 \\
\hline & total & 10 & 21 & 31 \\
\hline & & & ind 2 & \\
\hline & & yes & $\underline{\text { no }}$ & $\underline{\text { total }}$ \\
\hline E1 Round 1 & yes & $\overline{3}$ & $\overline{7}$ & $\overline{10}$ \\
\hline & no & 3 & 18 & 21 \\
\hline & total & 6 & 25 & 31 \\
\hline & & & ind 2 & \\
\hline & & yes & $\underline{\text { no }}$ & total \\
\hline E2 Round 1 & yes & 3 & $\overline{15}$ & $\overline{18}$ \\
\hline & no & 3 & 10 & 13 \\
\hline & total & 6 & 25 & 31 \\
\hline & & & ind 2 & \\
\hline & & yes & $\underline{\text { no }}$ & $\underline{\text { total }}$ \\
\hline E1 Round 2 & yes & 3 & $\overline{7}$ & $\overline{10}$ \\
\hline & no & 7 & 14 & 21 \\
\hline & total & 10 & 21 & 31 \\
\hline & & & ind 2 & \\
\hline & & yes & $\underline{\text { no }}$ & total \\
\hline E2 Round 2 & yes & 8 & $\overline{10}$ & $\overline{18}$ \\
\hline & no & 2 & 11 & 13 \\
\hline & total & 10 & 21 & 31 \\
\hline & & & und & \\
\hline & & yes & $\underline{\text { no }}$ & total \\
\hline E1 Round 2 & yes & 4 & 6 & 10 \\
\hline & no & 14 & 17 & 21 \\
\hline & total & 18 & 13 & 31 \\
\hline
\end{tabular}

Key: I=Inexperienced; E=Experienced 
Table D9. Intrarater Reliability for the Seated Flexion Test $(n=31)$

\begin{tabular}{|c|c|c|c|c|c|}
\hline Examiner & $\begin{array}{l}\text { Agreement } \\
(\%)\end{array}$ & $\begin{array}{l}\text { Kappa } \\
(95 \% \mathrm{CI})\end{array}$ & P-value & $\kappa \max$ & $\kappa / \kappa \max$ \\
\hline I1 & 90 & .708 & $.000^{*}$ & .90 & .79 \\
\hline I2 & 77 & .517 & $.004 *$ & .93 & .56 \\
\hline E1 & 87 & .665 & $.000^{*}$ & .83 & .80 \\
\hline E2 & 84 & .665 & $.00^{*}$ & .93 & .72 \\
\hline
\end{tabular}

Key: $\mathrm{I}=$ Inexperienced; $\mathrm{E}=$ Experienced; * indicates significance at $\mathrm{p}=.05$

Table D10. Intrarater Distributions for the Seated Flexion Test

\begin{tabular}{lllll}
\hline & & yes & no & total \\
I1 Round 1 & I1 Round 2 & & & \\
& yes & 5 & 2 & 7 \\
& no & 1 & 23 & 24 \\
& total & 6 & 25 & 31 \\
& I2 Round 2 & & & \\
I2 Round 1 & yes & 8 & 4 & 12 \\
& no & 3 & 16 & 19 \\
& total & 11 & 20 & 31 \\
& E1 Round 2 & & & \\
E1 Round 1 & yes & 6 & 3 & 9 \\
& no & 1 & 21 & 22 \\
& total & 7 & 24 & 31 \\
& E2 Round 2 & & & \\
E2 Round 1 & yes & 10 & 2 & 12 \\
& no & 3 & 16 & 19 \\
& total & 13 & 18 & 31 \\
\hline
\end{tabular}

Key: I=Inexperienced; E=Experienced 
Table D11. Interrater Reliability for the Seated Flexion Test $(\mathrm{n}=31)$

\begin{tabular}{|c|c|c|c|c|c|}
\hline Examiner & Agreement(\%) & $\begin{array}{l}\text { Kappa } \\
(95 \% \mathrm{CI})\end{array}$ & P-value & кmax & $\begin{array}{l}\kappa / \kappa \max \\
(\%)\end{array}$ \\
\hline \multicolumn{6}{|l|}{ Round 1} \\
\hline $\mathrm{I} 1 \mathrm{x}$ I2 & 58 & .043 & .798 & .63 & .07 \\
\hline I1XE1 & 68 & .162 & .360 & .83 & .20 \\
\hline I1xE2 & 58 & .043 & .789 & .63 & .07 \\
\hline I2xE1 & 52 & -.069 & .694 & .79 & -.09 \\
\hline I2xE2 & 61 & .184 & .305 & 1 & . 184 \\
\hline E1xE2 & 52 & -.069 & .694 & .79 & -.09 \\
\hline \multicolumn{6}{|l|}{ Round 2} \\
\hline $\mathrm{I} 1 \mathrm{x} 22$ & 65 & .137 & .408 & .61 & .22 \\
\hline I1XE1 & 71 & .125 & .483 & .90 & .14 \\
\hline I1xE2 & 58 & .069 & .656 & .50 & .14 \\
\hline I2xE1 & 55 & -.074 & .664 & .69 & -.11 \\
\hline I2xE2 & 61 & .188 & .291 & .86 & .22 \\
\hline E1xE2 & 42 & -.274 & .092 & .58 & -.47 \\
\hline
\end{tabular}

Key: I=Inexperienced; E=Experienced; * indicates significance at $\mathrm{p}=.05$

Table D12. Interrater Distributions for the Seated Flexion Test

\begin{tabular}{|c|c|c|c|c|}
\hline & & & and 1 & \\
\hline & & yes & $\underline{\text { no }}$ & total \\
\hline I1 Round 1 & yes & 3 & $\overline{4}$ & $\overline{7}$ \\
\hline & no & 9 & 15 & 24 \\
\hline & total & 12 & 19 & 31 \\
\hline & & & and 1 & \\
\hline & & yes & $\underline{\text { no }}$ & total \\
\hline E1 Round 1 & yes & 3 & 6 & $\overline{9}$ \\
\hline & no & 4 & 18 & 22 \\
\hline & total & 7 & 24 & 31 \\
\hline & & & and 1 & \\
\hline & & yes & $\underline{\text { no }}$ & total \\
\hline E2 Round 1 & yes & 3 & $\overline{9}$ & $\overline{12}$ \\
\hline & no & 4 & 15 & 19 \\
\hline & total & 7 & 24 & 31 \\
\hline
\end{tabular}




\begin{tabular}{|c|c|c|c|c|}
\hline \multirow{5}{*}{ E1 Round 1} & \multicolumn{4}{|c|}{$\underline{\text { I2 Round } 1}$} \\
\hline & & yes & $\underline{\text { no }}$ & total \\
\hline & yes & 3 & $\overline{6}$ & $\overline{9}$ \\
\hline & no & 9 & 13 & 22 \\
\hline & total & 12 & 19 & 31 \\
\hline \multirow{5}{*}{ E2 Round 1} & & \multicolumn{3}{|c|}{$\underline{\text { I2 Round } 1}$} \\
\hline & & yes & $\underline{\text { no }}$ & total \\
\hline & yes & 6 & $\overline{6}$ & 12 \\
\hline & no & 6 & 13 & 19 \\
\hline & total & 12 & 19 & 31 \\
\hline \multirow{5}{*}{ E1 Round 1} & & \multirow{2}{*}{\multicolumn{3}{|c|}{$\underline{\text { E2 Round } 1}$}} \\
\hline & & yes & & \\
\hline & yes & 3 & 6 & 9 \\
\hline & no & 9 & 13 & 22 \\
\hline & total & 12 & 19 & 31 \\
\hline \multirow{5}{*}{ I1 Round 1} & & \multicolumn{3}{|c|}{ I2 Round 2} \\
\hline & & yes & $\underline{\text { no }}$ & $\underline{\text { total }}$ \\
\hline & yes & 3 & 3 & 6 \\
\hline & no & 8 & 17 & 25 \\
\hline & total & 11 & 20 & 31 \\
\hline \multirow{5}{*}{ E1 Round 1} & & \multicolumn{3}{|c|}{$\underline{\text { I1 Round } 2}$} \\
\hline & & yes & $\underline{\text { no }}$ & $\underline{\text { total }}$ \\
\hline & yes & 2 & 5 & 7 \\
\hline & no & 4 & 20 & 24 \\
\hline & total & 6 & 25 & 31 \\
\hline \multirow{5}{*}{ E2 Round 1} & & \multicolumn{3}{|c|}{$\underline{\text { I1 Round } 2}$} \\
\hline & & yes & $\underline{\text { no }}$ & total \\
\hline & yes & 3 & 10 & 13 \\
\hline & no & 3 & 15 & 18 \\
\hline & total & 6 & 25 & 31 \\
\hline
\end{tabular}




\begin{tabular}{|c|c|c|c|c|}
\hline & & & ind & \\
\hline & & yes & $\underline{\text { no }}$ & total \\
\hline E1 Round 2 & yes & 2 & $\overline{5}$ & $\overline{7}$ \\
\hline & no & 9 & 15 & 24 \\
\hline & total & 11 & 20 & 31 \\
\hline & & & and & \\
\hline & & yes & $\underline{\text { no }}$ & $\underline{\text { total }}$ \\
\hline E2 Round 2 & yes & 6 & 7 & 13 \\
\hline & no & 5 & 13 & 18 \\
\hline & total & 11 & 20 & 31 \\
\hline & & & und & \\
\hline & & yes & $\underline{\text { no }}$ & $\underline{\text { total }}$ \\
\hline E1 Round 2 & yes & 1 & 6 & 7 \\
\hline & no & 12 & 12 & 24 \\
\hline & total & 13 & 18 & 31 \\
\hline
\end{tabular}

Key: I=Inexperienced; E=Experienced

Table D13. Intrarater Reliability for the Supine to Long Sit Test $(n=31)$

\begin{tabular}{|c|c|c|c|c|c|}
\hline Examiner & $\begin{array}{l}\text { Agreement } \\
(\%)\end{array}$ & $\begin{array}{l}\text { Карра } \\
(95 \% \mathrm{CI})\end{array}$ & P-value & $\kappa \max$ & $\kappa / \kappa \max$ \\
\hline I1 & 84 & .676 & $.000 *$ & .94 & .72 \\
\hline $\mathrm{I} 2$ & 87 & .735 & $.000 *$ & 1 & .735 \\
\hline E1 & 81 & .54 & $.002 *$ & .69 & .78 \\
\hline E2 & 65 & .241 & .179 & .93 & .26 \\
\hline
\end{tabular}

Key: $\mathrm{I}=$ Inexperienced; $\mathrm{E}=$ Experienced; $*$ indicates significance at $\mathrm{p}=.05$ 
Table D14. Intrarater Distributions for the Supine to Long Sit Test

\begin{tabular}{lllll}
\hline & & yes & no & total \\
I1 Round 1 Round 2 & & & \\
& yes & 12 & 3 & 15 \\
& no & 2 & 14 & 16 \\
& total & 14 & 17 & 31 \\
I2 Round 1 & I2 Round 2 & & & \\
& yes & 16 & 2 & 18 \\
& no & 2 & 11 & 13 \\
& total & 18 & 13 & 31 \\
E1 Round 1 & E1 Round 2 & & & \\
& yes & 6 & & 11 \\
& no & 1 & 5 & 20 \\
& total & 7 & 19 & 31 \\
& & & 24 & \\
E2 Round 1 & E2 Round 2 & & & 19 \\
& yes & 14 & 5 & 12 \\
& no & 6 & 6 & 31 \\
\hline
\end{tabular}

Key: $\mathrm{I}=$ inexperienced; $\mathrm{E}=$ Experienced

Table D15. Interrater Reliability for the Supine to Long Sit Test $(n=31)$

\begin{tabular}{|c|c|c|c|c|c|}
\hline Examiner & Agreement $(\%)$ & $\begin{array}{l}\text { Kappa } \\
(95 \% \text { CI })\end{array}$ & P-value & кmax & $\begin{array}{l}\kappa / \kappa \max \\
(\%)\end{array}$ \\
\hline \multicolumn{6}{|l|}{ Round 1 } \\
\hline $\mathrm{I} 1 \mathrm{xI} 2$ & 55 & -.091 & .605 & .81 & -.11 \\
\hline I1XE1 & 58 & .479 & $.006^{*}$ & .74 & .65 \\
\hline I1xE2 & 55 & .360 & $.038 *$ & .74 & .49 \\
\hline $\mathrm{I} 2 \mathrm{xE} 1$ & 45 & -.048 & .768 & .57 & -.08 \\
\hline $\mathrm{I} 2 \mathrm{xE} 2$ & 61 & .130 & .47 & .93 & .14 \\
\hline E1xE2 & 53 & .152 & .332 & .52 & .23 \\
\hline \multicolumn{6}{|l|}{ Round 2} \\
\hline$\overline{\mathrm{I} 1 \mathrm{xI} 2}$ & 45 & .111 & .524 & .51 & .22 \\
\hline I1XE1 & 74 & .114 & .469 & .52 & .22 \\
\hline I1xE2 & 68 & .121 & .465 & .62 & .20 \\
\hline $\mathrm{I} 2 \mathrm{xE} 1$ & 45 & -.008 & .955 & .35 & -.02 \\
\hline $\mathrm{I} 2 \mathrm{xE} 2$ & 58 & .188 & .291 & .86 & .22 \\
\hline E1xE2 & 55 & .054 & .664 & .28 & .19 \\
\hline
\end{tabular}

Key: $\mathrm{I}=$ Inexperienced; $\mathrm{E}=$ Experienced; * indicates significance at $\mathrm{p}=.05$ 
Table D16. Interrater Distributions for the Supine to Long Sit Test

\begin{tabular}{|c|c|c|c|c|}
\hline I1 Round 1 & $\begin{array}{l}\text { yes } \\
\text { no } \\
\text { total }\end{array}$ & $\begin{array}{l}\frac{\text { yes }}{8} \\
10 \\
18 \\
\end{array}$ & $\begin{array}{c}\text { und } 1 \\
\frac{\text { no }}{7} \\
6 \\
13 \\
\end{array}$ & $\begin{array}{l}\frac{\text { total }}{15} \\
16 \\
31 \\
\end{array}$ \\
\hline E1 Round 1 & $\begin{array}{l}\text { yes } \\
\text { no } \\
\text { total }\end{array}$ & $\begin{array}{l}\frac{\text { yes }}{9} \\
6 \\
15 \\
\end{array}$ & $\begin{array}{l}\text { und } 1 \\
\frac{\text { no }}{2} \\
14 \\
16\end{array}$ & $\begin{array}{l}\frac{\text { total }}{11} \\
20 \\
31\end{array}$ \\
\hline E2 Round 1 & $\begin{array}{l}\text { yes } \\
\text { no } \\
\text { total }\end{array}$ & $\begin{array}{l}\frac{\text { yes }}{12} \\
3 \\
15 \\
\end{array}$ & $\begin{array}{l}\text { und } 1 \\
\frac{\text { no }}{7} \\
9 \\
16\end{array}$ & $\begin{array}{l}\frac{\text { total }}{19} \\
12 \\
31 \\
\end{array}$ \\
\hline E1 Round 1 & $\begin{array}{l}\text { yes } \\
\text { no } \\
\text { total }\end{array}$ & $\begin{array}{l}\frac{\text { yes }}{6} \\
12 \\
18\end{array}$ & $\begin{array}{c}\frac{\text { und } 1}{\text { no }} \\
5 \\
8 \\
13\end{array}$ & $\begin{array}{l}\text { total } \\
11 \\
20 \\
31\end{array}$ \\
\hline E2 Round 1 & $\begin{array}{l}\text { yes } \\
\text { no } \\
\text { total }\end{array}$ & $\begin{array}{l}\frac{\text { yes }}{12} \\
6 \\
18 \\
\end{array}$ & $\begin{array}{l}\text { und } 1 \\
\frac{\text { no }}{7} \\
6 \\
13 \\
\end{array}$ & $\begin{array}{l}\frac{\text { total }}{19} \\
12 \\
31\end{array}$ \\
\hline E1 Round 1 & $\begin{array}{l}\text { yes } \\
\text { no } \\
\text { total }\end{array}$ & $\begin{array}{l}\frac{\text { yes }}{8} \\
11 \\
19\end{array}$ & $\begin{array}{l}\frac{\text { ond }}{\frac{\text { no }}{3}} \\
9 \\
12\end{array}$ & $\begin{array}{l}\frac{\text { total }}{11} \\
20 \\
31\end{array}$ \\
\hline
\end{tabular}




\begin{tabular}{|c|c|c|c|c|}
\hline \multirow[b]{2}{*}{ I1 Round 1} & \multicolumn{4}{|c|}{ I2 Round 2} \\
\hline & $\begin{array}{l}\text { yes } \\
\text { no } \\
\text { total }\end{array}$ & $\begin{array}{l}\text { yes } \\
9 \\
9 \\
18 \\
\end{array}$ & $\begin{array}{l}\frac{\text { no }}{5} \\
8 \\
13 \\
\end{array}$ & $\begin{array}{l}\frac{\text { total }}{14} \\
17 \\
31 \\
\end{array}$ \\
\hline E1 Round 1 & $\begin{array}{l}\text { yes } \\
\text { no } \\
\text { total }\end{array}$ & $\begin{array}{l}\frac{\text { yes }}{4} \\
10 \\
14\end{array}$ & $\begin{array}{l}\text { und } \\
\frac{\text { no }}{3} \\
14 \\
17\end{array}$ & $\begin{array}{l}\frac{\text { total }}{7} \\
24 \\
31\end{array}$ \\
\hline E2 Round 1 & $\begin{array}{l}\text { yes } \\
\text { no } \\
\text { total }\end{array}$ & $\begin{array}{l}\frac{\text { yes }}{10} \\
4 \\
14 \\
\end{array}$ & $\begin{array}{l}\text { und } \\
\frac{\text { no }}{10} \\
7 \\
17\end{array}$ & $\begin{array}{l}\frac{\text { total }}{20} \\
11 \\
31 \\
\end{array}$ \\
\hline E1 Round 2 & $\begin{array}{l}\text { yes } \\
\text { no } \\
\text { total }\end{array}$ & $\begin{array}{l}\frac{\text { yes }}{4} \\
14 \\
18 \\
\end{array}$ & $\begin{array}{l}\text { und } \\
\frac{\text { no }}{3} \\
10 \\
13\end{array}$ & $\begin{array}{l}\text { total } \\
7 \\
24 \\
31 \\
\end{array}$ \\
\hline E2 Round 2 & $\begin{array}{l}\text { yes } \\
\text { no } \\
\text { total }\end{array}$ & $\begin{array}{l}\frac{\text { yes }}{13} \\
5 \\
18\end{array}$ & $\begin{array}{l}\text { und } \\
\frac{\text { no }}{7} \\
6 \\
13\end{array}$ & $\begin{array}{l}\frac{\text { total }}{20} \\
11 \\
31\end{array}$ \\
\hline E1 Round 2 & $\begin{array}{l}\text { yes } \\
\text { no } \\
\text { total }\end{array}$ & $\begin{array}{l}\text { yes } \\
5 \\
15 \\
20\end{array}$ & $\begin{array}{l}\text { und } \\
\text { no } \\
2 \\
9 \\
11\end{array}$ & $\begin{array}{l}\text { total } \\
7 \\
24 \\
31\end{array}$ \\
\hline
\end{tabular}

Key: I=Inexperienced; E=Experienced 
Table D17. Interrater comparisions of Experienced and Inexperienced Examiners $(n=31)$

\begin{tabular}{|c|c|c|c|c|}
\hline Interrater Reliability & Supine to Long Sit & March & Seated Flexion & Standing Flexion \\
\hline \multirow[t]{2}{*}{ Experienced Examiners } & R1: Slight $(\kappa=.152)$ & $\begin{array}{l}\text { R1: unable to be } \\
\text { calculated }\end{array}$ & R1: Poor $(\kappa=-.069)$ & R1: Poor $(\kappa=-.220)$ \\
\hline & R2: Slight $(\kappa=.054)$ & $\begin{array}{l}\text { R2: unable to be } \\
\text { calculated }\end{array}$ & R2: Poor $(\kappa=-.274)$ & R2: Poor $(\kappa=-.026)$ \\
\hline \multirow[t]{2}{*}{ Inexperienced Examiners } & R1: Poor $(\kappa=-.091)$ & R1: Poor $(\kappa=-.037)$ & R1: Slight $(\kappa=.043)$ & R1: Poor $(\kappa=-.154)$ \\
\hline & R2: Slight $(\kappa=.111)$ & R2: Poor $(\kappa=-.090)$ & R2: Slight $(\kappa=.137)$ & R2: Slight $(\kappa=.011)$ \\
\hline
\end{tabular}

Key: R1=round 1; R2=round 2 
Figure D1. Examiner Recruitment Process

\section{Contact all Graduate} students, Certified Athletic Trainers from HealthWorks, Certified Athletic Trainers from WVU, and Certified Athletic Trainers from WU
2 Graduate students and 2 employed Certified Athletic Trainers respond. HIPAA and consent forms are filled out

Figure D2. Recorder Recruitment Process

\begin{tabular}{|l|l|l|}
\hline $\begin{array}{l}\text { Contact all graduate } \\
\text { students at WVU }\end{array}$ & $\begin{array}{l}4 \text { graduate students } \\
\text { respond. HIPAA } \\
\text { and consent forms } \\
\text { are filled out }\end{array}$ \\
\cline { 2 - 3 }
\end{tabular}

Figure D3. Subject Recuitment Process

Contact all ATEP, PATS, and a sport psych class about participating in the study. Desired number of subject $(n=50)$

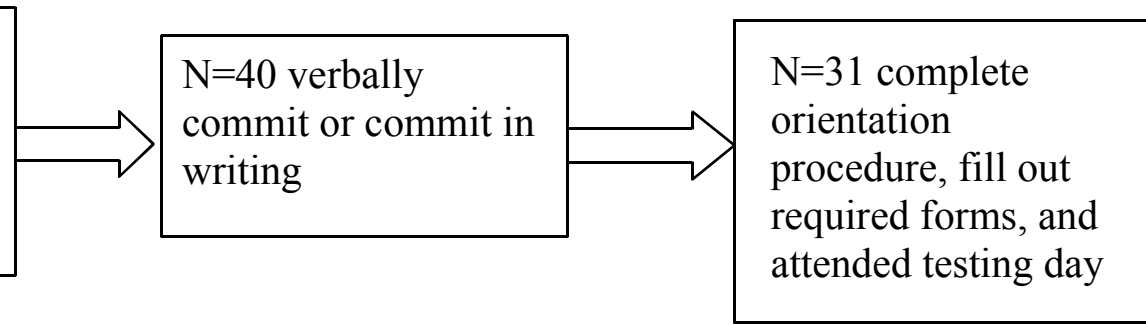




\section{APPENDIX E}

\section{RECOMMENDATIONS FOR FUTURE RESEARCH}

1. Recruit equal numbers of males and females as examiners for each category to remove potential gender biases.

2. Continue to differentiate examiners by the given definitions but also use different training sessions to further differentiate the two groups. For example, provide a more thorough training session for the experienced examiners while only providing a video and hand-outs to the inexperienced examiners.

3. Provide more opportunities to practice and receive feedback prior to the testing day.

4. Have a recognized SIJ expert evaluate each subject prior to testing to determine presence of SIJ dysfunction but make sure the examiners are blinded to the results.

5. Separate the two round of testing by a greater period of time to remove the risk of the examiners remembering their test results.

6. Recruit more examiners and subjects through the College of Physical Activity and Sport Sciences.

7. Incorporate a pretest questionnaire to determine the extent of each examiner's knowledge and understanding of the history and evaluation process off the SIJ.

8. Combine the results of a set of tests to determine the presence of SIJ dysfunction (eg: if $3 / 4$ tests are positive, then the individual has a dysfunction.

9. Record height and weight of each subject.

10. Record hand and eye dominance of each examiner

11. Have more mandatory warm-up exercises to remove the risk of false positives in the second round of testing. Suggested warm-up exercises include a mandatory cardiovascular warm-up as well as stretching of the hamstrings, hip flexors, quadriceps, and gluteal muscles.

12. Utilize a more accurate/correct version of the Supine-to-Long Sit test. 


\section{ADDITIONAL REFERENCES}

40. Franke BA. Formative dynamics: the pelvic girdle. J Man Manipulative Ther. 2003;11(1):1240.

41. Mackarey PJ. Sacroiliac joint dysfunction secondary to leg length discrepancy in a long distance runner. Orthop Phys Ther Prac. 2000;12(3):7-14.

42. Schneider M, Homonai R, Moreland B, Delitto A. Interexaminer reliability of the prone leg length analysis procedure. J Man Physiol Ther. 2007;30:514-521.

43. van der Wurff P, Hagmeijer RHM, Meyne W. Clinical tests of the sacroiliac joint: a systematic methodological review. Part 1: reliability. Man Ther. 2000;5(1)30-36.

44. Levin U, Nilsson-Wikmar L, Stenstrom CH. Variability within and between evaluations of sacroiliac pain with the use of distraction testing. J Man Physiol Ther. 2005;28(9):688-697.

45. Laslett M, Williams M. The reliability of selected pain provocation tests for sacroiliac joint pathology. Spine. 1998;19(11)1243-1249.

46. Kokmeyer DJ, van der Wurff P, Aufdenkampe G, Fickenscher TCM. The reliability of multitest regimens with sacroiliac pain provocation tests. J Man Physiol Therap. 2002;25(1):42-50.

47. Sizer Jr PS, Phelps V, Thompsen K. Disorders of the sacroiliac joint. Pain Prac. 2002;2(1):1734.

48. Leboeuf-Yde C, va Dijk J, Franz C, Hustad S, Olsen D, Pihl T, Robech R, Vendrup SS, Bendix T, Kyvik KO. Motion palpation findings and self-reported low back pain in a population-based study sample. JMPT. 2002;25:80-87.

49. Prather H. Pelvis and sacral dysfunction in sports and exercise. Phys Med Rehabil Clin N Am. 2000;11(4):805-824.

50. van Wingerden JP, Vleeming A, Buruk HM, Raissadat K. Stabilization of the sacroiliac joint in vivo: verification of muscular contribution to force closure of the pelvis. Eur Spine J.

2004;13:199-205.

51. Knutson GA. The sacroiliac sprain: neuromuscular reactions, diagnosis, and treatment with pelvic blocking. JACA. 2004;41(8):32-41.

52. van der Wurff P, Buijs EJ, Groen GJ. A multitest regimen of pain provocation tests as an aid to reduce unneccessary minimally invasive sacroiliac joint procedures. Arch Phys Med Rehabil. 2006;87:10-14.

53. Cuppett M, Paladino J. The anatomy and pathomechanics of the sacroiliac joint. Ath Ther Today. 2001;6(4):6-14. 
54. Puhakka KB, Melsen F, Jurik AG, Boel LW, Vesterby A, Egund N. MR imaging of the normal sacroiliac joint with correlatioin to histology. Skeletal Radiol. 2004;33:15-28.

55. Jackson R. The Pelvic Girdle 1992. Chapter 2: anatomy p 6-24 Chapter 3 p 25-27

56. Rosatelli AL, Agur AM, Chhaya S. Anatomy of the Interosseus Region of the Sacroiliac Joint. Sports Phys Ther. 2006;36(4):200-208.

57. Woodley SJ, Kennedy E. Anatomy in practice: the sacrotuberous ligament. Physiother. 2005;33(3):91094.

58. Moore KL, Dalley AF. Clinically Oriented Anatomy. $4^{\text {th }}$ ed. Baltimore, MD: Lippincott, Williams and Wilkins; 2006.

59. Berthelot JM. Provocative sacroiliac joint maneuvers and sacroiliac joint block are unrelaible for diagnosing sacroiliac joint pain. Joint, Bone, Spine. 2006;73(1):17-21.

60. Sturesson B. Load and movements of the sacroiliac joints. Acta Orthop Scand. 1999;70:79.

61. Schache AG, Blanch P, Rath D, Wrigley T, Bennell K. Three-dimensional angular kinematics of the lumbar spine and pelvis during running. Human Movement Sci. 2002;21:273-293.

62. Chou LH, Slipman CW, Bhagia SM, Tsaur L, Bhat AL, Isaac Z, Gilchrist R, El Abd OH, Lenrow DA. Inciting events initiating injection-proven sacroiliac joint syndrome. Pain Med. 2004;5(1):26-32.

63. Weiner DK, Sakamoto S, Perera S, Breuer P. Chronic low back pain in older adults: prevalence, reliability, and validity of physical examination findings. J Am Geriatr Soc. 2006;54:11-20.

64. Stuber KJ. Specificity, sensitivity, and predictive values of clinical tests of the sacroiliac joint: a systematic review of the literature. J Can Chirop Assoc. 2007;51(1):30-41.

65. Toussaint R, Gawlik CS,Rehder U, Ruther W.Sacroiliac joint diagnostics in the Hamburg Construction Workers Study. JManipulative Physiol Ther. 1999;22:139-143.

66. Irwin RW, Minick RP, Ambrosius WT. Age, body mass index, and gender differences in sacroiliac joint pathology. Am J Phys Med Rehabil. 2007;86:37-44.

67. Rumball JS, Lebrun CM, Di Ciacca SR, Orlando K. Rowing Injuries. Sports Med. 2005;35(6):537-555.

68. Timm KE. Sacroiliac joint dysfunction in elite rowers. J Orthop Sports Phys Ther. 1999;29(5):288-293.

69. Timm KE. Sacroiliac joint dysfunction in a marathon runner. Ath Ther Today. 1998;9:48-49. 
70. Warren PH. Management of a patient with sacroiliac joint dysfunction: a correlation of hip range of motion asymmetry with sitting and standing postural habits. J Man Manipulative Ther. 2003;11(3):153-159.

71. Kline CM. Sacroiliac joint dysfunction diagnosis. J Am Chiroprac Assoc. 2006;11:1-4.

72. Godges JJ, Varnum DR, Sanders KM. Impairment-based examination and disability management of an elderly woman with sacroiliac region pain. Phys Ther. 2002;82:812-821.

73. Reynolds KE. Sacroiliac dysfunction: a proactive approach. Br J Midwifery. 2003;11(8):476452.

74. Snijders CJ, Hermans PFG, Niesing R, Spoor CW, Stoeckart R. The influence of slouching and lumbar support on iliolumbar ligaments, intervertebral discs, and sacroiliac joints. Clin Biomech. 2004;19:323-329.

75. Kasunich NJ. Changes in low back pain in a long distance runner after stretching the iliotibial band. J Chiroprac Med. 2003;2:37-40.

76. Cayea D, Perera S, Weiner DK. Chronic low back pain in older adults: what physicians know, what they think they know, and what they should be taught. J Am Geriatr Soc. 2006;54:17721777.

77. Fukui S, Nosaka S. Pain patterns originating from the sacroiliac joints. J Anesth. 2002;16:245247.

78. Petersen T, Laslett M, Thorsen H, Manniche C, Ekdahl C, Jacobsen S. Diagnostic classification of non-specific low back pain. A new system integrating patho-anatomc and clinical categories. Physiother Theory Prac. 2003;19:213-237.

79. Grieve E. Diagnostic tests for mechanical dysfunction of the sacroiliac joints. J Man Manipulative Ther. 2001;9(4):198-206.

80. Danaberg HJ. Gait style as an etiology to chronic postural pain, part II The postural compensatory process. J Am Podiatr Med Assoc. 1993; 83(11):615-624.

81. Botte R. An interpretation of the pronation syndrome and foot types of patients with low back pain. J Am Podiatr Med Assoc. 1981;71:243-252.

82. O'Sullivan PB, Beales DJ, Beetham JA, Cripps J, Graf F, Lin IB, Tucker B, Avery A. Altered motor control strategies in subjects with sacroiliac pain during the active straight leg raise test. Spine. 2002;27(1):E1-E8.

83. Slipman CW, Sterenfeld EB, Chou LH, Herzog R, Vresilovic E. The predictive value of provocative sacroiliac joint stress maneuvers in the diagnosis of sacroiliac joint syndrome. Arch Phys Med Rehabil. 1998;79:288-291. 
84. Broadhurst NA, Bond MJ. Pain provocative tests for the assessment of sacroiliac joint dysfunction. J Spinal Disord. 1998;11:341-345.

85. Strender LE, Sjoblom A, Sundell K Ludwig Taube A. Interexaminer relaibility in physical examination of patients with low back pain. Spine. 1997;22(7):814-820.

86. Levin U, Nilsson-Wikmar LN, Harms-Ringdahl K, Stenstrom CH. Variability of forces applied by experienced physiotherapists during provocation of the sacroiliac joint. Clin Biomech. 2001;16:300-306. 